\title{
The use of the PARIHS framework in implementation research and practice-a citation analysis of the literature
}

\author{
Anna Bergström ${ }^{1,2^{*}}$ (D) Anna Ehrenberg ${ }^{3,4}$, Ann Catrine Eldh ${ }^{5,6}$, lan D. Graham ${ }^{7,8}$, Kazuko Gustafsson ${ }^{3,9}$, \\ Gillian Harvey ${ }^{4}$, Sarah Hunter ${ }^{10}$, Alison Kitson ${ }^{10,11}$, Jo Rycroft-Malone ${ }^{12}$ and Lars Wallin ${ }^{3,13}$
}

\begin{abstract}
Background: The Promoting Action on Research Implementation in Health Services (PARIHS) framework was developed two decades ago and conceptualizes successful implementation (SI) as a function ( $f$ ) of the evidence (E) nature and type, context (C) quality, and the facilitation $(F),[S I=f(E, C, F)]$. Despite a growing number of citations of theoretical frameworks including PARIHS, details of how theoretical frameworks are used remains largely unknown. This review aimed to enhance the understanding of the breadth and depth of the use of the PARIHS framework.

Methods: This citation analysis commenced from four core articles representing the key stages of the framework's development. The citation search was performed in Web of Science and Scopus. After exclusion, we undertook an initial assessment aimed to identify articles using PARIHS and not only referencing any of the core articles. To assess this, all articles were read in full. Further data extraction included capturing information about where (country/ countries and setting/s) PARIHS had been used, as well as categorizing how the framework was applied. Also, strengths and weaknesses, as well as efforts to validate the framework, were explored in detail.

Results: The citation search yielded 1613 articles. After applying exclusion criteria, 1475 articles were read in full, and the initial assessment yielded a total of 367 articles reported to have used the PARIHS framework. These articles were included for data extraction. The framework had been used in a variety of settings and in both high-, middle-, and low-income countries. With regard to types of use, 32\% used PARIHS in planning and delivering an intervention, 50\% in data analysis, 55\% in the evaluation of study findings, and/or 37\% in any other way. Further analysis showed that its actual application was frequently partial and generally not well elaborated.

Conclusions: In line with previous citation analysis of the use of theoretical frameworks in implementation science, we also found a rather superficial description of the use of PARIHS. Thus, we propose the development and adoption of reporting guidelines on how framework(s) are used in implementation studies, with the expectation that this will enhance the maturity of implementation science.
\end{abstract}

Keywords: Citation analysis, PARIHS framework, Implementation science, Knowledge translation

\footnotetext{
* Correspondence: anna.bergstrom@kbh.uu.se

'Department of Women's and Children's health, Uppsala Global Health

Research on Implementation and Sustainability (UGHRIS), Uppsala, Sweden

${ }^{2}$ Institute for Global Health, University College London, London, UK

Full list of author information is available at the end of the article
}

(c) The Author(s). 2020 Open Access This article is licensed under a Creative Commons Attribution 4.0 International License, which permits use, sharing, adaptation, distribution and reproduction in any medium or format, as long as you give appropriate credit to the original author(s) and the source, provide a link to the Creative Commons licence, and indicate if changes were made. The images or other third party material in this article are included in the article's Creative Commons licence, unless indicated otherwise in a credit line to the material. If material is not included in the article's Creative Commons licence and your intended use is not permitted by statutory regulation or exceeds the permitted use, you will need to obtain permission directly from the copyright holder. To view a copy of this licence, visit http://creativecommons.org/licenses/by/4.0/. The Creative Commons Public Domain Dedication waiver (http://creativecommons.org/publicdomain/zero/1.0/) applies to the data made available in this article, unless otherwise stated in a credit line to the data. 


\section{Contributions to the literature}

- Describes how a well-established theoretical framework-PAR-

IHS-has been operationalized in the scientific literature and

provides examples of its use in implementation studies.

- The findings underline that descriptions of the use of the

framework generally were not that transparent and often partial.

- Findings also point at difficulties in using the framework, such

as lack of guidance on key steps to overcome barriers and

support implementation

- Identifies the need of common guidelines on how theories,

models, and frameworks should be reported in research articles.

\section{Introduction}

There has been an increased use of theoretical frameworks in the field of implementation science in the last decade, with most developed in the last two decades [1, 2]. Tabak et al. identified 61 theoretical models used in dissemination and implementation science [3]. However, while theoretical frameworks are increasingly being cited, more research is needed to understand how they are chosen and applied, and how their use relates to improved implementation outcomes $[1,4]$. Variously described in the form of theories, frameworks, or models, all strive to provide conceptual clarity on different aspects of implementation practice and research. For consistency, we will refer to these as theoretical frameworks, or simply "frameworks."

The Promoting Action on Research Implementation in Health Services (PARIHS) framework is a multidimensional framework which was developed to explicitly challenge the pipeline conceptualization of implementation [5]. The PARIHS framework is a commonly used conceptual framework [1,4] that posits successful implementation (SI) as a function ( $\mathrm{f}$ ) of the nature and type of evidence (E) (including research, clinical experience, patient experience, and local information), the qualities of the context $(\mathrm{C})$ of implementation (including culture, leadership, and evaluation), and the way the implementation process is facilitated (F) (internal and/or external person acting as a facilitator to enable the process of implementation); $S I=f(E, C, F)$. The framework was informed by Rogers' Diffusion of Innovations [6] and various organizational theories and theories from social science [7] and generated inductively by working with clinical staff to help them understand the practical nature of getting evidence into practice. The PARIHS framework was initially published in 1998 [5] and updated based on a conceptual analysis in 2002 [8] and further primary research [9]. A further refinement was undertaken in 2015 [10], resulting in the integrated or iPARIHS. Articles using the revised version are not included in the citation analysis reported here. The PARIHS framework has been described as a determinant framework in that it specifies determinants that act as barriers and enablers influencing implementation outcomes [2]. Skolarus et al. [1] identified Kitson et al. [5] as one of the two primary originating sources of influence in their citation analysis of dissemination and implementation frameworks.

Despite the growing number of citations of theoretical frameworks in scientific articles, the detail of how frameworks are used remains largely unknown. Systematic reviews of the application of two other commonly used frameworks [1], the Knowledge to Action framework [11] and the Consolidated Framework for Implementation Research [12], both reported that use of these frameworks, beyond simply citation, was uncommon. While PARIHS has been widely cited, it has also been scrutinized; in 2010, Helfrich et al. published a qualitative critical synthesis of studies that had used the PARIHS framework [13], finding six core concept articles and 18 empirical articles. One of the reported findings was that PARIHS was generally used as an organizing framework for analysis. At the time, no studies used PARIHS prospectively to design implementation strategies [13]. A systematic review applying citation analysis to map the use of PARIHS (similar to those undertaken for the Knowledge to Action framework (KTA) [11] and the Consolidated Framework for Implementation Research (CFIR) [12]) has not yet been performed.

Systematic reviews can contribute to the development of existing theoretical frameworks by critically reviewing what authors state as their weaknesses and strengths; they can also direct future and current users of frameworks to examples of using the frameworks in different ways. To contribute to this development from the perspective of the PARIHS framework, we undertook a citation analysis of the published peer-reviewed literature that focused on the reported use of PARIHS (and its main elements), in what contexts the framework has been applied, and what scholars who have used the PARIHS framework (and its main elements) report as its strengths, limitations, and validity.

\section{Methods}

The method used for this study is citation analysis, i.e., the examination of the frequency and patterns of citations in scientific articles, in this case articles citing the core PARIHS framework publications. A team of researchers with engagement in the development and/or use of the PARIHS framework was constituted. Initially, the group decided on the core publications for the citation analysis. Four articles were selected as they represented the key stages of the framework's development, namely the original paper that described PARIHS, plus 
three subsequent papers that informed and outlined revisions to the framework:

1. Kitson A, Harvey G, McCormack B. Enabling the implementation of evidence-based practice: a conceptual framework. Qual Health Care. 1998;7(3):149-58.

2. Rycroft-Malone J, Kitson A, Harvey G, McCormack B, Seers K, Titchen A, et al. Ingredients for change: revisiting a conceptual framework. BMJ Quality Saf. 2002;11(2):174-80.

3. Rycroft-Malone J, Harvey G, Seers K, Kitson A, McCormack B, Titchen A. An exploration of the factors that influence the implementation of evidence into practice. J Clin Nurs. 2004;13(8):913-24.

4. Kitson AL, Rycroft-Malone J, Harvey G, McCormack B, Seers K, Titchen A. Evaluating the successful implementation of evidence into practice using the PARiHS framework: theoretical and practical challenges. Implement Sci. 2008;3:1.

\section{Citation search}

Citation searches were performed by an information specialist (KG) to retrieve published articles citing any of the four core articles. The searches were performed in two citation databases: Web of Science and Scopus. The first searches were performed between 31 March 2016 and 1 April 2016. Later, 6 September 2019, additional searches were performed in respective databases. These searches were limited to citations that were published 1 April 2016-31 August 2019 to update the result from the first searches. All citations that were published September 1998 (i.e., when Kitson et al 1998 was published)-31 August 2019 (i.e., prior to the search date) in respective databases were collected in EndNote Library. Endnote was used for checking duplicates and retrieving full texts. To manage the scope of the citation analysis, we opted to only include articles in English published in peer-reviewed scientific journals. The searches in Web of Science were, because of the subscription, limited to Web of Science Core Collection without Book Citation Index.

\section{Data extraction}

The Preferred Reporting Items for Systematic Reviews and Meta-Analyses (PRISMA) flow diagram [14] for the data extraction is provided in Fig. 1. Initially, an assessment to identify the articles that used the PARIHS framework in any other way than merely referencing one or more of the core articles was performed (Additional file 1). For this initial assessment, all articles were read in full. After identifying articles where the PARIHS framework was used, data extraction was undertaken using a tailor-made data capture form (Additional file 1).
The data capture form was developed and piloted in iterative cycles by the research team. Apart from capturing information about where (country/countries and setting/s) and with whom (professional groups and roles) PARIHS had been applied, the form included questions on whether PARIHS was used in one or more of the following ways:

1) In planning and delivering an intervention,

2) In data analysis,

3) In the evaluation of study findings, and/or

4) In any other way.

Each of these questions was followed by an openended item for extracting information on how this was reported [15]. To enhance reliability and data richness, each reviewer copy-pasted sections of the article corresponding to the open-ended reply into the data extraction form when appropriate and indicated page, column, and row. Two additional items captured whether the PARIHS framework had been tested or validated, as well as any reported strengths and weaknesses of the framework. Thus, we report on what the authors of the included articles claim to have done, rather than a judgment as to how and to what extent they actually used the PARIHS framework.

For data extraction and validation, the research team was divided into four pairs, ensuring that each article was assessed separately by at least two research team members. The pairs received batches of 20 articles at a time. Variations in the assessments were discussed until consensus was reached within the pair(s). Further, queries detected within the pairs were raised and discussed with the whole research team, until consensus was achieved. Regular whole-team online meetings were held to consolidate findings between every new batch of articles and throughout the development and analysis process. In total, the group had > 20 online meetings and four face-to-face meetings from the initial establishment of the group in January 2015.

\section{Data analysis}

Categorical data were analyzed using descriptive statistics, whereas the open-ended items were analyzed qualitatively [16], including the collated extractions of data to illustrate each of the four types of use (i.e., how the PARIHS framework was depicted in terms of (1) planning and delivering an intervention, (2) analysis, (3) evaluation of study findings, and/or (4) in any other way).

Applying a content analysis approach [17], members of the research team worked separately with the texts extracted from the reviewed articles. The extracts for each open-ended item were read and reread, to get a 


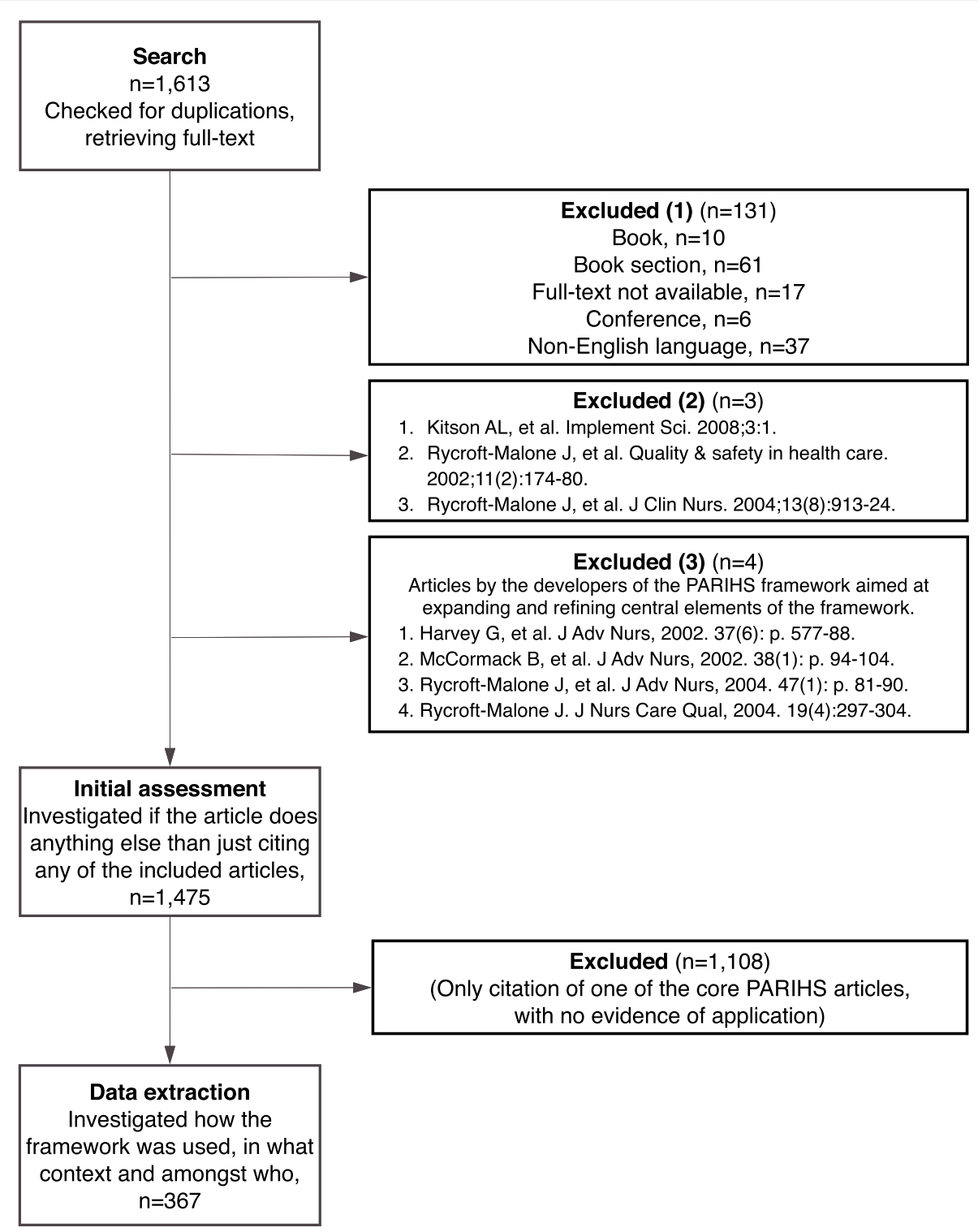

Fig. 1 Adapted PRISMA flow diagram

sense of the whole. Next, variations were identified and formed as categories. Findings for each question were summarized in short textual descriptions, which were shared with the whole team. In a face-to-face meeting, the data relating to each question were critically discussed and comparisons were made between the findings for each question, to identify overlaps and relationships about how PARIHS has been used.

\section{Results}

After duplicate control, 1613 references remained. These were sorted by language and type of publication. In this phase, 131 references categorized as books, book chapters, conference proceedings, and publications written in
non-English language were excluded. Also, three of the four core articles (i.e., the three citing Kitson et al. [5] which was the starting point for development of the PARIHS framework and therefore did not appear in the citation search) were excluded from the database $[8,9$, 18], as were four articles expanding and refining PARIHS [19-22]. Accordingly, 1475 articles remained, and after the assessment excluding those merely citing PARIHS, a further 1108 articles were excluded, leaving 367 articles that cited one or more of the core articles, and made explicit use of the PARIHS framework (see Fig. 1 and Table 1).

Of these 367 articles, 235 cited Kitson et al. [5], 208 cited Kitson et al. [18], 136 cited Rycroft-Malone et al. 


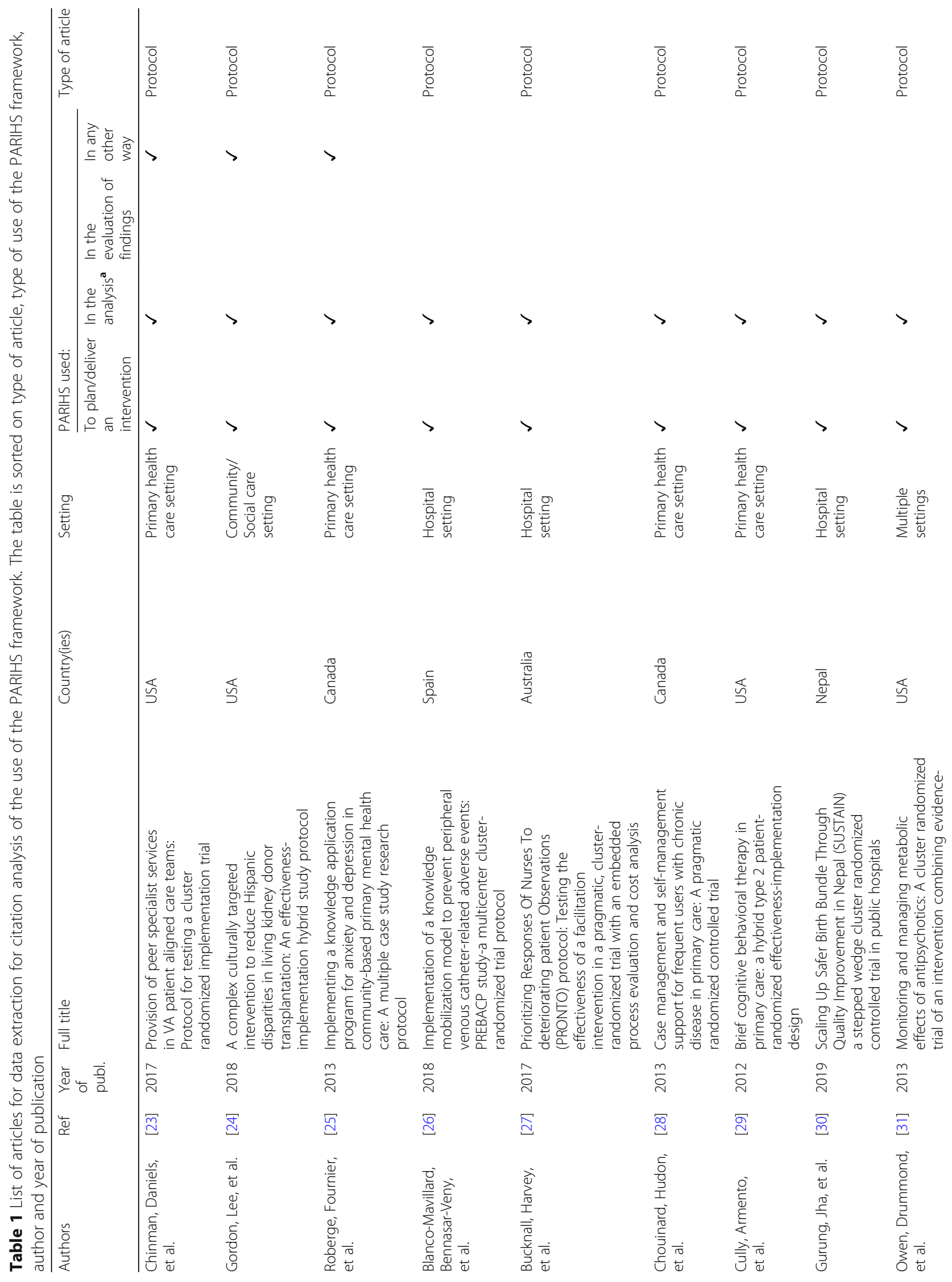




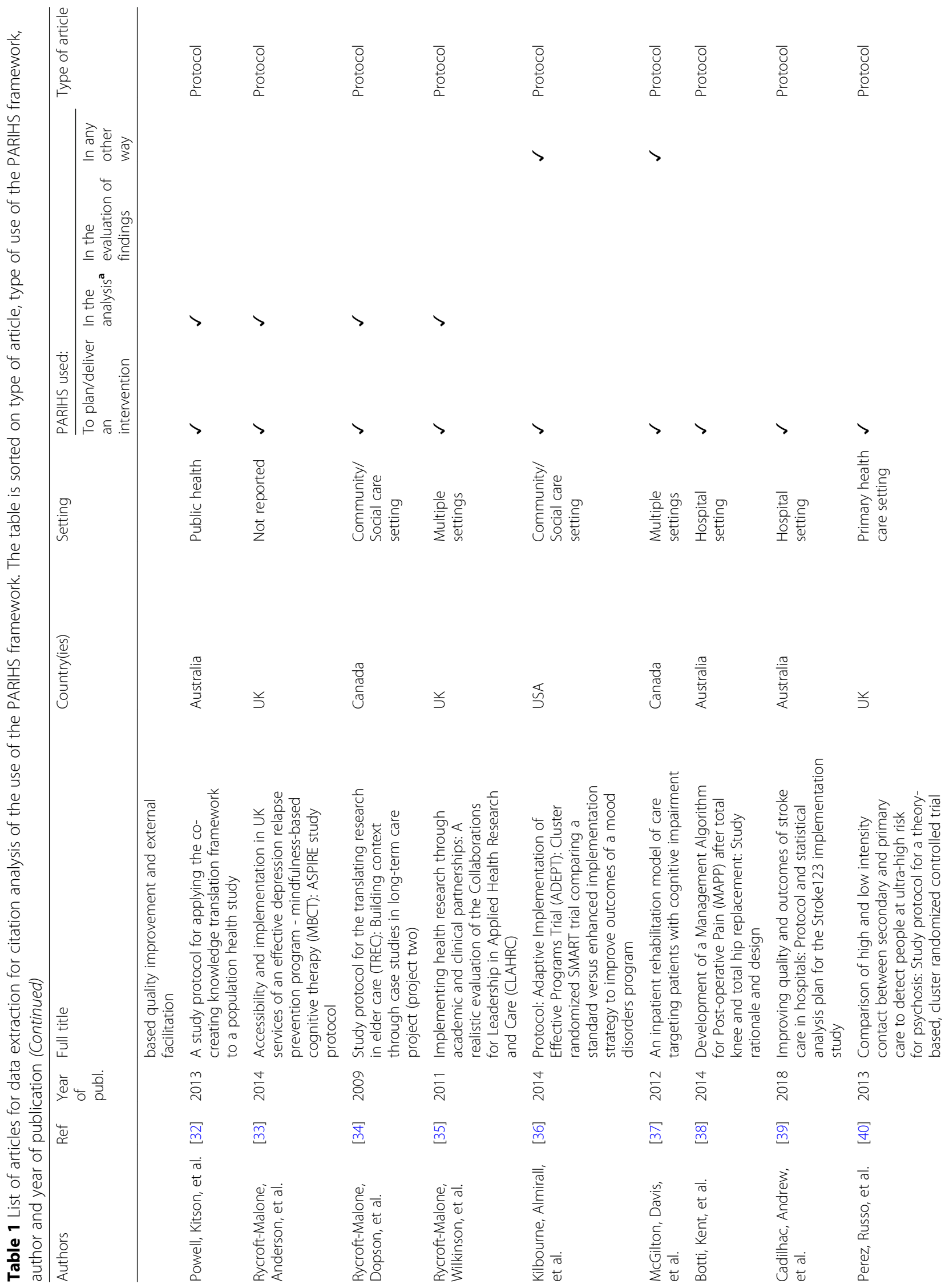




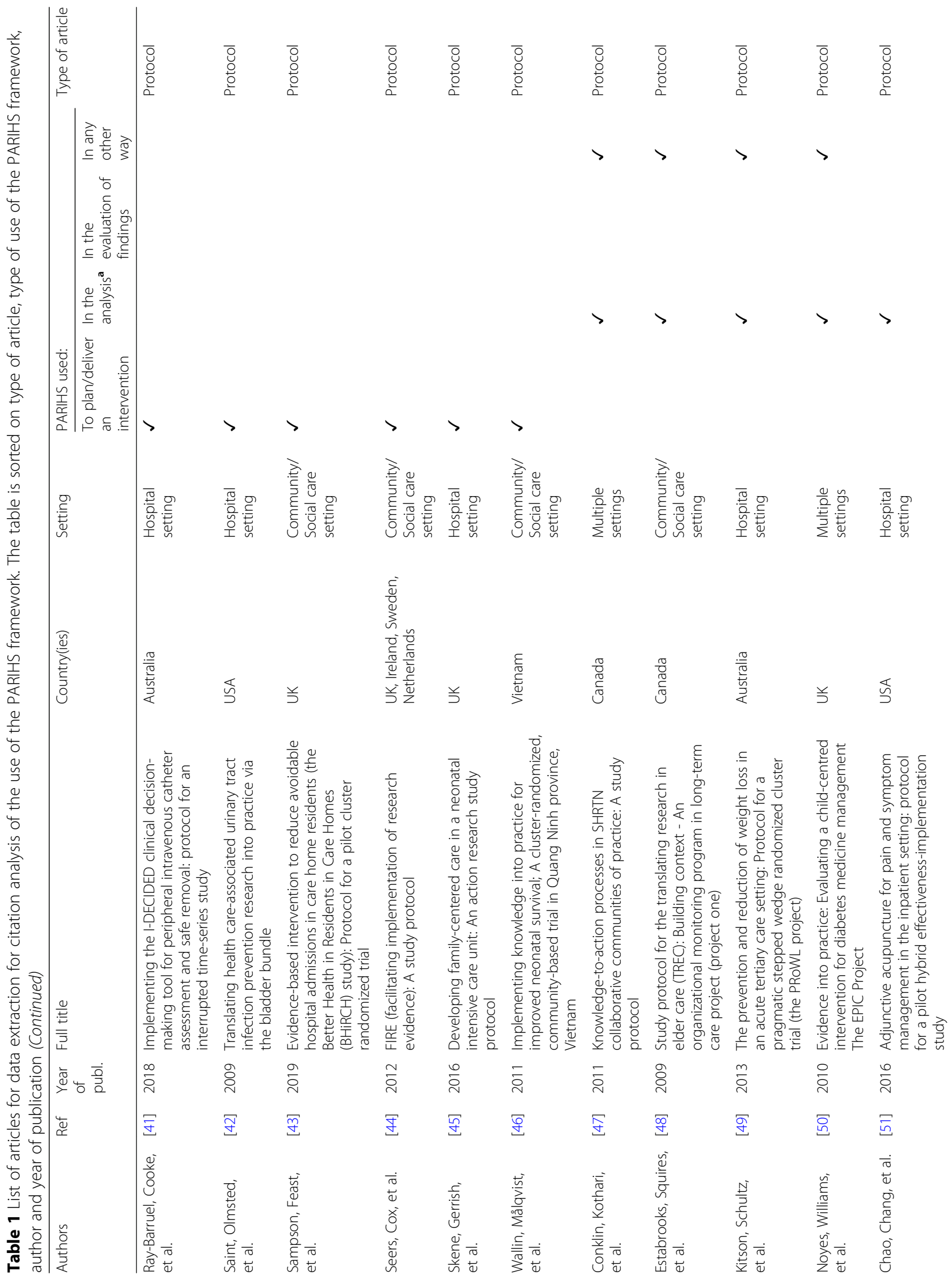




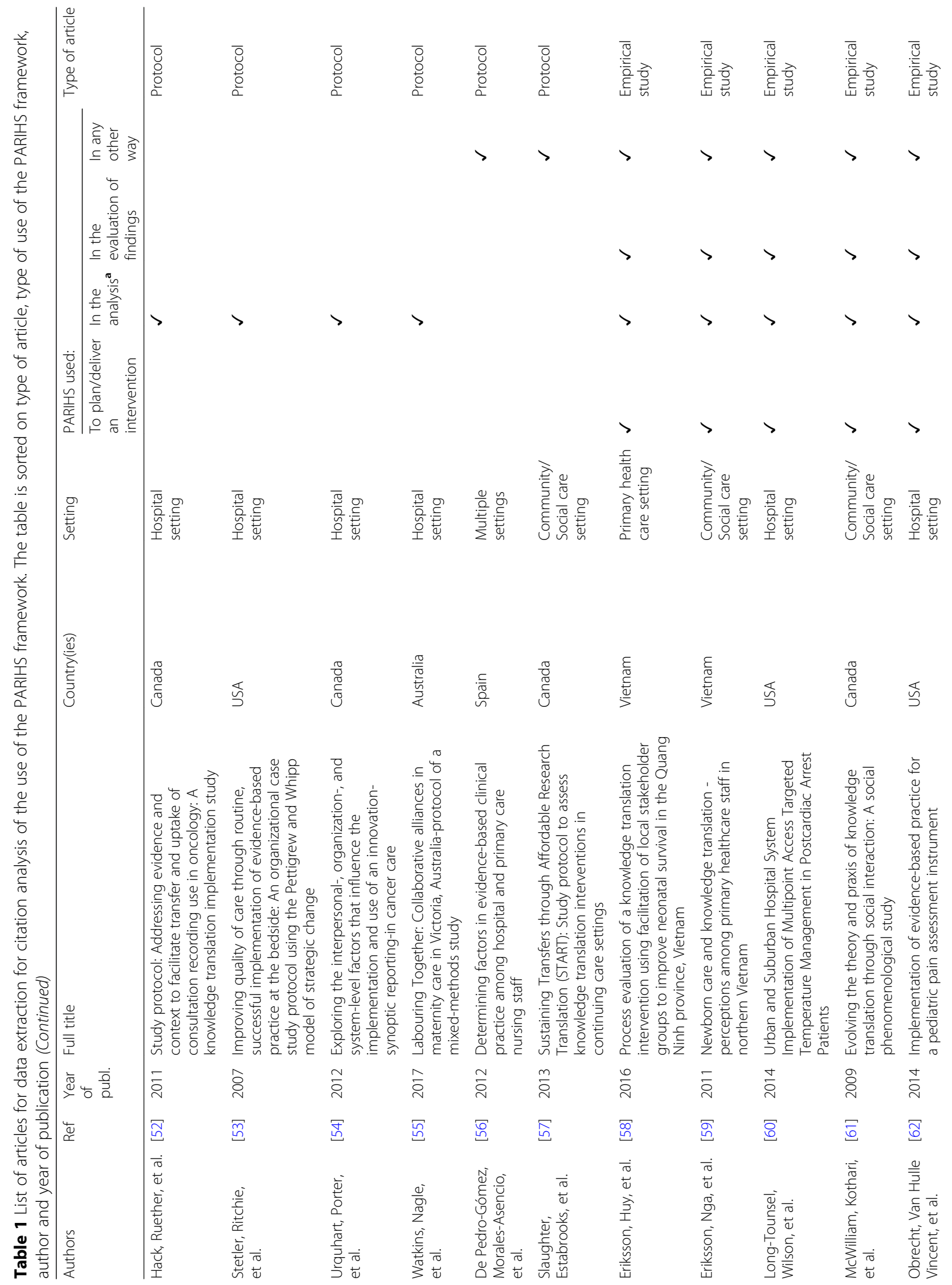




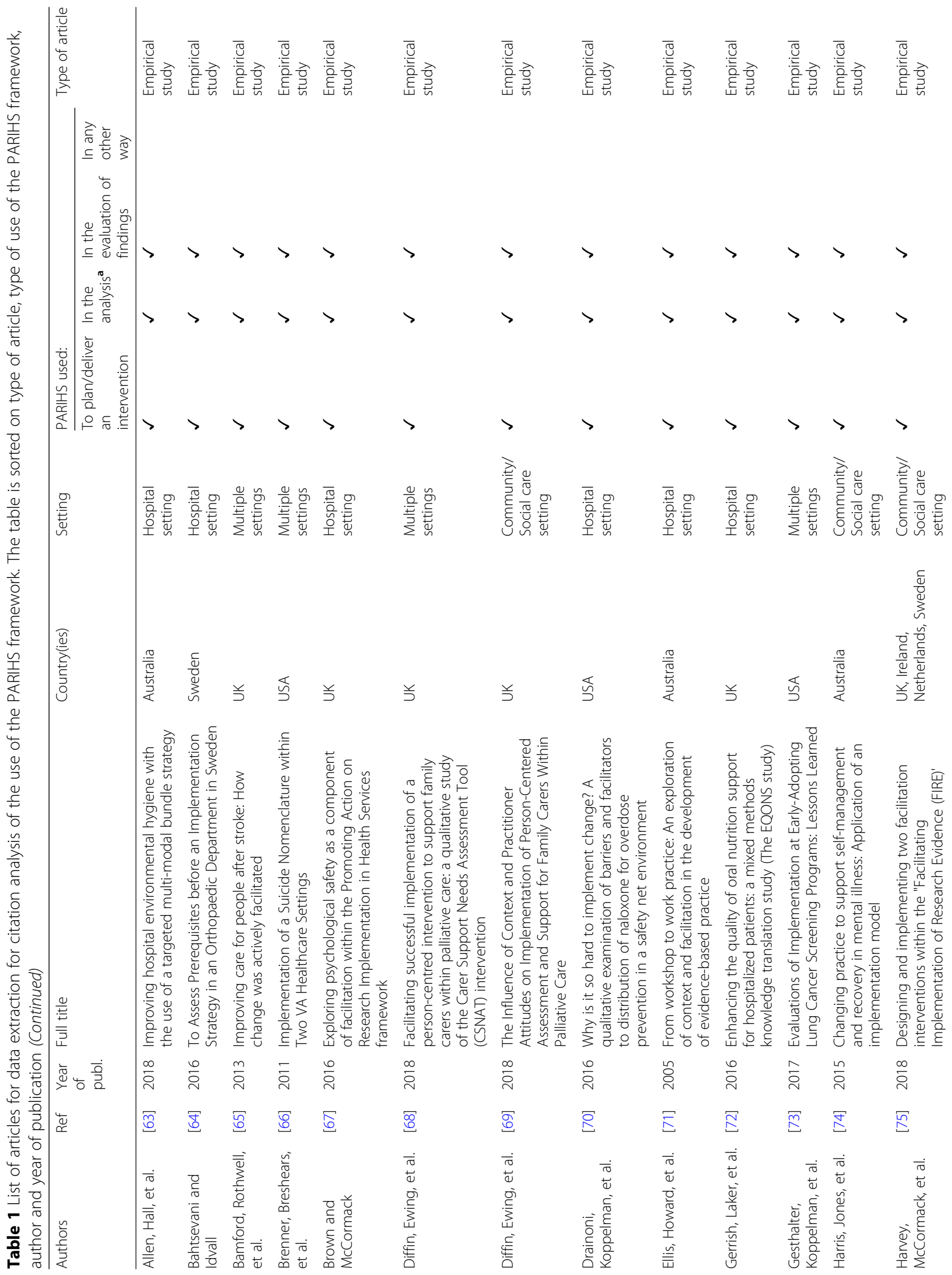




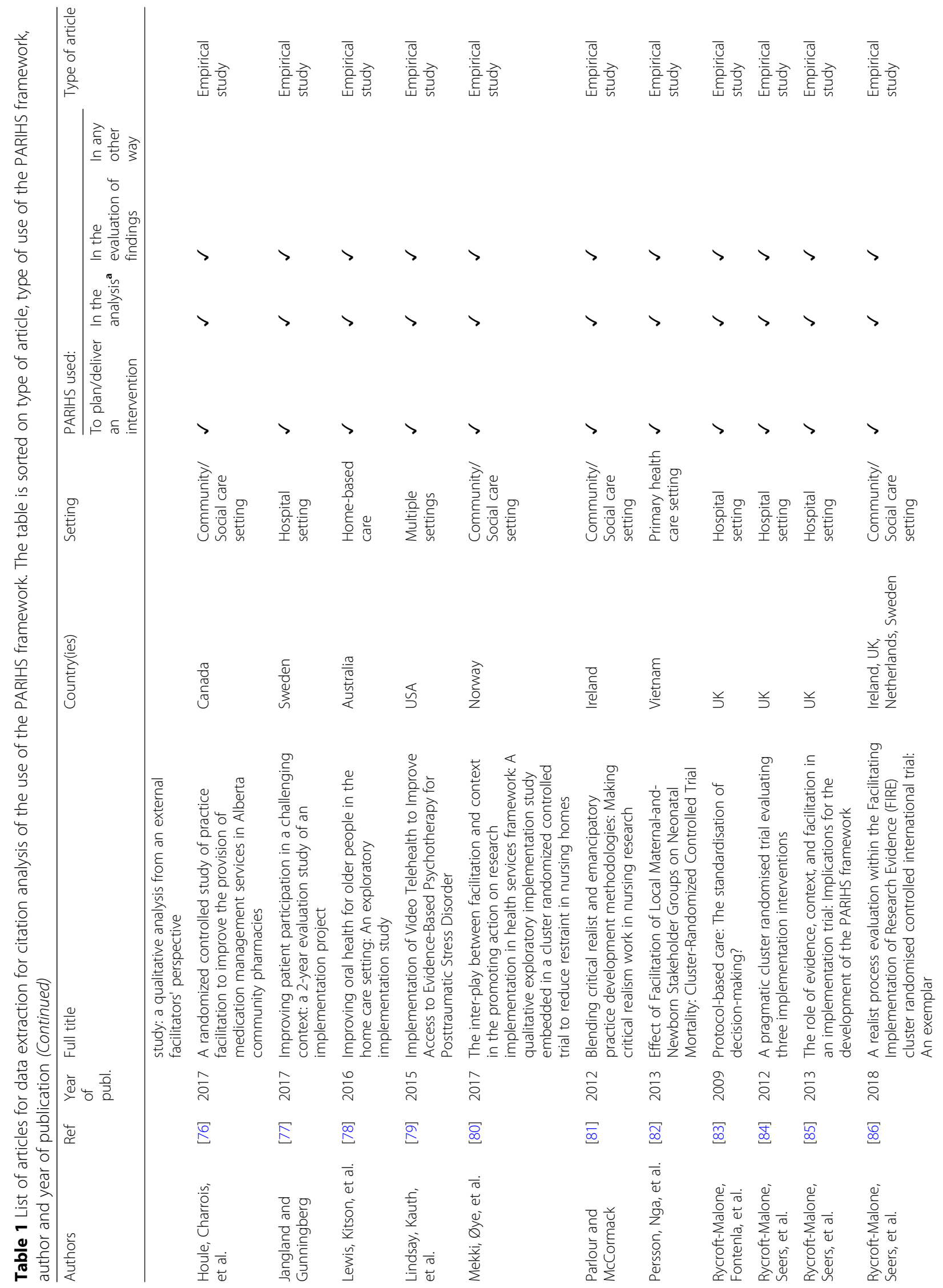




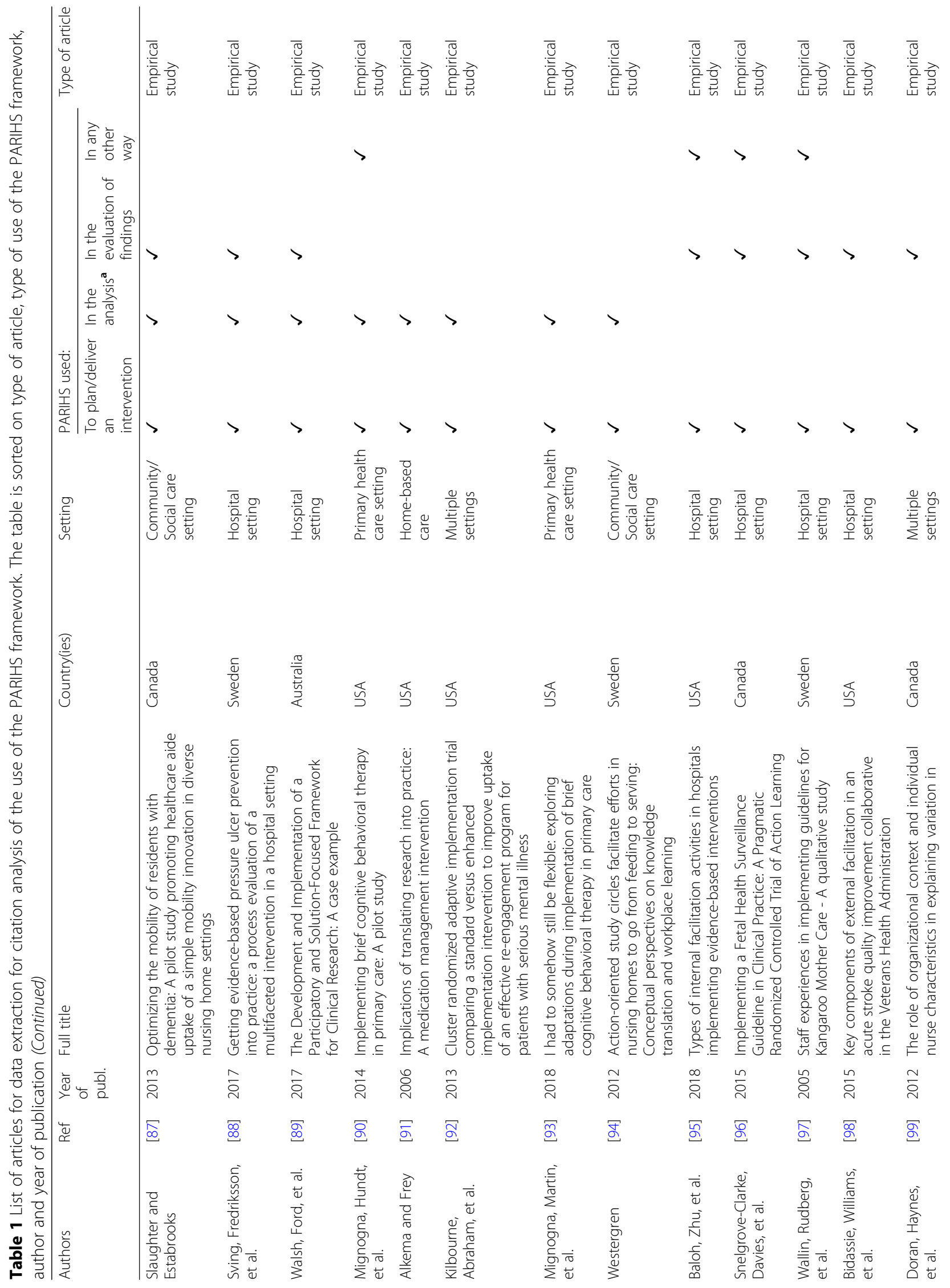




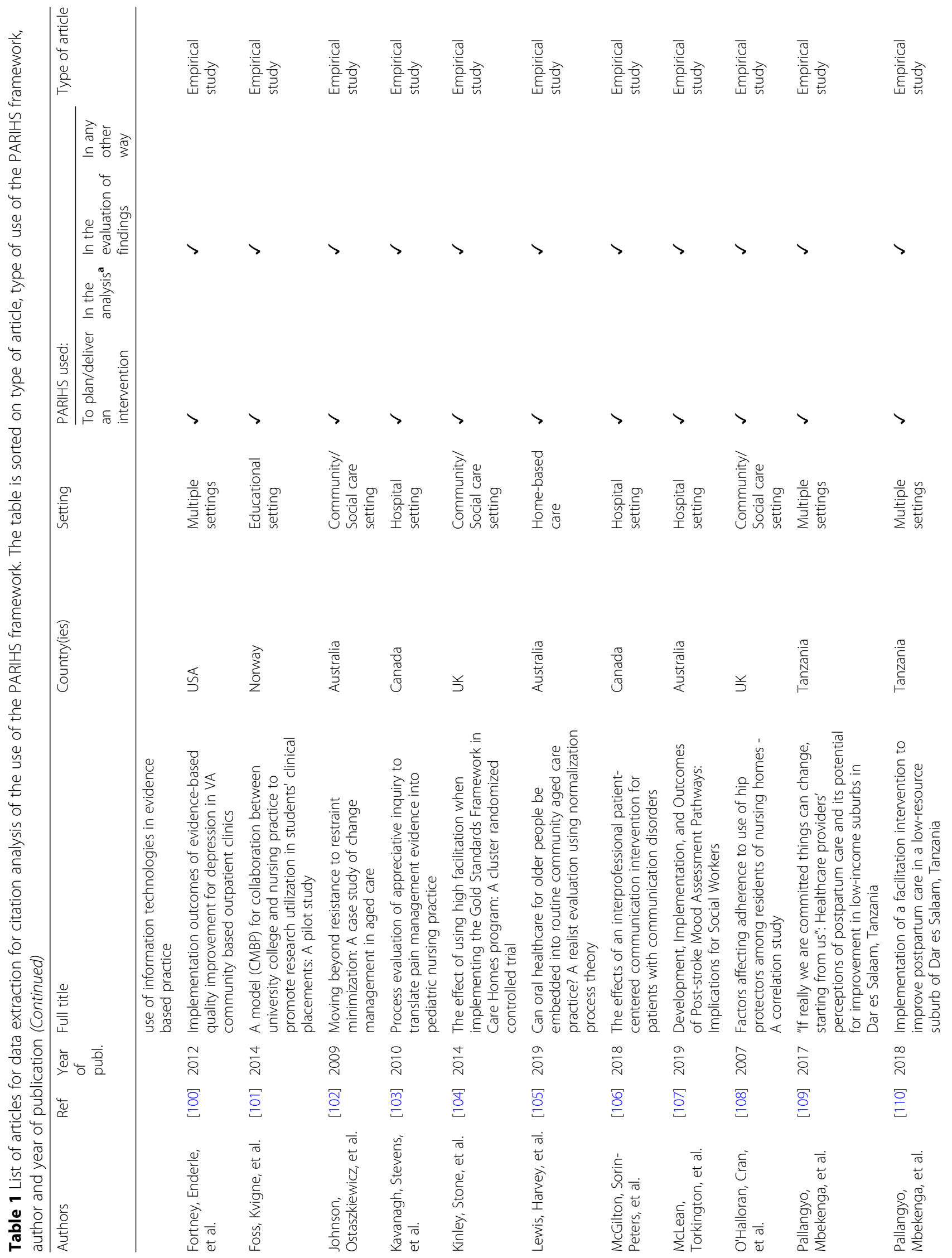




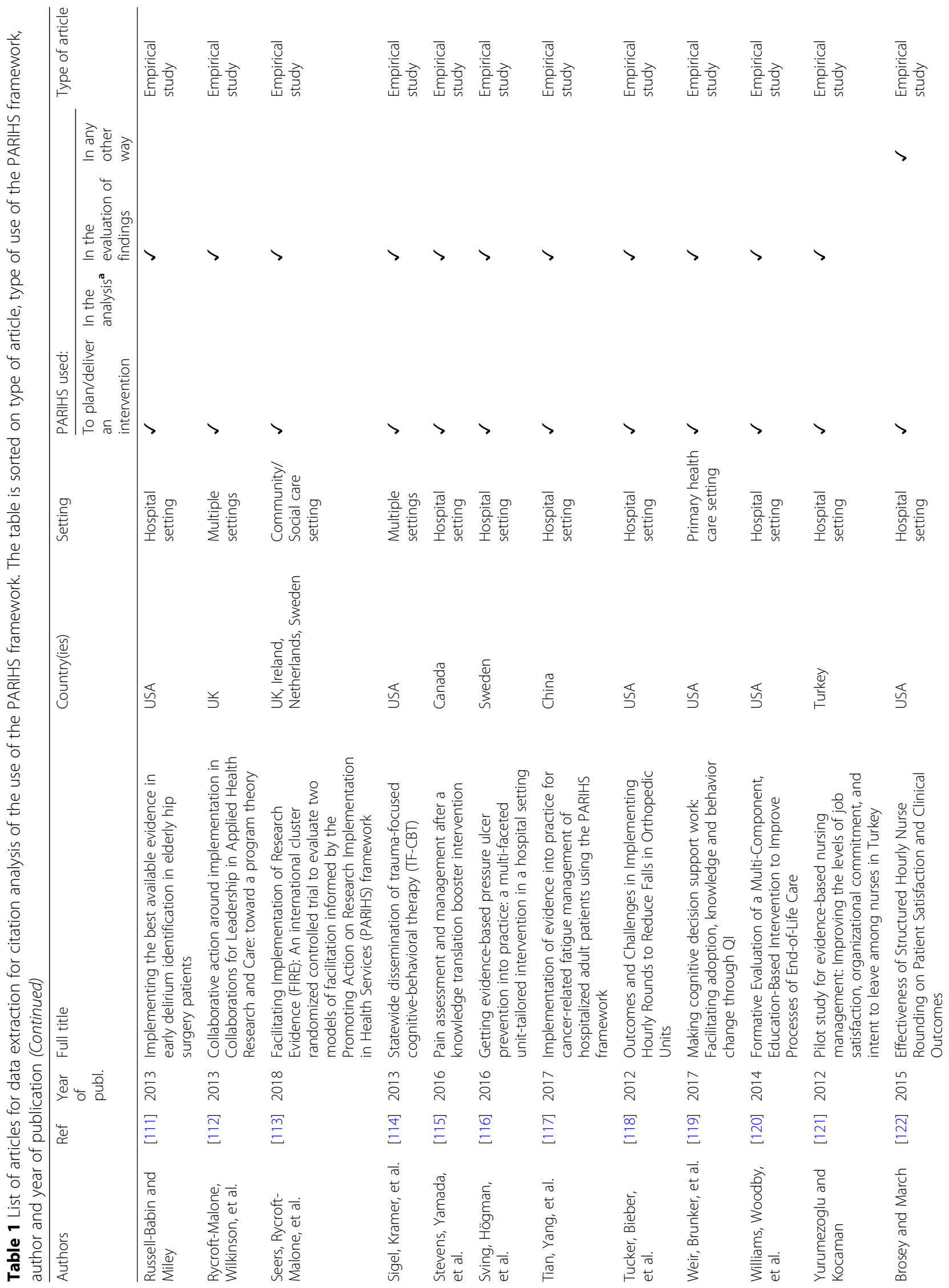




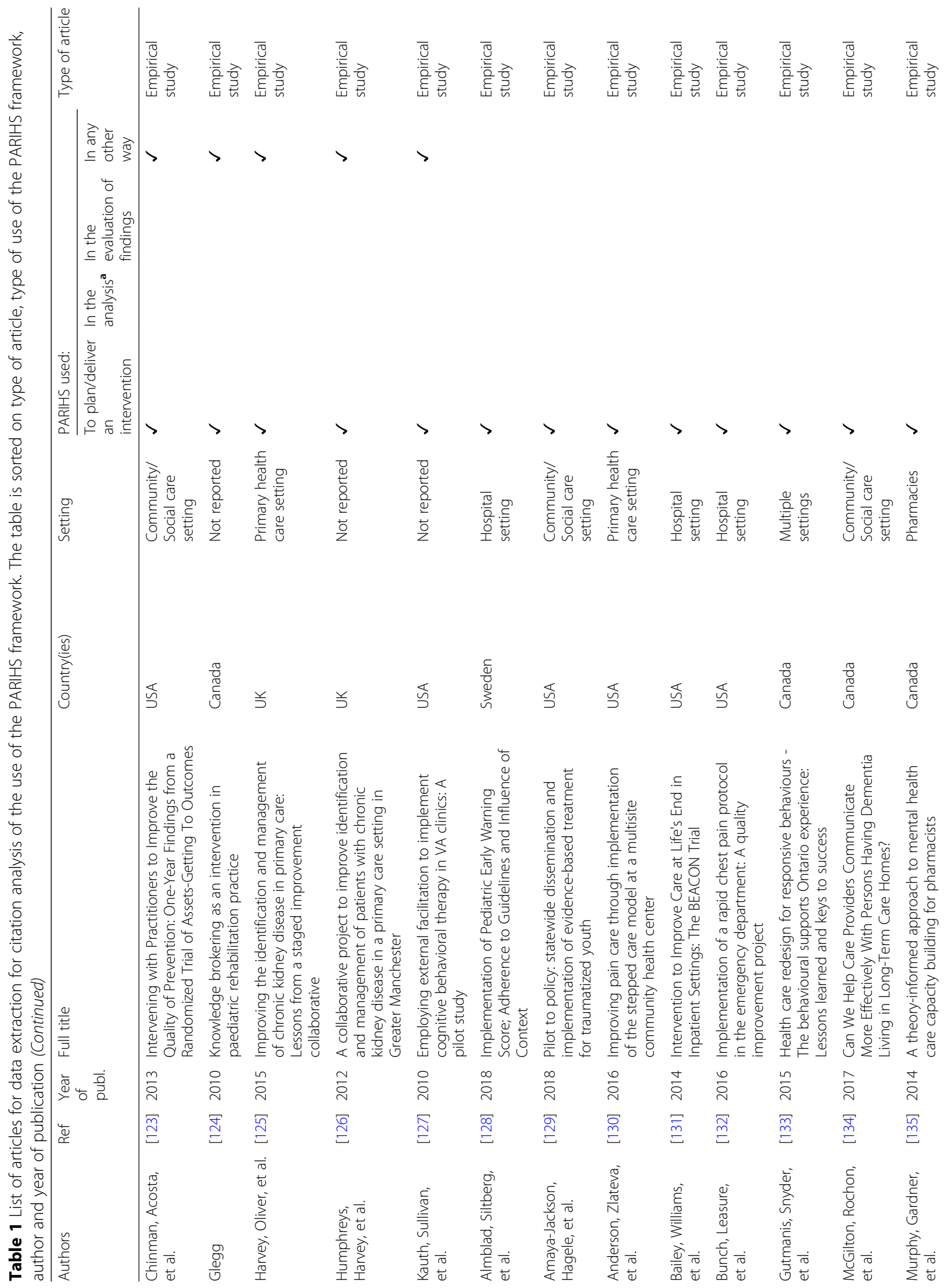




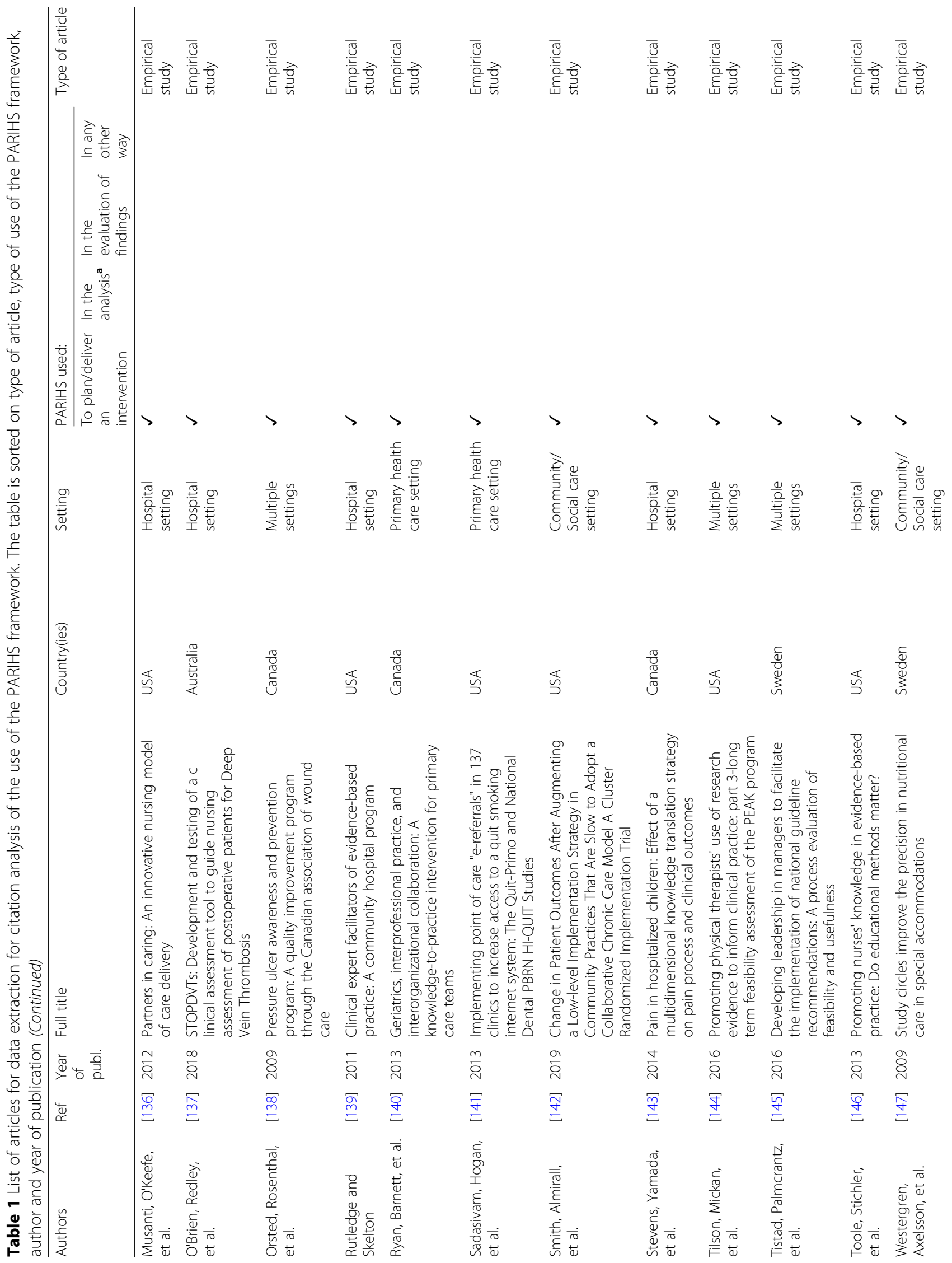




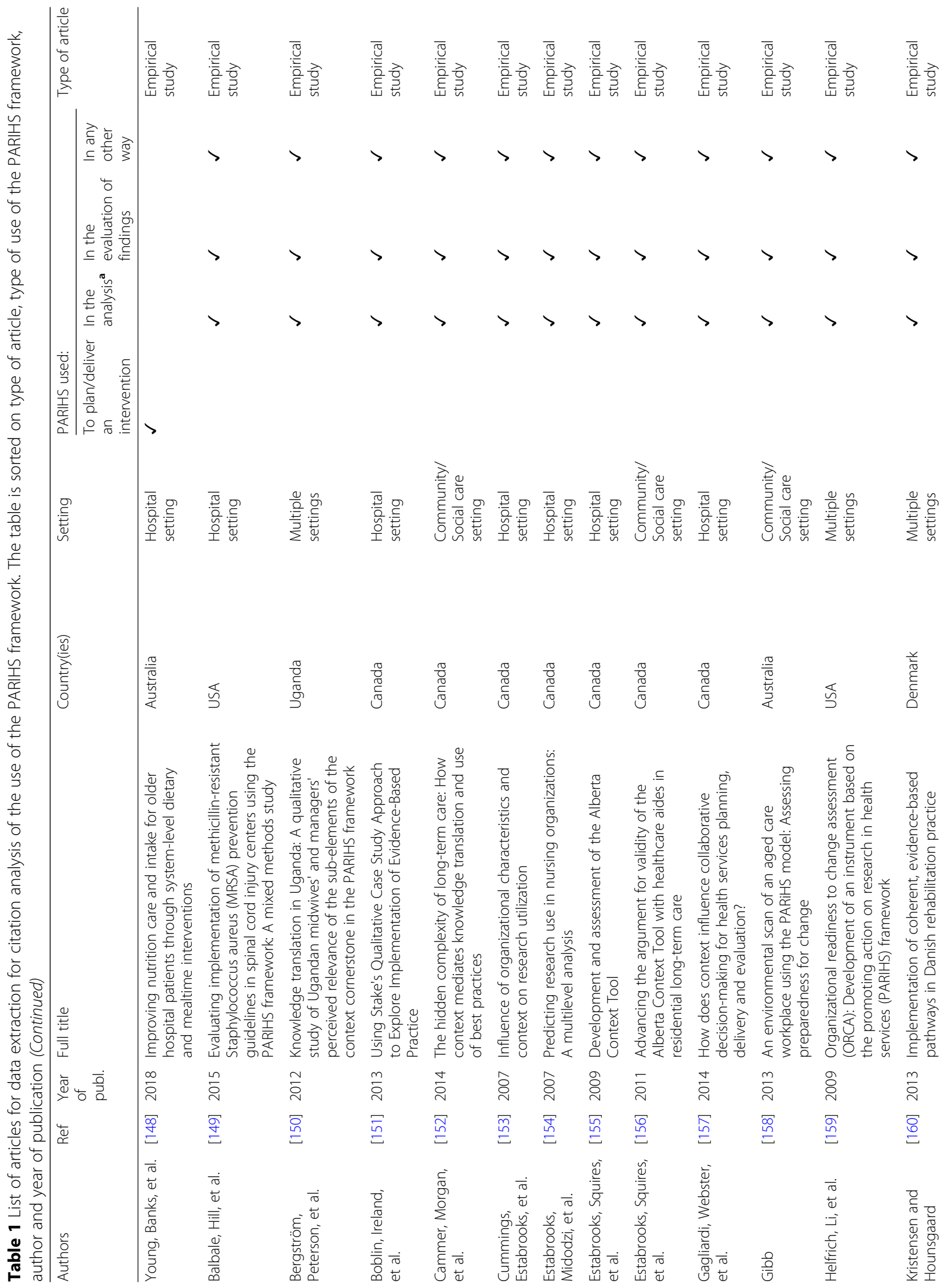




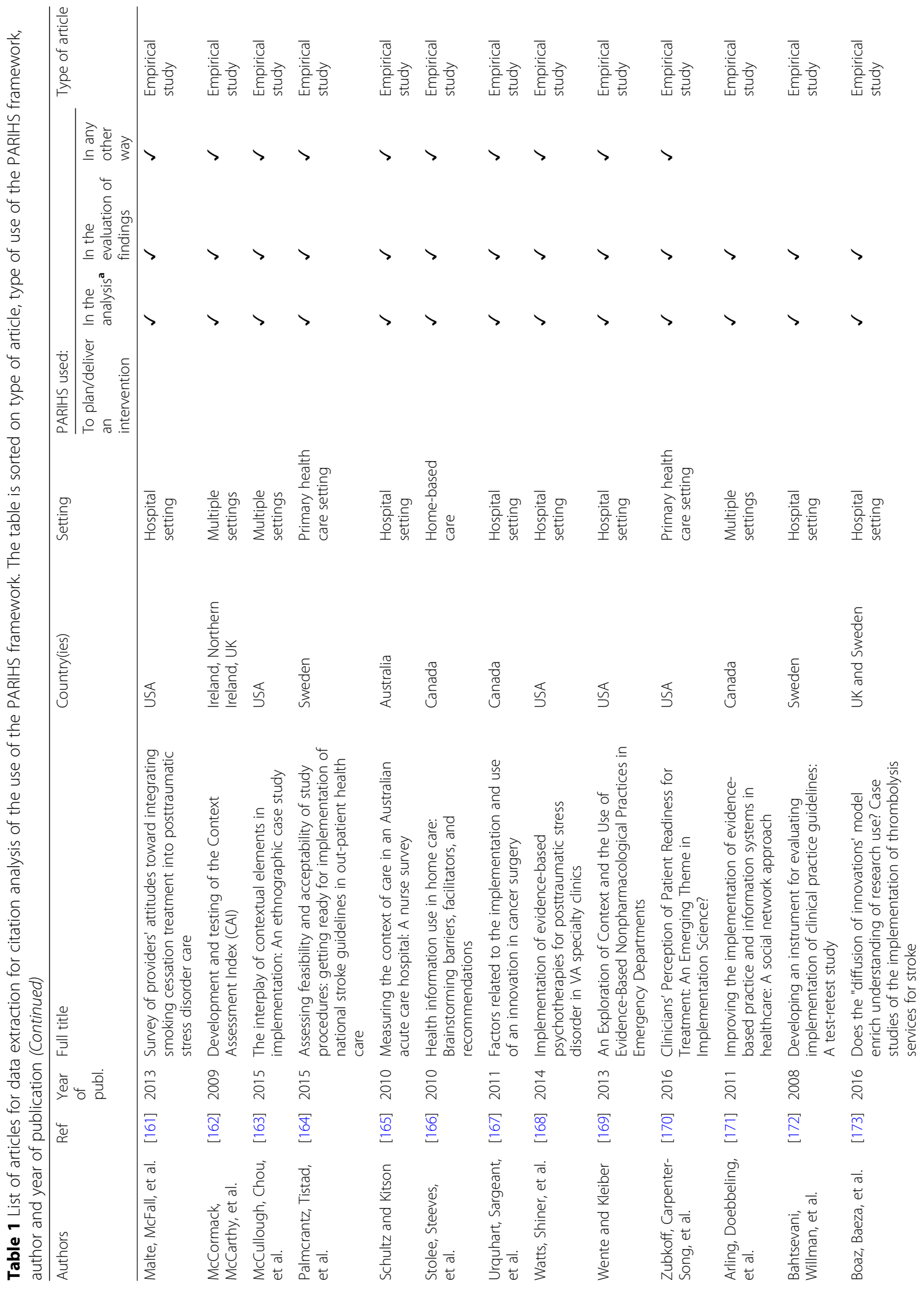




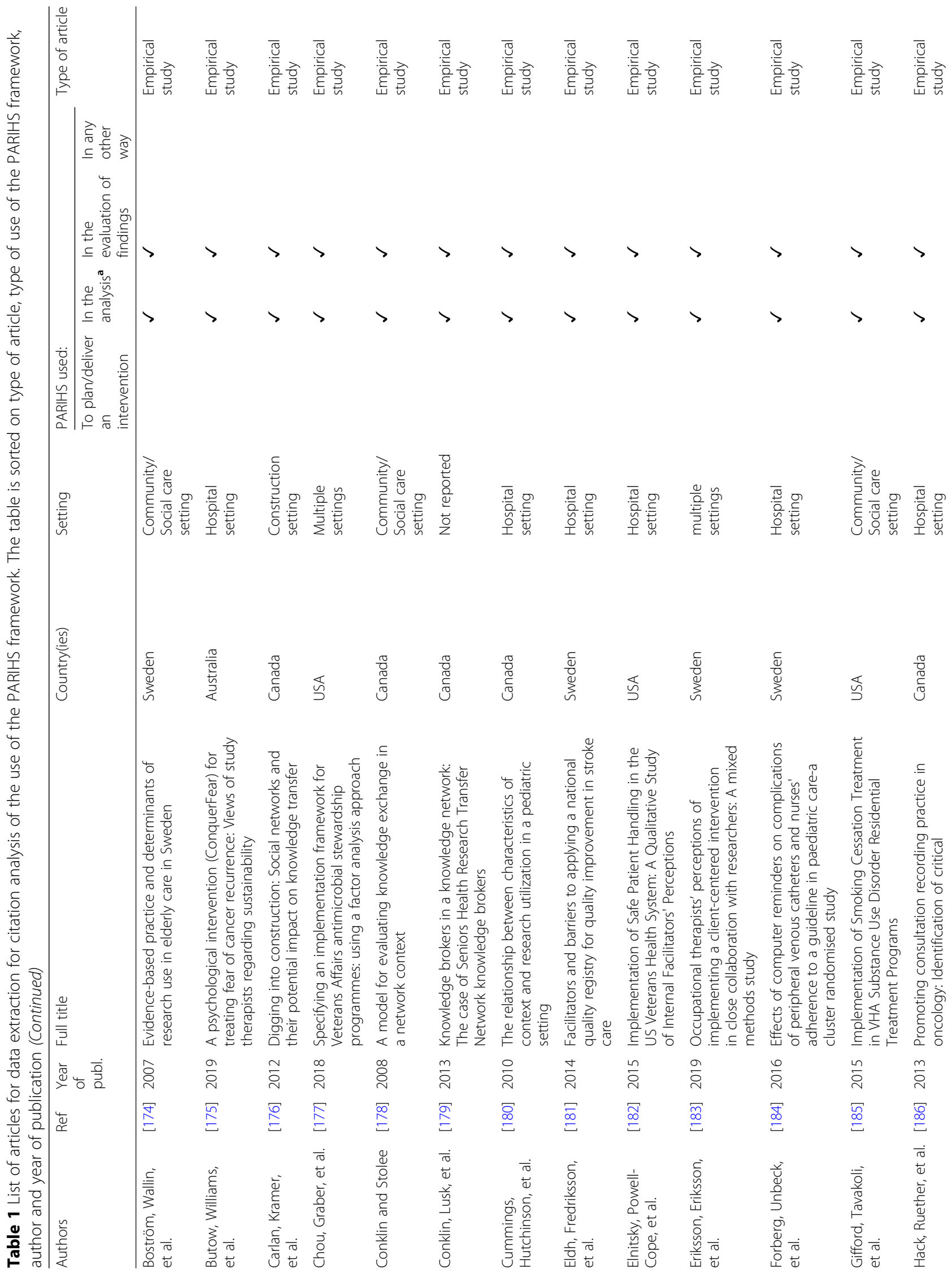




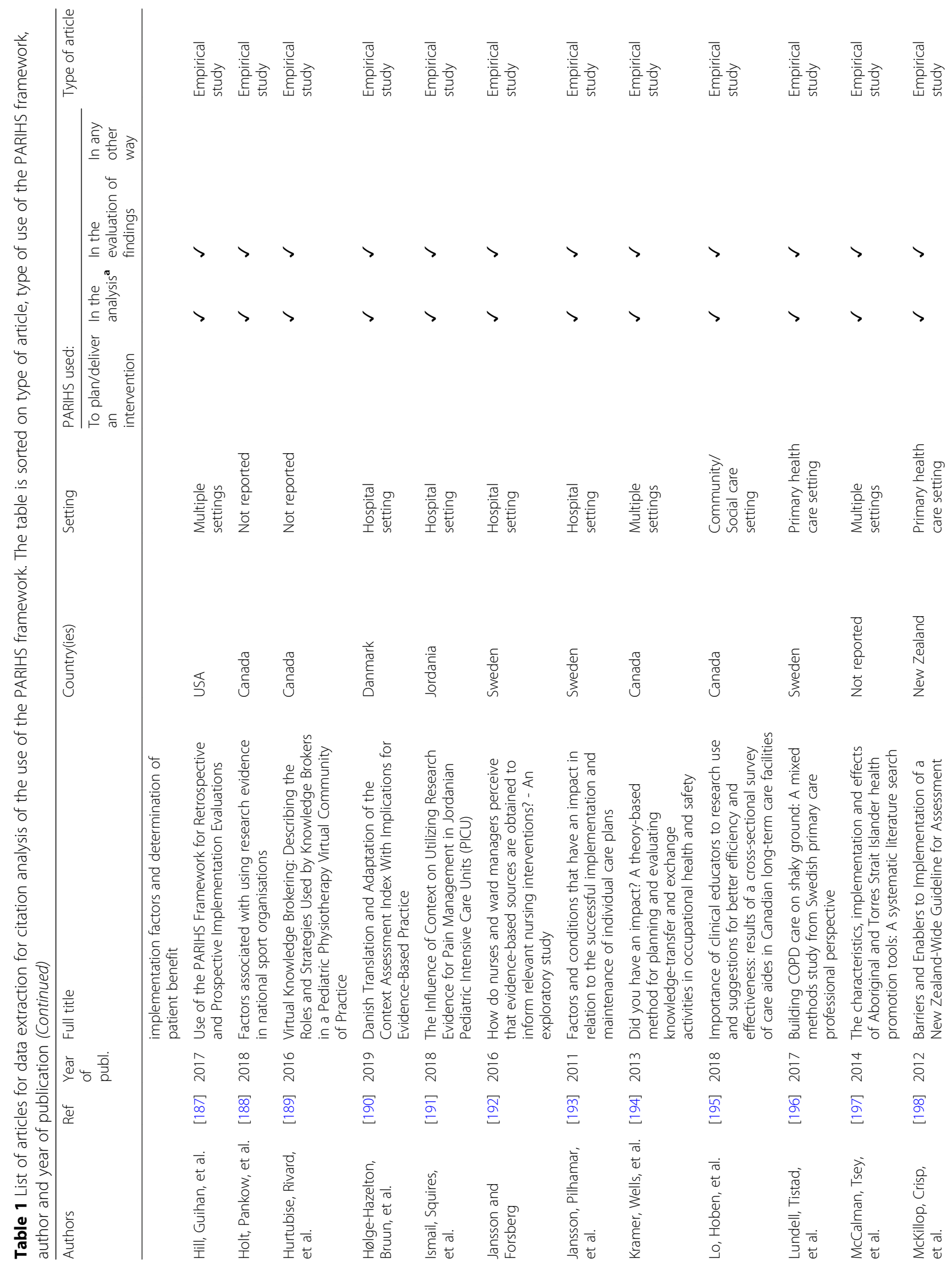




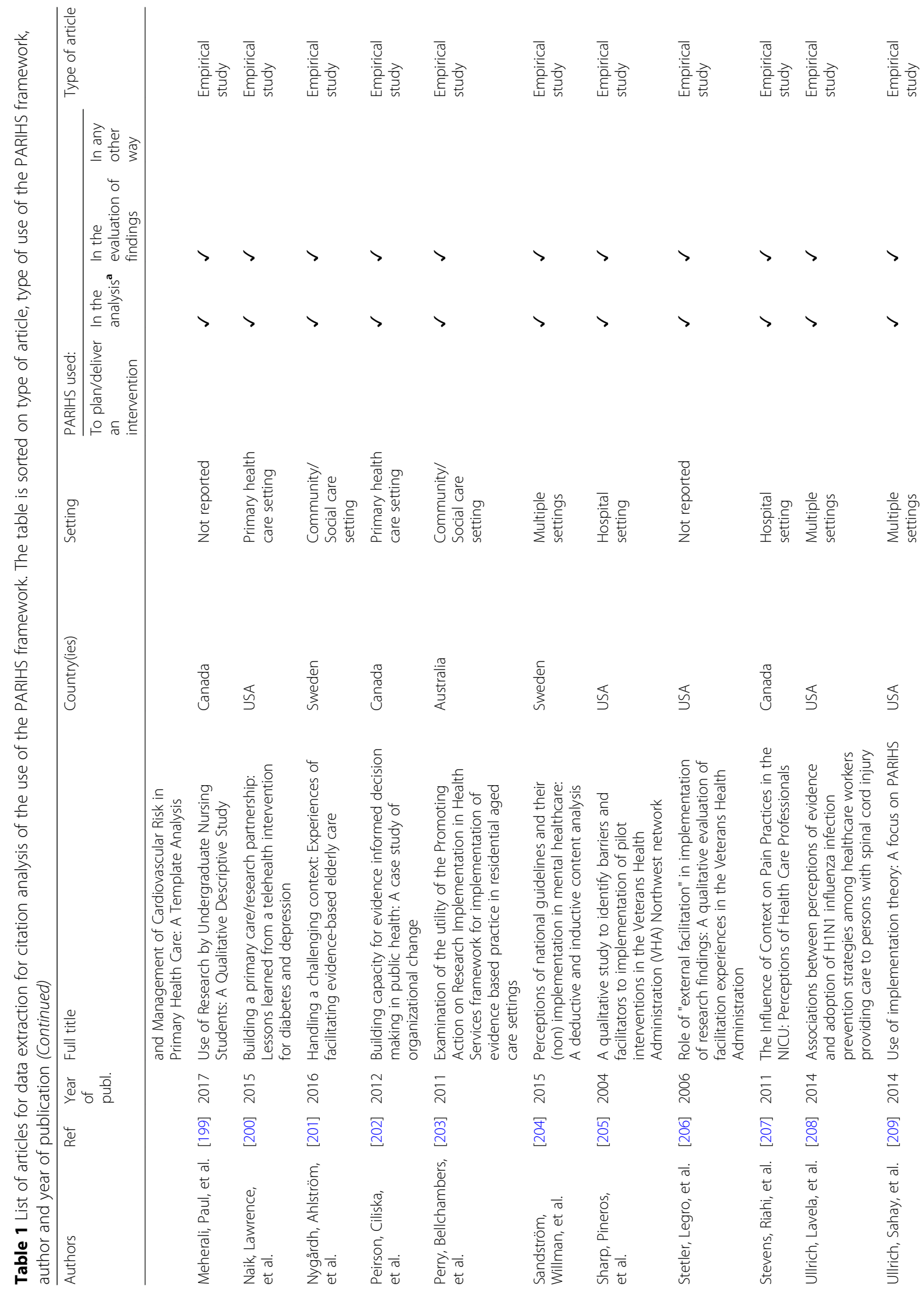




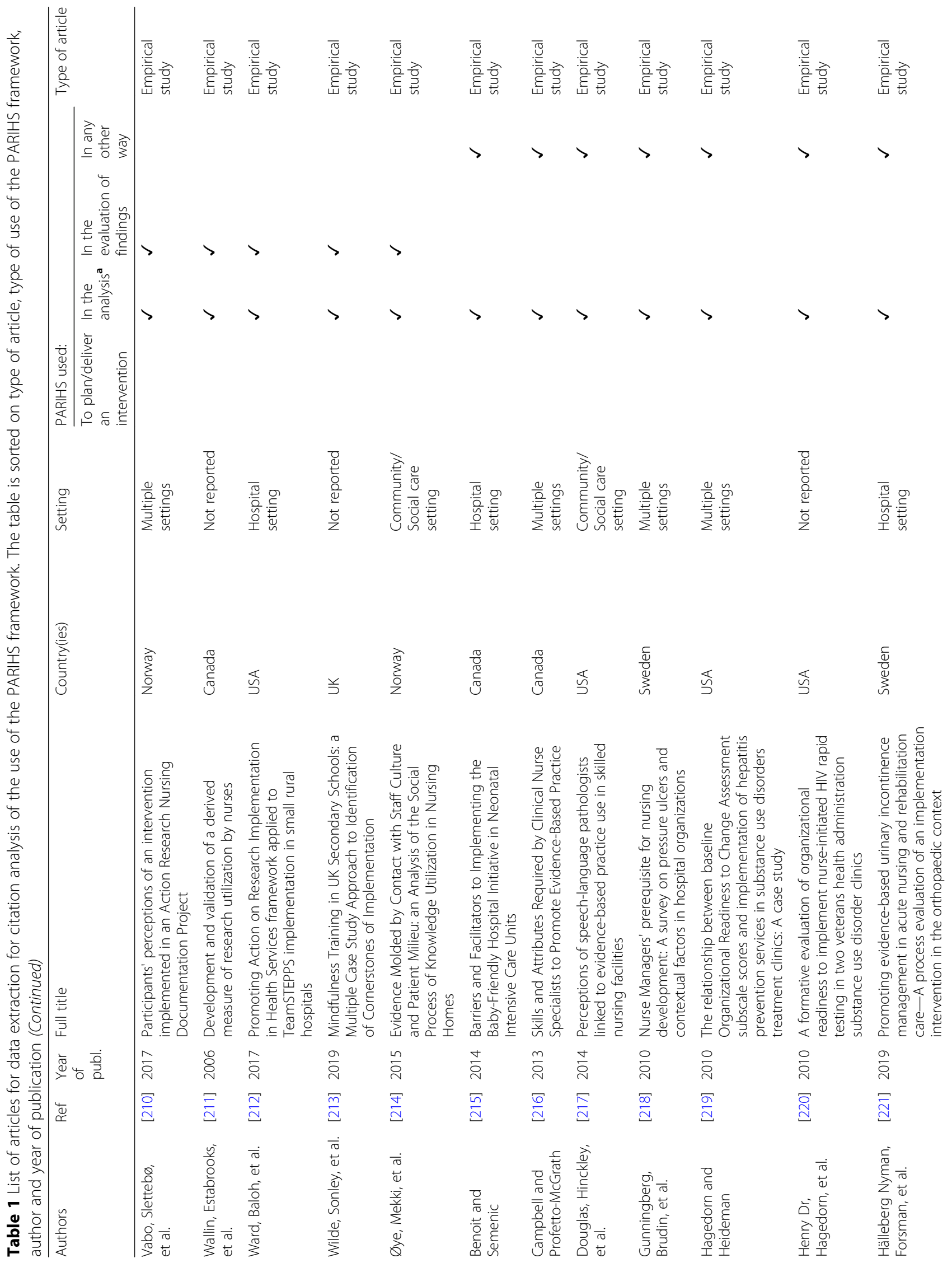




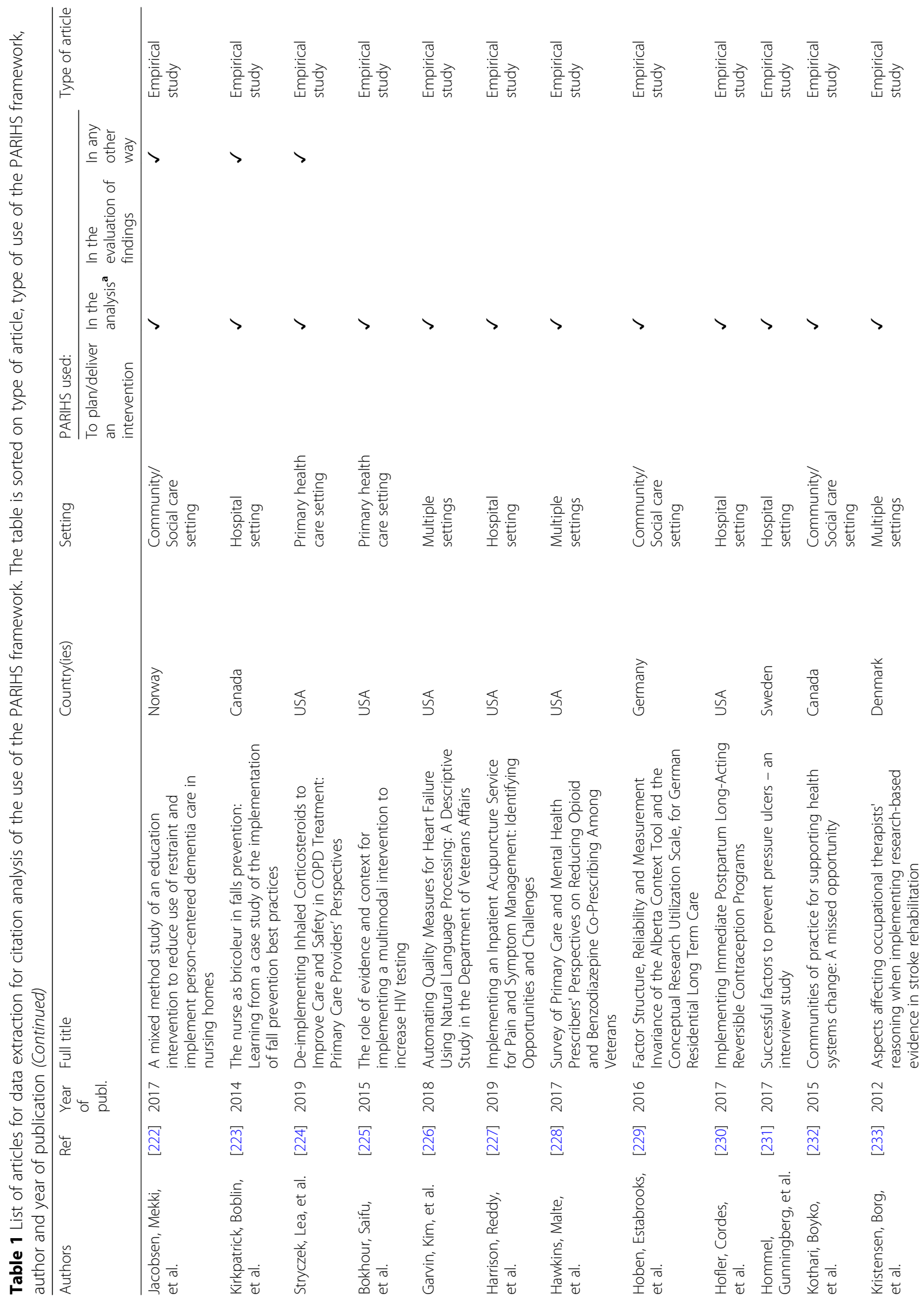




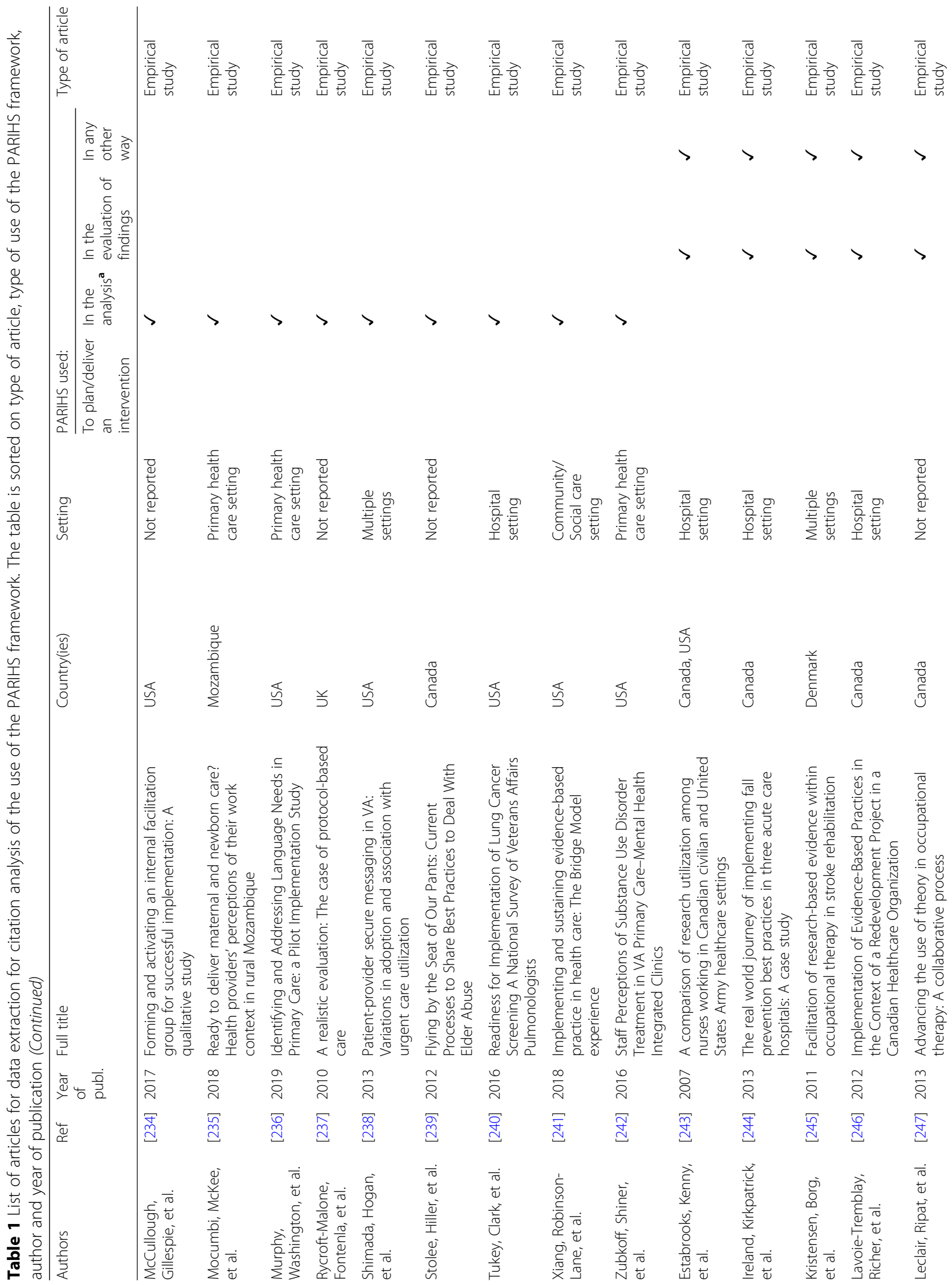




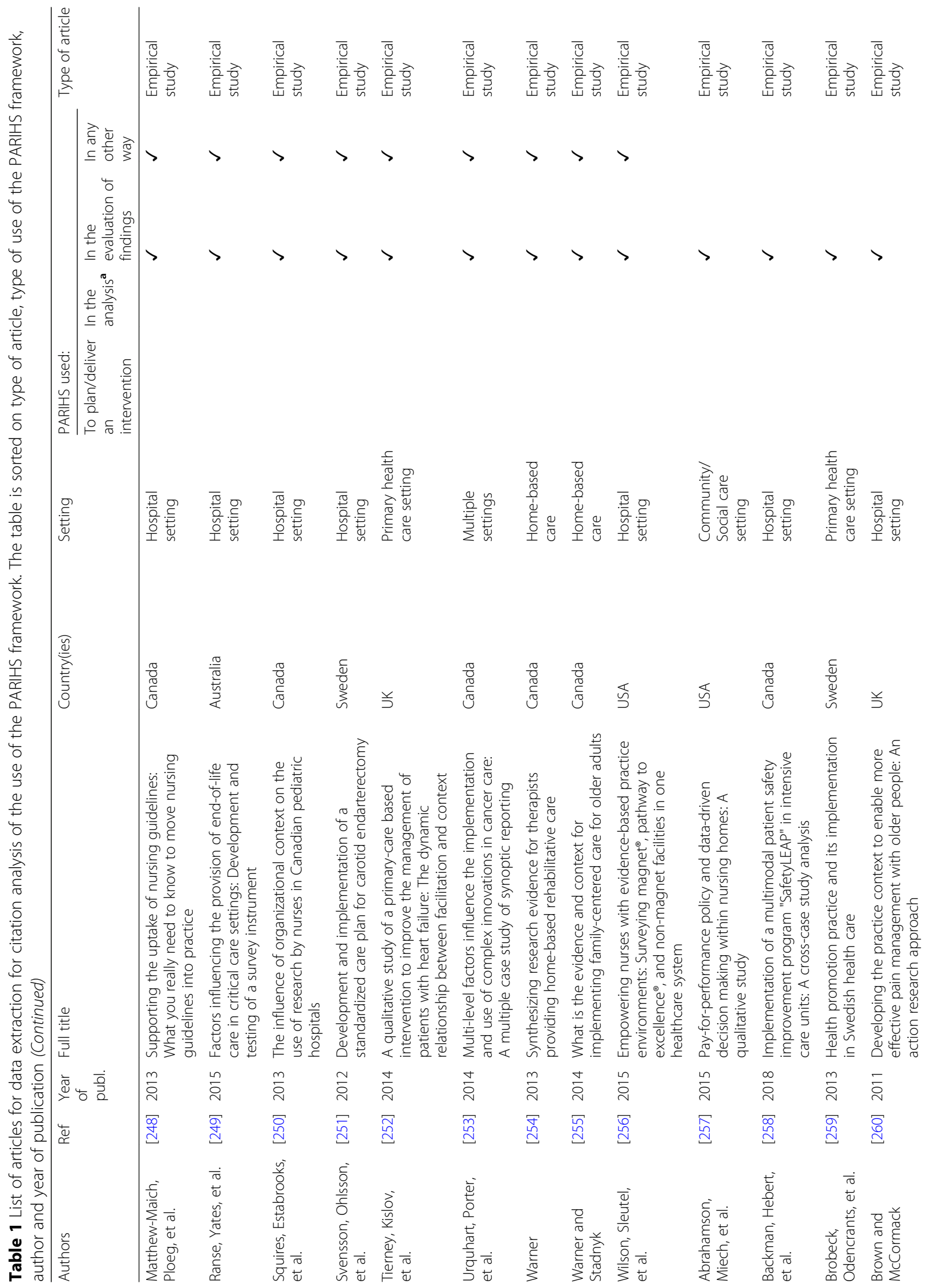




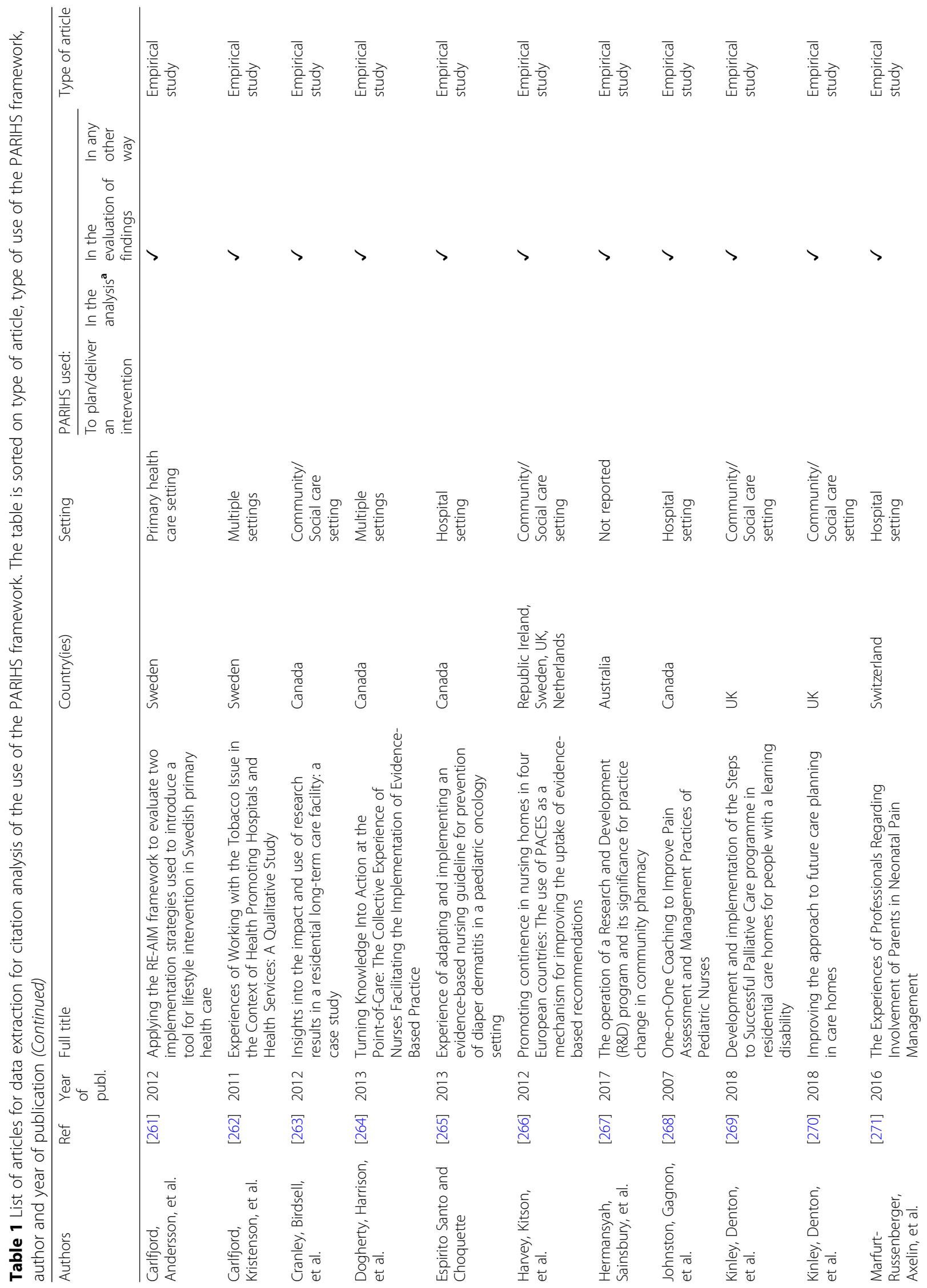




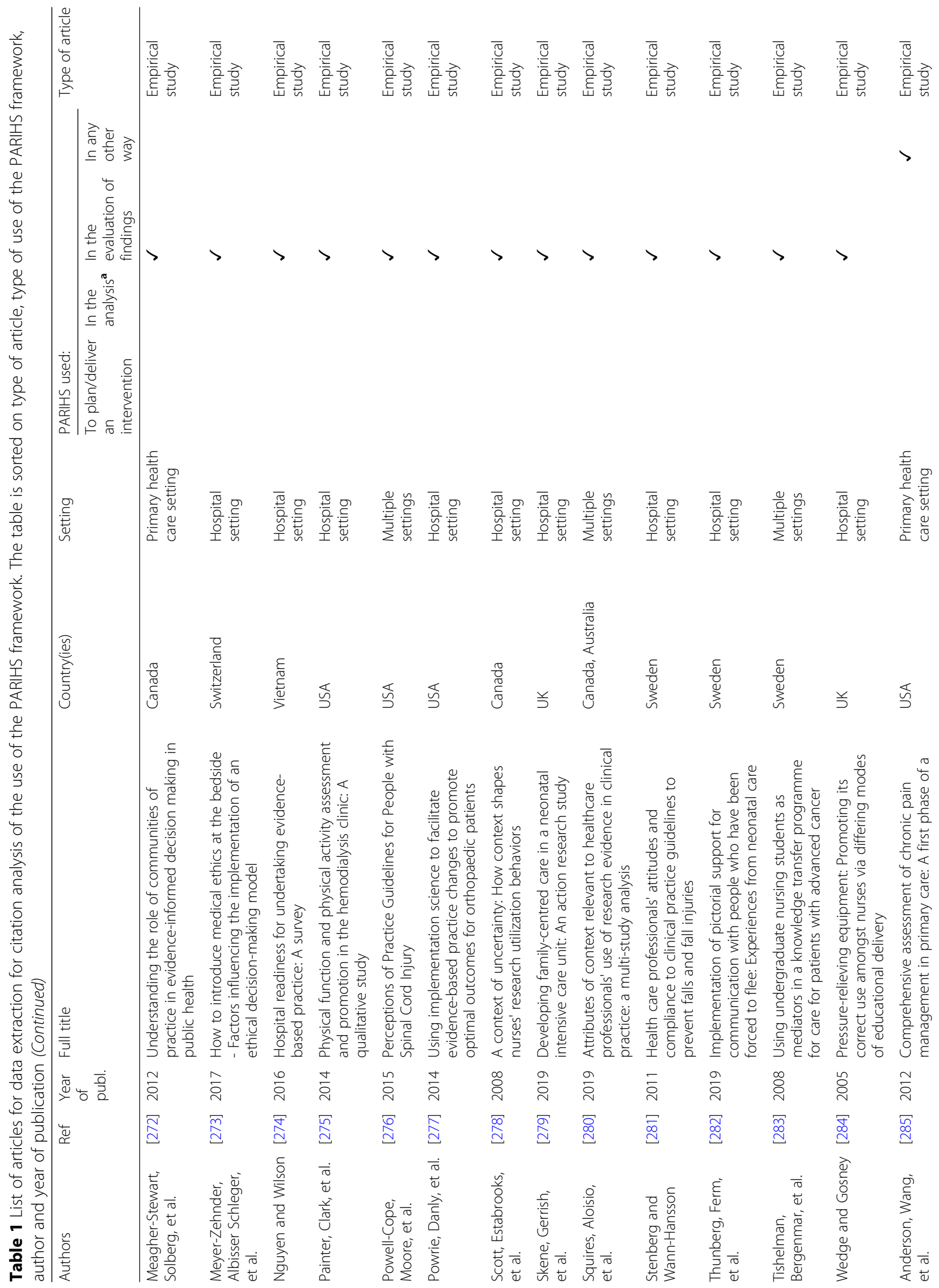




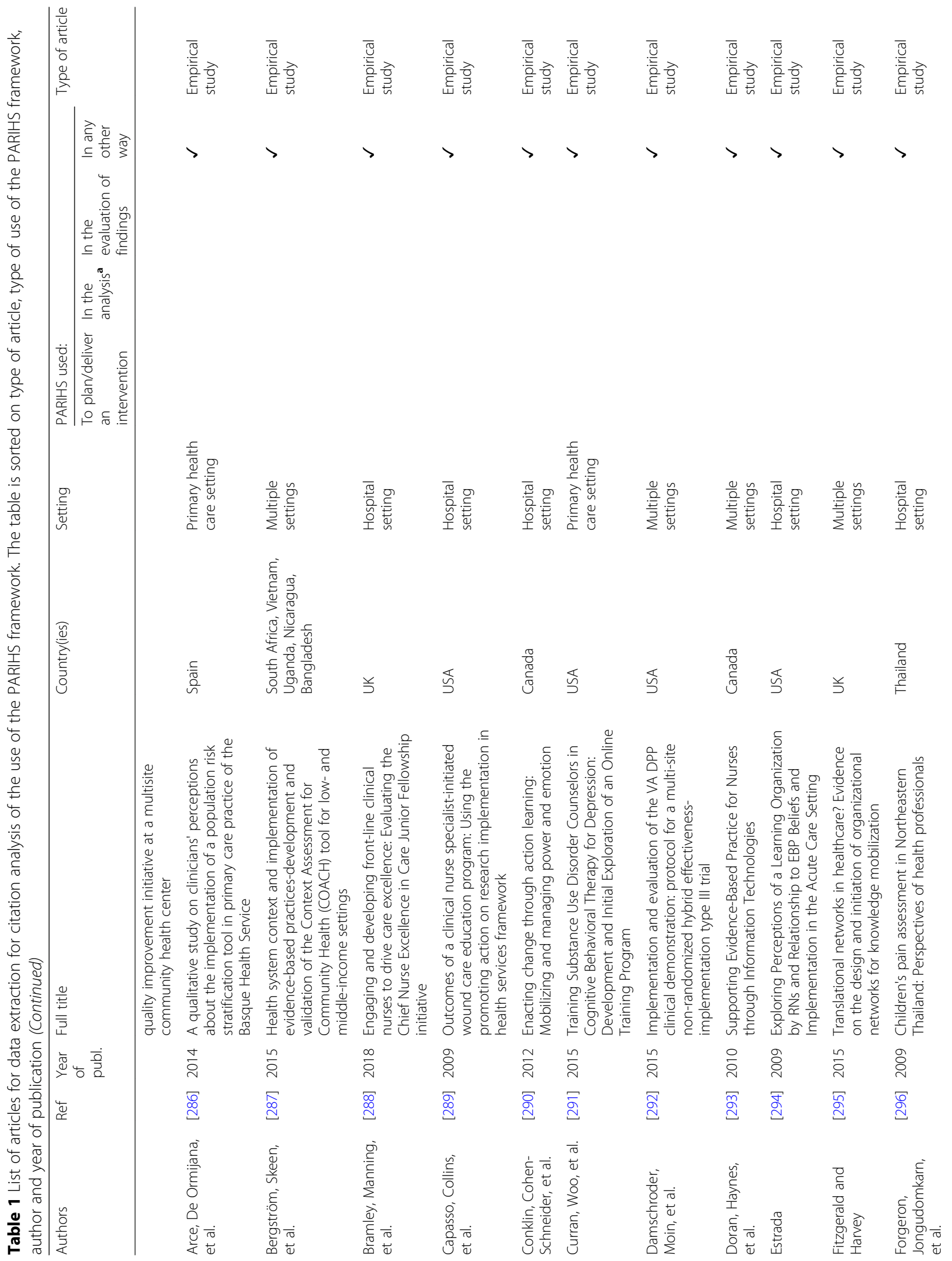




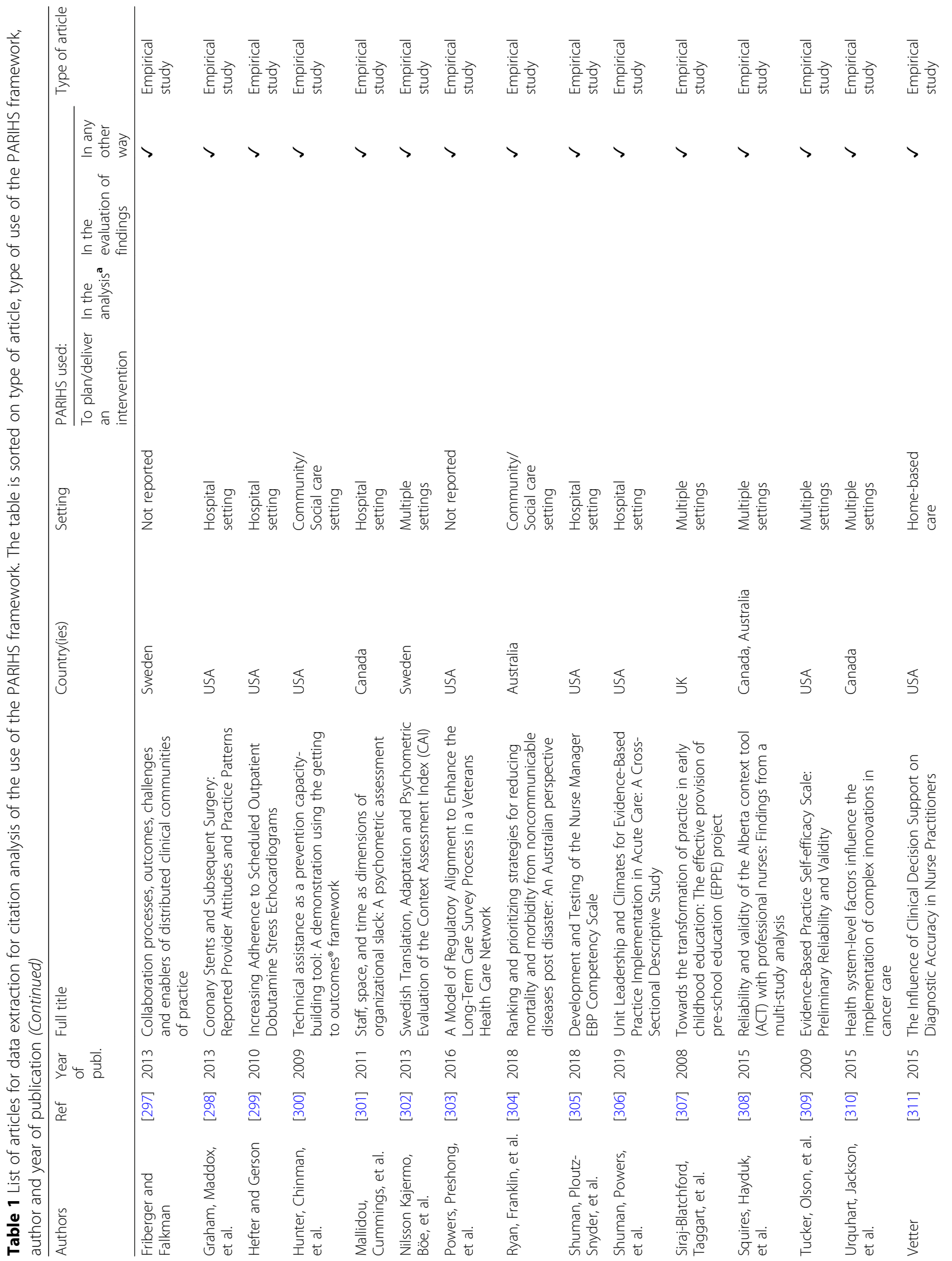




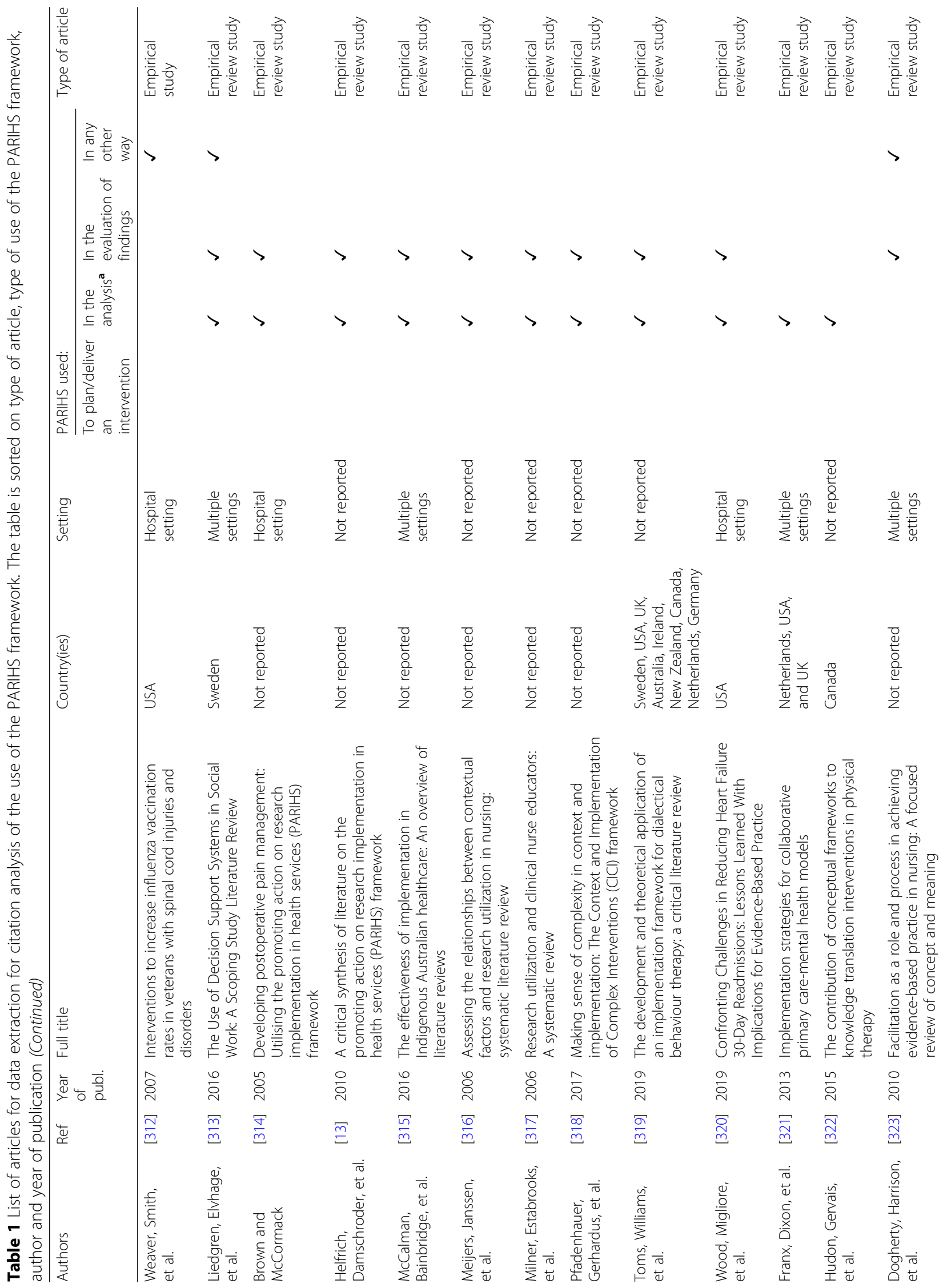




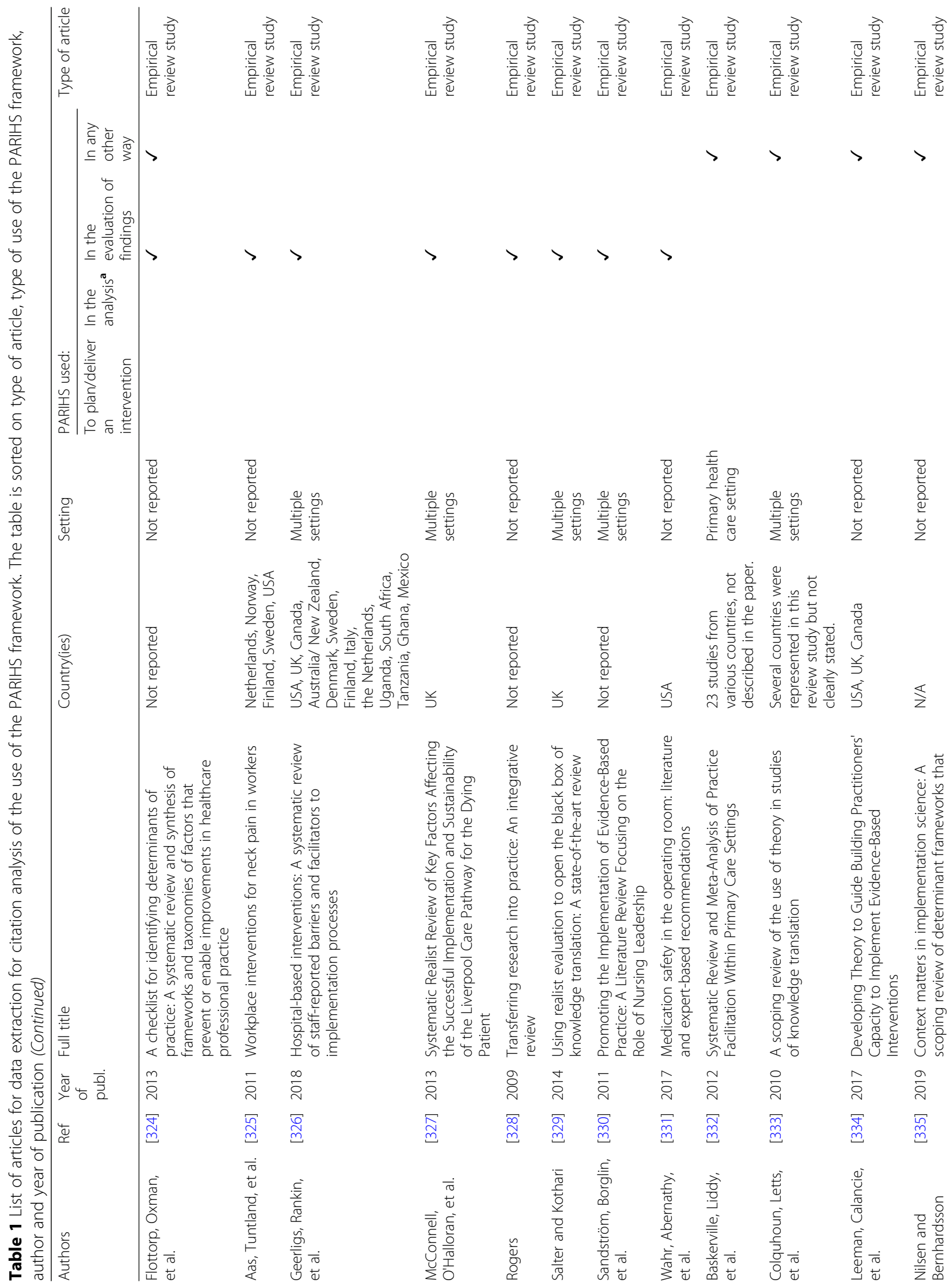




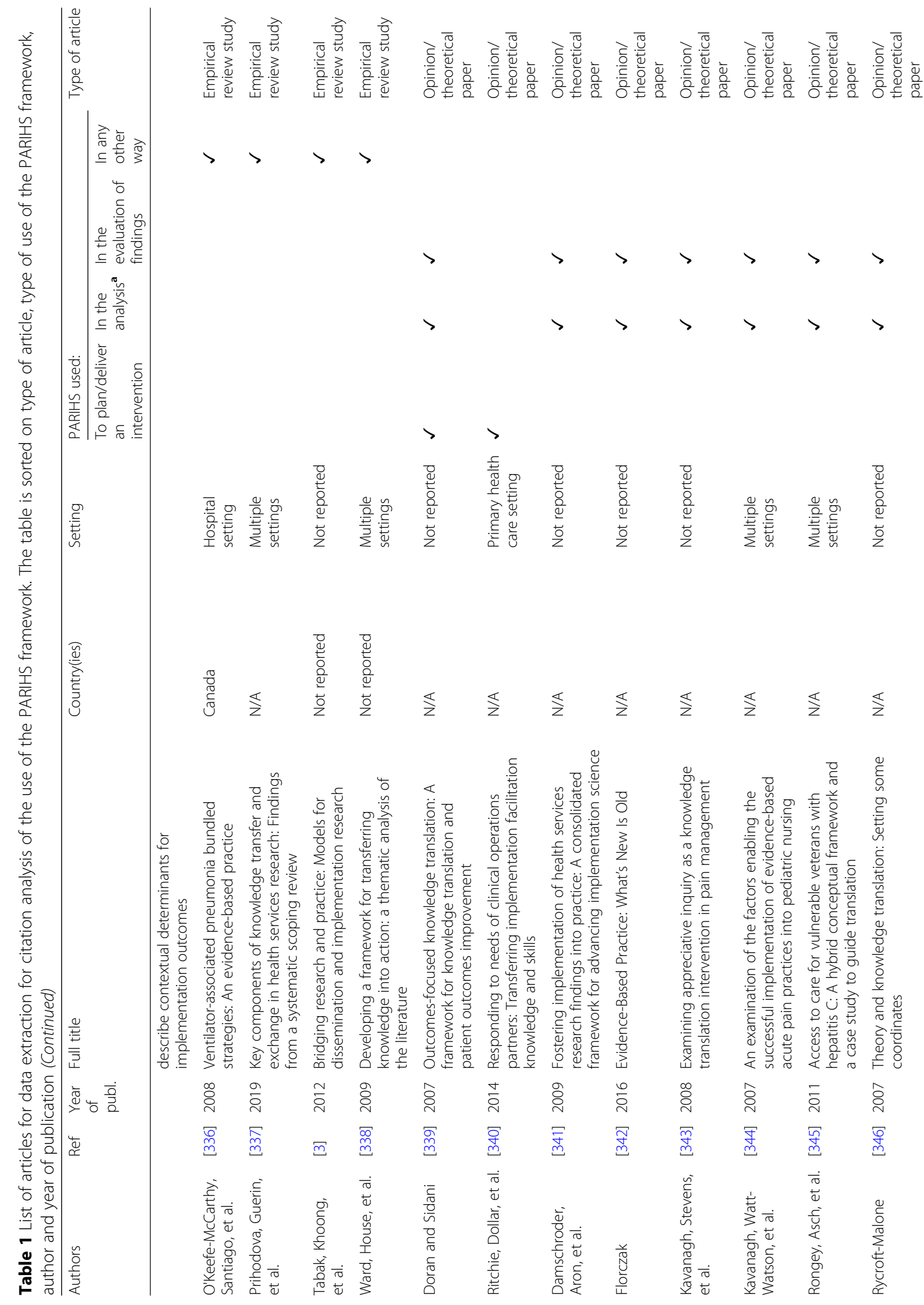




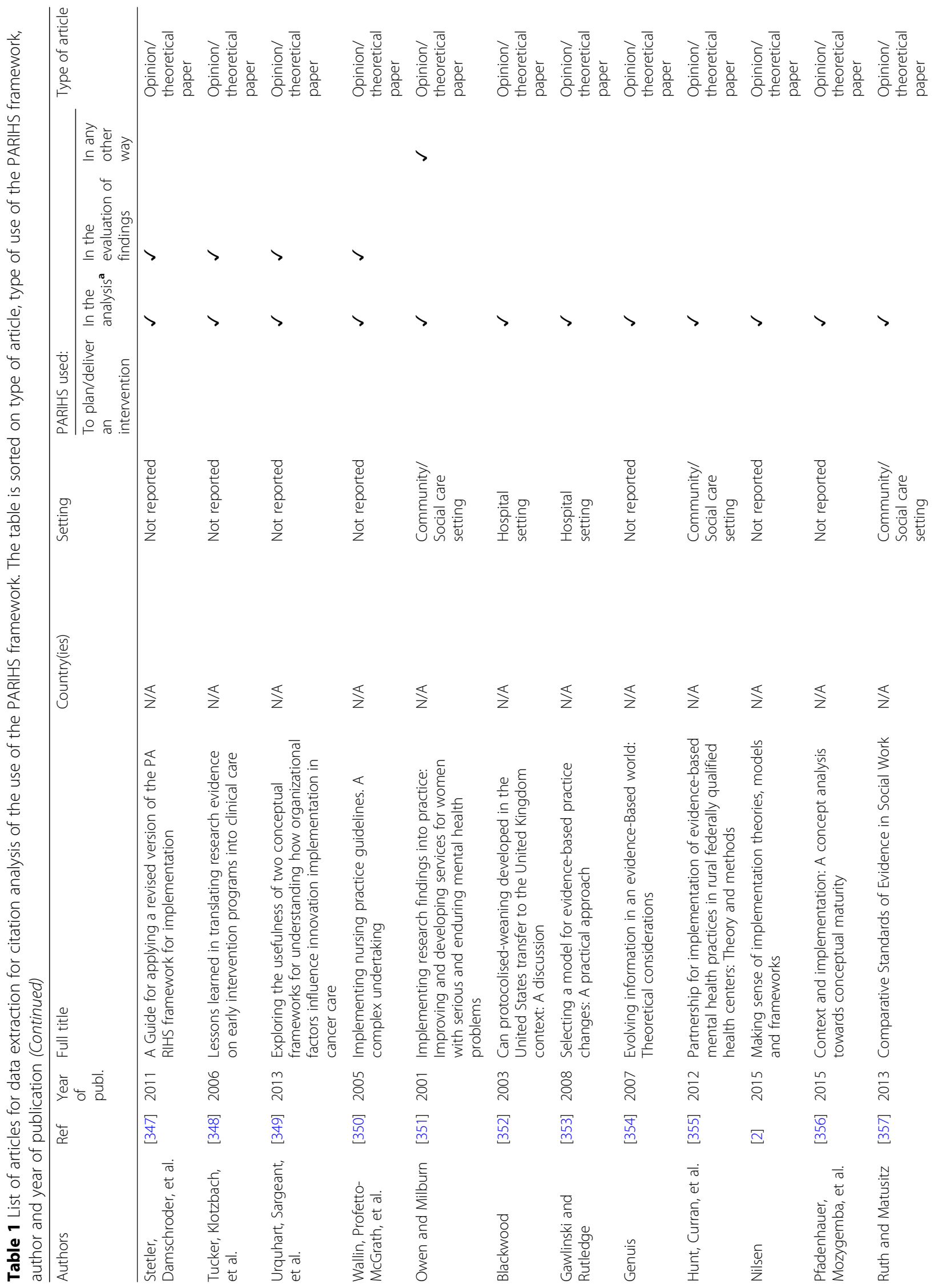




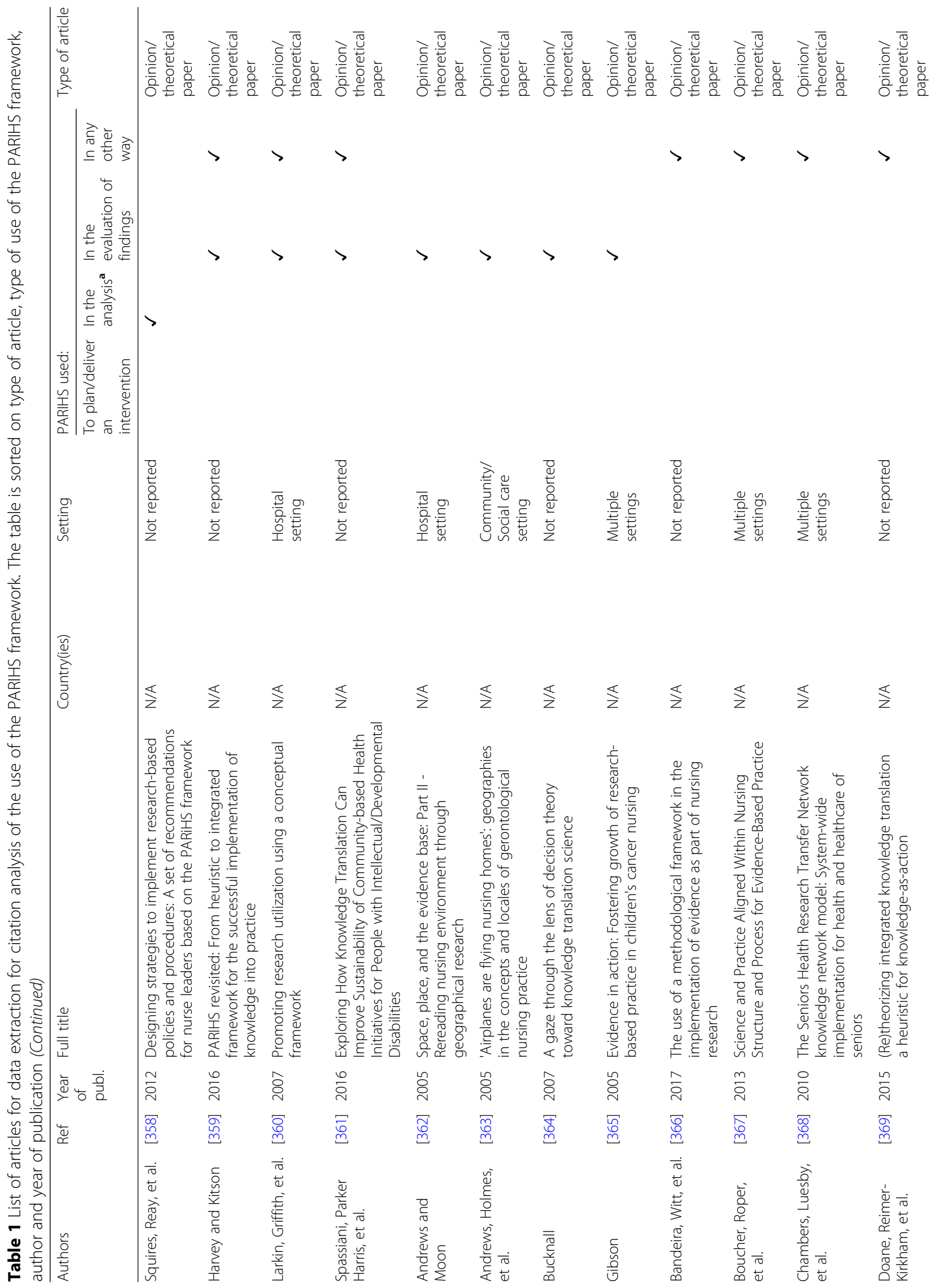




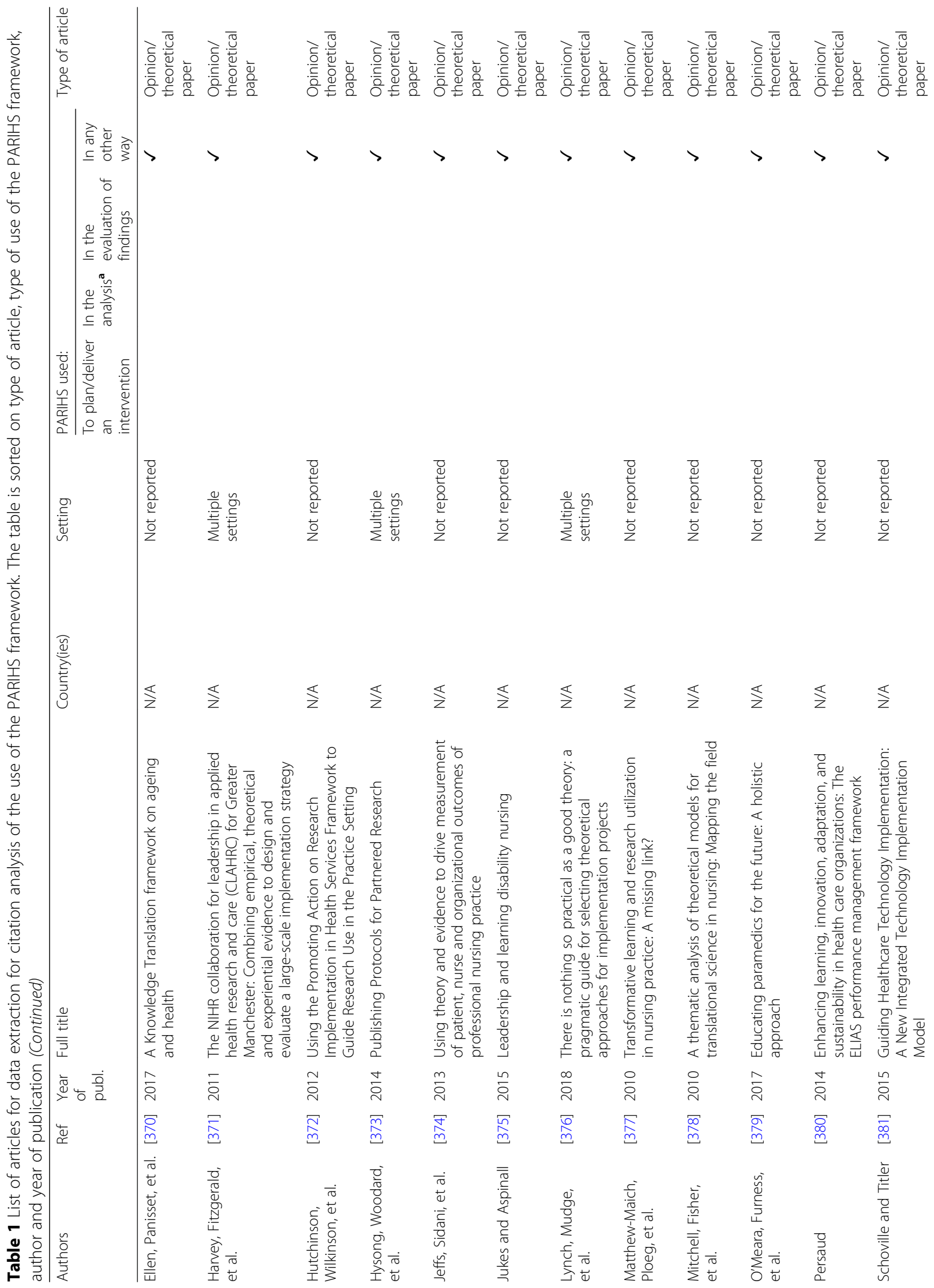




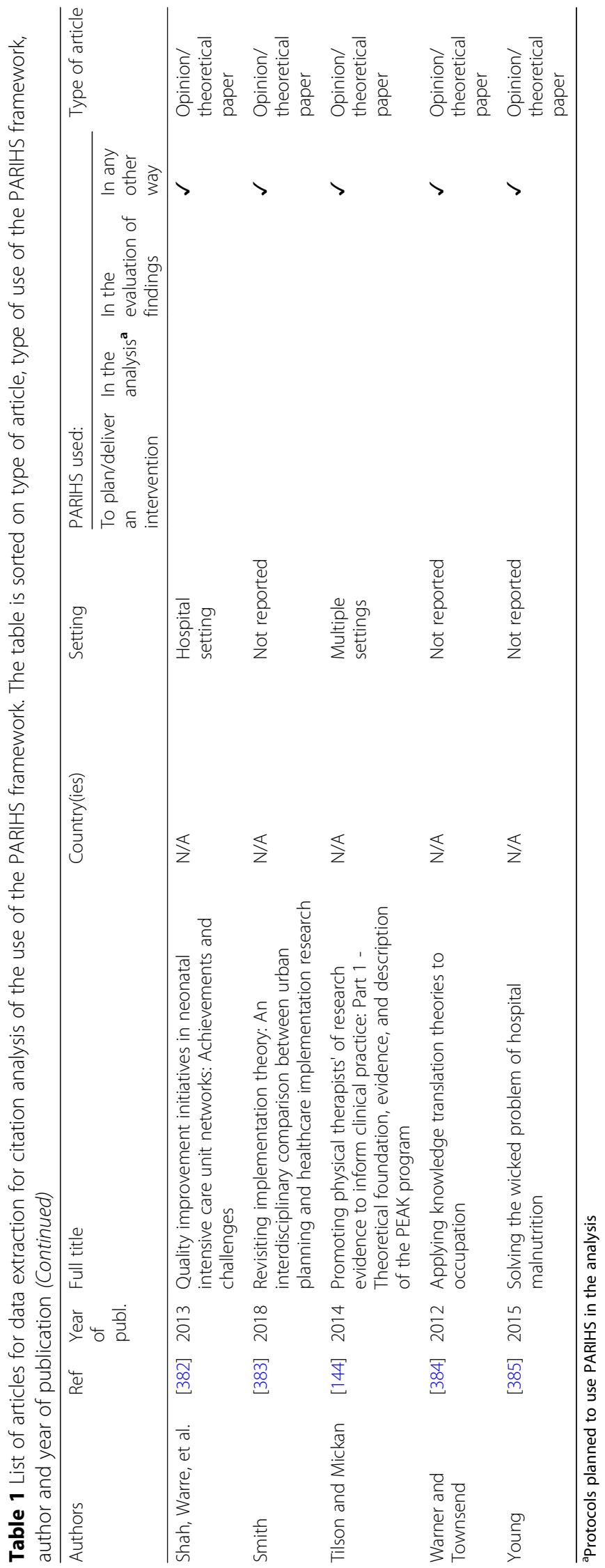


[8], and 92 cited Rycroft-Malone et al. [9]. In total, the 367 articles consisted of 35 protocols [25, 28, 29, 31-38, $40,42,44-50,52-54,56,57]$. A further 255 articles reported empirical studies:

- 91 where PARIHS guided the development of the intervention [58-82, 84-143, 145, 146, 386-388],

- 92 intervention studies where PARIHS did not guide the development of an intervention [149, 152, 153, 155, $156,158,160,162,167,168,171,176,178,179,182-185$, 194, 201-203, 205-209, 211, 212, 214, 217, 219-223, 225, 234-236, 243-245, 249-252, 254, 255, 258-261, 263, 265, 266, 268-270, 273, 274, 276-285, 287-292, 296, 297, 299-301, 303-312],

- 72 non-intervention studies $[150,151,154,157,159$, $161,163-166,169,170,172-175,177,180,181,186-$ 193, 195-200, 204, 210, 213, 215, 216, 218, 224, $226-$ 233, 237-242, 246-248, 253, 256, 257, 262, 264, 267, $271,272,275,286,293-295,298,302]$

In addition, the database included 28 empirical review studies [3, 13, 313, 314, 316-338, 389] and 49 opinion/ theoretical articles [2, 144, 339-385]. In terms of professional focus, about $65 \%$ of the included articles involved nursing.

In the following sections, references have been added to the categorical items in the data extraction while we have opted only to provide examples of references to the findings from the qualitative exploration of how the PARIHS framework was operationalized in detail.

\section{Settings}

Of the articles reporting type of setting where the implementation project/research took place, a majority were undertaken in hospitals $(n=126)[26,27,30,38,39,41$, $42,45,49,51-55,60,62-64,67,70-72,77,84,85,88$, $89,95-98,103,106,107,111,115-118,120-122,128$, $131,132,136,137,139,143,146,149,151,153-155$, $157,161,165,167-169,172,173,175,180-182,184$, 186, 190-193, 205, 207, 212, 215, 221, 223, 227, 230, 231, 240, 243, 244, 246, 248-251, 256, 258, 260, 265, 268, 271, 273-275, 277-279, 281, 282, 284, 288-290, 294, 296, 298, 299, 301, 305, 306, 312, 314, 320, 336, $352,353,360,362,382,386,388]$, followed by a combination of multiple healthcare settings $(n=80)[31,35,37$, $47,50,56,65,66,68,73,79,92,99,100,109,110,112$, $114,133,138,144,145,150,159,160,162,163,171$, $177,183,187,194,197,204,208-210,216,218,219$, 226, 228, 233, 238, 245, 253, 262, 264, 276, 280, 283, 287, 292, 293, 295, 302, 307-310, 313, 321, 323, 326, $327,329,330,333,337,338,344,345,365,367,368$, 371, 373, 376, 387, 389], community/social care settings $(n=54)[24,34,36,43,44,46,48,57,59,61,69,74-76$, $80,81,86,87,94,102,104,108,113,123,129,134,142$, $152,156,158,174,178,185,195,201,203,214,217$,
222, 229, 232, 241, 257, 263, 266, 269, 270, 300, 304, $351,355,357,363]$, primary health care $(n=34)[23,25$, $28,29,40,58,82,90,93,119,125,130,140,141,164$, $170,196,198,200,202,224,225,235,236,242,252$, 259, 261, 272, 285, 286, 291, 332, 340], and home-based care $(n=7)[78,91,105,166,254,255,311]$. Five articles were derived from special settings such as construction [176], education [101], pharmacies [135], urban planning [383], and public health institutions [32]. In 44 articles $[2,3,13,33,124,126,127,179,206,211,220,237,239$, $247,297,316,317,322,324,325,328,339,341-343$, $346-350,354,356,358,364,369,372,374,375,377$, $378,380,381,384,385]$, the setting was not reported or not applicable (e.g., opinion/theoretical articles). For empirical studies and published protocols, about $28 \%$ were derived from research in the USA, 22\% from Canada, $10 \%$ from Sweden, and 10\% from the UK. The remaining articles mainly originated from other high-income countries in Europe; in addition, there were a few articles reporting studies in low- and middle-income countries, including Vietnam, Tanzania, Mozambique, and Uganda $[46,82,110,150,235,287]$.

\section{Timing of different types of articles}

The types of articles published using the PARIHS framework changed over time, with an increase in the number of empirical studies from 2004 onwards, as illustrated in Fig. 2. As the search for articles for this review only included the first eight months of 2019, the graph is limited to full years (i.e., 1998 through 2018).

\section{Use of PARIHS}

Figure 3 depicts how PARIHS was used by type of article. Although authors frequently claimed that PARIHS was used in one or more ways, details as to how the framework was used were often lacking.

\section{The application of PARIHS to plan and deliver an intervention}

In total, 117 (32\%) articles claimed to use the PARIHS framework to plan and deliver an intervention [23-46, 58-82, 84-143, 145, 146, 339, 340, 386-388]. Predominantly, these were empirical studies $(n=91)$ [58-82, 84$143,145,146,386-388]$ but also two opinion/theoretical articles [339, 340] and 24 protocols [23-46]. Of the 117 articles, about half stated that the framework was used for theoretically informing, framing, or guiding an intervention (e.g., [82, 103, 105, 134, 386]). However, in these studies, PARIHS was referred to only in a general sense, in that the core elements of the framework were said to have informed the planning of the study. There was a lack of detail provided about what elements of the framework were used and how they were operationalized to plan and deliver an intervention. In the other half of 


\section{Types of published articles published before 31st December 2018 using the PARIHS framework}

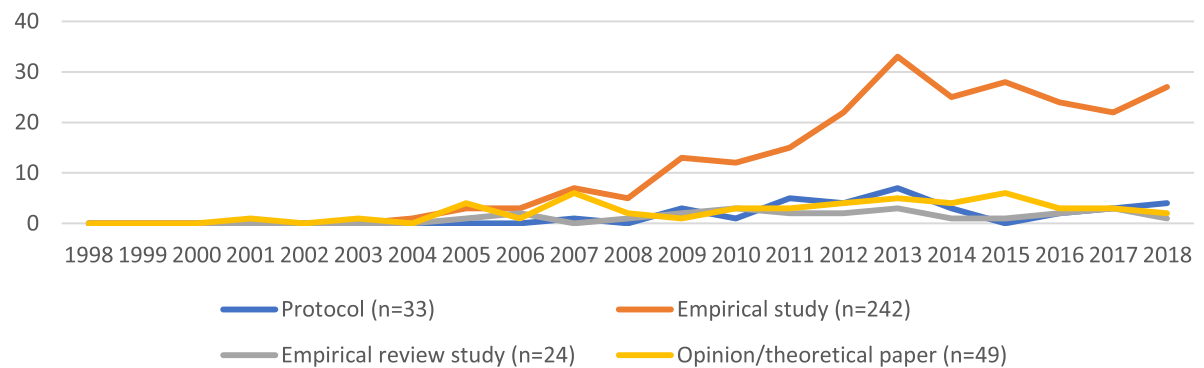

Fig. 2 Types of articles published before December 31 using the PARIHS framework

the 117 articles, it was described more specifically that one or more elements of the framework had been used. Most commonly the facilitation element (e.g., [58, 80, 92, 98, 110]) was referred to as guiding an implementation strategy. The articles that provided explicit descriptions of interventions using facilitation employed strategies such as education, reminders, audit-andfeedback, action learning, and evidence-based quality improvement, and roles including internal and external facilitators and improvement teams to enable the uptake of evidence (e.g., [23, 79, 125, 142]). Some articles drew on the PARIHS framework more specifically, to understand the role of organizational context in implementation (e.g., $[34,63,145,340])$.

\section{The application of PARIHS in data analysis}

There were 184 (50\%) articles where the PARIHS framework was reported to be used in the analysis $[2,13,23-$ $35,47-55,58-82,84-94,149-242,313,314,316-322$, $339,341-358,386,389]$. Most of these involved empirical studies $(n=131)$ [58-82, 84-94, 149-242, 386] where PARIHS often was described as guiding or framing the data collection, e.g., developing an interview guide, and/or analysis, but with no further details. In articles that provided more detailed information, PARIHS was used to guide or frame qualitative analyses in about 50 studies (e.g., [67, 94, 173, 178, 207]). Of these, around 20 used a deductive approach in that they used the elements and sub-elements to structure the analytic process

\section{THE USE OF THE PARIHS FRAMEWORK MAPPED BY TYPE OF ARTICLE}

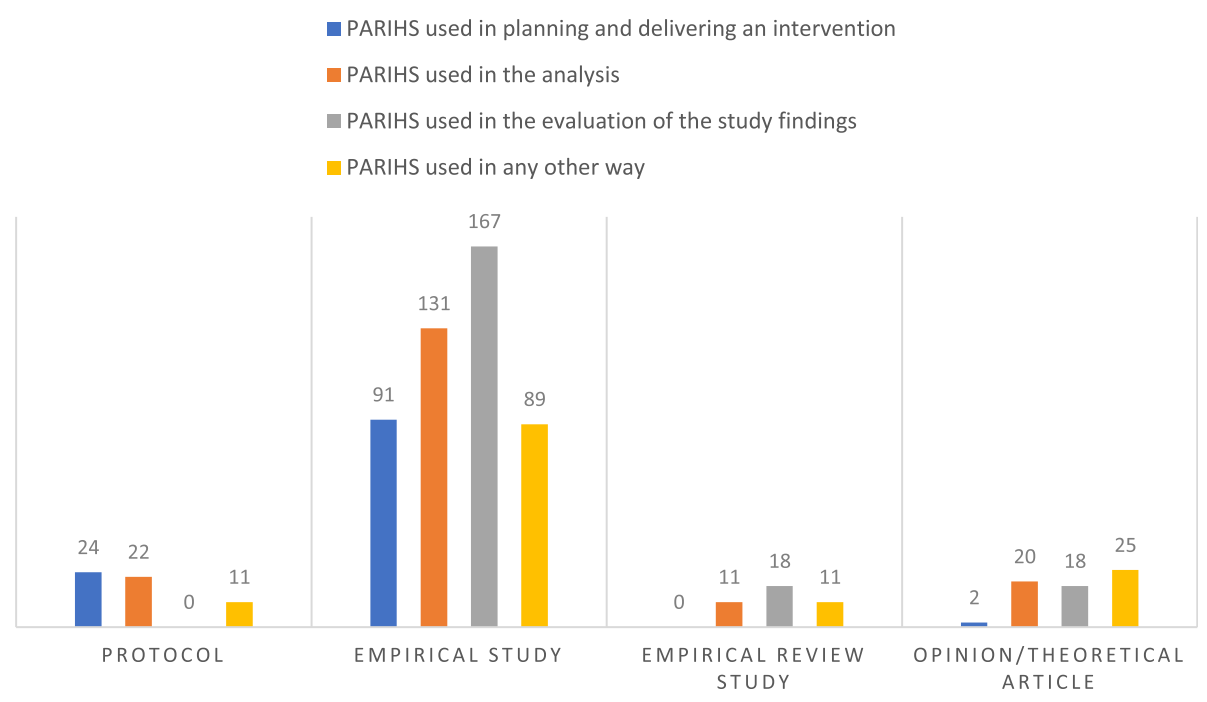

Fig. 3 Use of the PARIHS framework by type of article 
(e.g., [150, 170, 188, 215, 242]). About 35 studies applied PARIHS for quantitative analysis, (e.g., [69, 168, 174, 190, 211]). In half of these, the Alberta Context Tool (e.g., [155, 165, 180, 195, 229]) and the Organizational Readiness to Change Assessment Tool (e.g., [74, 159, 219, 240]) were used; both these tools being derived from PARIHS. Empirical studies using the PARIHS framework in the analysis encompassed primarily all three main elements of PARIHS (e.g., [166, 181, 193, 221]) and the context domain (e.g., [78, 152, 153, 207]), and in lesser extent the evidence (e.g., [185, 208, 214]) and the facilitation domain (e.g., [58, 67, 79, 182]).

Eleven review studies [13, 313, 314, 316-322, 389] used the framework for the analysis; findings were mapped to PARIHS elements in a few studies [316, 317, 389]; one described that their data had been "analysed through the lens of PARIHS" (p1) [389]. A couple of the review studies had PARIHS as the object for analysis, comparing it with other frameworks [318, 322]. This approach was also common in the 20 opinion/theoretical articles [2, 339, 341-348, 350-358], where the PARIHS framework itself was the focus of the analysis (e.g., [341, $349,354]$ ). In these articles, the analysis was performed in different ways, primarily through mapping and comparing PARIHS to other frameworks or models or even policies, but also for general discussions on implementation and evidence-based practice. Among the 185 articles that reported using the PARIHS framework in the analysis, there were also 22 protocols where authors reported that the intention was to use the framework in the analysis [23-35, 47-55].

\section{The application of PARIHS in the evaluation of study findings}

A total of 203 (55\%) included articles provided information on how the PARIHS framework was used in the evaluation of study findings, in terms of contributing to the discussion and interpretation of results $[13,52,58-$ 82, 84-89, 95-121, 149-214, 243-259, 261-284, 313, $314,316-320,323-331,339,341-350,359-365,386$, 389]. The majority $(n=167)$ of these were empirical studies [52, 58-82, 84-89, 95-121, 149-214, 243-259, 261-284, 386].

We found two main approaches to how the PARIHS framework was used in the evaluation of study findings. First, PARIHS was used to organize the discussion of the findings (e.g., [73, 87, 109, 166, 214]), where the framework and/or its elements were used to provide a structure for reporting or generally discussing the findings, or both, for example in stating that the key elements of PARIHS were reflected in the study findings. Second, the framework was used to consider the implications of the study's findings (e.g., [81, 84, 170, 207, 361]), where the framework or its elements (varying between one (e.g., [75, 195, 211]), two (e.g., [71, 86, 105]), and all the three main elements (e.g., [80, 261, 269])) enabled authors to elaborate on findings, or reflect on the implications of their study to evaluate the PARIHS framework itself. Specifically, we found some empirical articles reported evaluating the PARIHS element "context" by means of context tools (e.g., [155]). In addition, an evaluation of the study findings using the framework was identified in 18 opinion/theoretical articles [339, 341-350, 359-365] and 18 empirical review studies [13, 313, 314, 316-320, 323-331, 389]. Among the opinion/ theoretical articles, there were papers evaluating other theoretical constructions in relation to the PARIHS framework (e.g., [364]).

\section{The application of PARIHS in any other way}

A total of 136 (37\%) reported using PARIHS in some other way than directly informing the planning and delivery of an intervention or analyzing and evaluating findings $[3,23-25,36,37,47-50,56-62,90,95-97$, 122-127, 144, 149-170, 215-224, 243-256, 285-313, 323, 324, 332-338, 351, 359-361, 366-385]. A majority of these articles $(n=89)$ were empirical studies [58-62, 90, 95-97, 122-127, 149-170, 215-224, 243-256, 285$312]$, and about half of these described the use of PARIHS as an overall guide to frame the study (e.g., [58, 60, $168,222,285,303])$. A similar finding was apparent in the 11 protocols [23-25, 36, 37, 47-50, 56, 57]; about half of these also referred to the use of PARIHS to guide and frame the study design (e.g., [47, 48, 50, 57]).

An alternative use of PARIHS in empirical studies involved focusing on one of the three PARIHS elements $(n=17)$ and investigating them in greater depth, most notably context $(n=10)$ (e.g., $[155,232])$ and facilitation $(n=7)$ (e.g., [307, 312]). A total of 25 opinion/theoretical articles [144, 351, 359-361, 366-385] reported using the PARIHS framework in some other way, including a discussion about PARIHS as part of presenting a general overview of theories and frameworks to inform implementation (e.g., [369, 376, 378, 384]), using PARIHS to augment, develop, or evaluate other implementation models and frameworks (e.g., [318, 359, 367, 374, 382]), and informing education and learning and teaching initiatives $[144,372]$. Empirical review articles $(n=11)$ included reviews of implementation frameworks [3, 313, 323, 324, 332-338], including PARIHS, a review of the facilitation dimension of PARIHS and a discussion of the potential to combine implementation and improvement methodologies.

\section{Testing and providing views on the validity of the framework}

A total of 102 (28\%) articles described testing or validating PARIHS, or provided comments on the validity of 
the framework $[3,13,23,24,35,44,46,58,60,62,64$, 67, 71, 74, 76, 78-81, 84, 85, 89, 98, 105, 107, 110, 113, $115,120,121,143,149,150,153,155,157-159,166$, $168,170,172,180-182,187,188,190,191,195,198$, 201, 203, 204, 206-209, 211, 212, 214, 229, 246, 249, 250, 252, 253, 255, 264, 267, 268, 277, 278, 280, 281, $287,303,308,314,316-319,322,323,326,330,332$, 333, 335, 336, 341, 342, 345-347, 349, 359, 364, 369, $381,386]$. Of these, 72 were empirical studies [4, 58, 60, $62,64,67,71,74,76,78-81,84,85,89,98,105,107$, $110,113,115,120,121,143,149,150,153,155,157-$ $159,166,168,170,172,180-182,187,188,190,191$, 195, 198, 201, 203, 204, 206-209, 211, 212, 214, 229, 246, 249, 250, 252, 253, 255, 264, 267, 268, 277, 278, $280,281,287,303,308,386]$, five were study protocols [23, 24, 35, 44, 46], 10 opinion/theoretical articles [341, $342,345-347,349,359,364,369,381]$, and 15 empirical reviews $[3,13,314,316-319,322,323,326,330,332$, 333, 335, 336]. Empirical studies either tested the whole or parts of the framework with a focus on:

- The validity of the whole framework (e.g., [24, 74, 157, 195, 209])

- The validity of context (e.g., [155, 190, 280, 287, 308])

- The validity of facilitation (e.g., [23, 58, 182, 206])

- The validity of evidence (e.g., [255])

- Identifying gaps in the framework (e.g., [64, 170, 326])

Over the review study period (1998 to 2019), among empirical studies, there was a shift from primarily studying the context element of the framework to more articles evaluating the whole framework. This was also evident in the pattern found in the protocols, which mostly focused on testing facilitation (e.g., [58, 182, 206]). Opinion/theoretical articles tended to critique the whole framework (e.g., [319, 326, 342, 349, 369]). Of the 15 empirical reviews, the majority focused on the whole framework (e.g., $[13,322,333])$, then on context (e.g., [316, 318, 335]) and then on facilitation (e.g., [323]). Of note is the lack of attention in the literature to the element of "evidence" in the PARIHS framework (examples of articles paying attention to evidence include [208, 255]).

The articles varied in detail, depth, and quality in terms of descriptions of how they went about testing the validity of the PARIHS framework. Approaches ranged from general observations of whether the research teams/users found the elements and sub-elements easy to use (e.g., $[62,188,203])$, to studies that used elements of context described in the PARIHS framework to validate new context measures across settings and groups (e.g., [150, 155, 207]). As one example, the Alberta Context Tool started from the PARIHS conceptualization of context to include dimensions of culture, leadership, and evaluation.

Regarding the strength and limitations of the PARIHS framework, about one third of the included articles reported on its strengths and about $10 \%$ commented on perceived limitations. The identified strengths included:

- Holistic implementation framework (e.g., [141, 164, $209,258])$ that is perceived as intuitive and accessible.

- Both practical and theoretical and therefore feasible to use by both clinicians and researchers; also seen as intuitive to use and accessible (e.g., [117, 209, 255]).

- Can be used as a tool: diagnostic/process/evaluative tool; predictive/explanatory tool or as a way to explain the interplay of factors (e.g., [93, 205, 255, 285, 379]).

- Can accommodate a range of other theoretical perspectives (including approaches such as social network theory, participatory action research, coaching, change management and other knowledge translation frameworks) (e.g., [93, 105, 245, 246]).

- Can be used successfully in a range of different contexts (low- and middle-income countries) [150] and services and for various groups of patients (disability, aged care) (e.g., [80, 113, 248, 312]).

Limitations of the PARIHS framework included:

- Poor operationalization of key terms leading to difficulties in understanding and an overlap of elements and sub-elements (e.g., [165, 285, 376]).

- Lack of practical guidance on steps to operationalize the framework (e.g., [209, 254]) with a subsequent lack of tools.

- Lack of information on the individual and their characteristics (e.g., [209, 361]) and their lack of understanding of evidence (e.g., [204, 390]).

- Too structured and does not acknowledge the multidimensionality and uncertainty of implementation (e.g., [143, 214]).

- Lack of acknowledgement of wider contextual issues such as the impact of professional, socio-political, and policy issues on implementation (e.g., $[115,143,285,354])$.

- Not providing support in how to overcome barriers to successful implementation (e.g., [88]).

\section{Discussion}

In a recent survey among implementation scientists, the PARIHS framework was found to be one of the sixth most commonly used theoretical frameworks [4]. Yet, in our review, about 23\% ( $n=367)$ of the identified 1614 articles citing any of the four selected core PARIHS articles used the framework in any substantial way. Similarly, a review of the CFIR found that 26/429 (6\%) of articles citing the framework were judged to use the framework in a meaningful way (i.e., used the CFIR to guide data collection, measurement, coding, analysis, and/or reporting) [12]. A citation analysis of the KTA framework found that about 14\% (146/1057) of screened abstracts described using the KTA to varying degrees, although only 10 articles were judged to have applied the framework in a fully integrated way to inform the design, 
delivery, and evaluation of implementation activities [11].

PARIHS has been used in a diverse range of settings but, similarly to other commonly used implementation frameworks, most often superficially or partially. The whole framework has seldom been used holistically to guide all aspects of implementation studies. Implementation science scholars have repeatedly argued that the underuse, superficial use, and misuse of implementation frameworks might reduce the potential scientific advancements in the field, but also the capacity for changing healthcare practice and outcomes [4]. The rationale for not using the whole PARIHS framework could be many, including the justified reason of only being interested in a particular element. As such, partial use cannot always be considered as inappropriate. Simultaneously, many researchers entering the field might be overwhelmed with the many frameworks available and the lack of guidance about how to select and operationalize them and using their elements [2, 4, 391]. The current citation analysis can thus help remedy a gap in the literature by revealing how the PARIHS framework has been used to date, in full or partially, and thus provides input to users of its potential use.

The use of theoretical frameworks in implementation science serves the purpose of guiding researchers' and practitioners' implementation plans and informing their approaches to implementation and evaluation. This includes decisions about what data to gather to describe and explain implementation, their hypotheses about action steps needed, how to account for the critical role of context, and providing a foundation for analysis and discussion [7]. The advancement of theoretically informed implementation science will, however, depend on much improved descriptions as to why and how a certain framework was used, and an enhanced and betterinformed critical reflection of the functionality of that framework. This review shows that the PARIHS framework has rarely been used as a whole; rather, certain elements tend to be applied, often retrospectively as indicated in Fig. 3 underlining the use of PARIHS in the evaluation of study findings, which resonates with the findings of reviews about the use of the KTA [2] and CFIR [11] frameworks. This could be as a result of a lack of theoretical coherence of some frameworks making them difficult to apply holistically, and/or a function of a general challenge that researchers face in operationalizing theory. However, this could also be a result of publishing constraints. While the PARIHS framework may have guided implementation or been implicitly used in the study design, it was rarely the focus of the publications. Further, the aims and scopes of scientific health care journals have historically prioritized clinical outcomes over implementation outcomes where one could expect a more detailed description of the use of theoretical frameworks. This may have resulted in authors not fully reporting their use of, e.g., the PARIHS framework.

The number of empirical studies using the PARIHS framework has steadily increased over the review period. There is also evidence to show that more research teams have contributed to critiquing the framework in terms of reporting on its strengths and limitations and its validity. The pattern of investigation is moving from studies on context, to more systematic explorations of facilitation, thus contributing to a more detailed understanding of the elements and sub-elements of the framework. The lack of focus on "evidence" identified in this review highlights the need for researchers and clinicians to focus on the multi-dimensionality of what is being implemented. Common patterns emerging in this review support the changes made to the most recent refinement of the PARIHS framework [359].

Consistent with other reviews of the use of theoretical frameworks in implementation science, we found that PARIHS was often not used as intended. Further, it was not always clear why the particular framework was chosen. Frequently, authors merely cite a framework without providing any further information about how the framework was used. The lack of clear guidance on how to operationalize frameworks might be one of the underlying reasons for this. Lastly, to enable a critical review of frameworks and further build collective understanding of implementation, we urge authors to be more explicit about how theory informs studies. Development and adoption of reporting guidelines on how framework(s) are used in implementation studies might assist in sharpening the link between the used framework(s) and the individual study, but could potentially also enhance the opportunities for advancing the scientific understanding of implementation.

\section{Limitations}

To increase study reliability during the review process, more than one person identified, assessed, and interpreted the data. We had regular meetings to discuss potential difficulties in assessing included articles, and subsequently, all decisions were resolved by consensus to enhance rigor. We used a rigorous search strategy, which was undertaken by an information specialist. The standardization of our processes across the team was also enhanced by the creation of an online data extraction form via Google. However, as the form was not linked to other software (e.g., Endnote), this added timeconsuming processes.

As we did not include articles that were not written in English, we may have limited the insights about the application of the PARIHS framework, particularly with relevance to different country contexts. Additionally, we 
did not search the grey literature for practical reasons concerning the size of the literature, which may also have provided some additional insights not reflected in this publication. We also limited our search to two databases, which may mean we missed some relevant articles. However, we are confident that we found the majority of relevant published evidence to address the review questions because of a rigorous approach to retrieval. Thus, we think the findings of our citation analysis on the use of PARIHS are generalizable for studies in English published in peer-reviewed journals.

\section{Conclusions}

The importance of theoretically underpinned implementation science has been consistently highlighted. Theory is important for maximizing the chances of study transferability, providing an explanation of implementation processes, developing and tailoring implementation interventions, evaluating implementation, and explaining outcomes. This review of the use of the PARIHS framework, one of the most cited implementation frameworks, shows that its actual use and application has been frequently partial and generally not well described. Our ability to advance the science of implementation and ultimately affect outcomes will, in part, be dependent on better use of theory. Therefore, it is incumbent on theory developers to generate accessible and applicable theories, frameworks, and models, and for theory users to operationalize these in a considered and transparent way. We propose that the development and adoption of reporting guidelines on how framework(s) are used in implementation studies might enhance the maturity of implementation science.

\section{Supplementary information}

Supplementary information accompanies this paper at https://doi.org/10. 1186/s13012-020-01003-0.

Additional file 1: Form for initial assessment and form for data extraction

\section{Acknowledgements}

The authors wish to acknowledge Sayna Bahraini, Heledd Owen Griffiths, and Veronica Costea for partaking in the initial assessment of retrieved articles.

\begin{abstract}
Authors' contributions
All authors made substantial contributions to the manuscript. $K G$ and $A B$ conducted the citation searches. $A B$ led the initial assessment. $A B, A E, A C E$, IDG, GH, AK, JRM, and LW developed the data extraction form and undertook data extraction in pairs of two. AB coordinated the data extraction. $A B$ analyzed the descriptive data and $A E, A C E, G H, S H, A K$, and $L W$ analyzed the qualitative data. $A B$ prepared figures and tables and drafted the manuscript together with $L W, A E, A C E, I D G, K G, G H, S H, A K$, and JRM revised the manuscript. All authors have read and gave final approval of the version of the manuscript submitted for publication.
\end{abstract}

\section{Funding}

IDG is a recipient of a CIHR Foundation Grant (FDN \#143237) and AB the recipient of a FORTE grant (COFAS-2, 2014-2733). The funders had no role in designing the study, retrieving, or analyzing included articles, decision to publish, or preparation of the manuscript. Open access funding provided by Uppsala University.

\section{Availability of data and materials}

The datasets generated and analyzed during the current study can be obtained through contacting the first author.

Ethics approval and consent to participate

Not applicable.

\section{Consent for publication}

Not applicable.

\section{Competing interests}

We acknowledge that $\mathrm{GH}, \mathrm{AK}$, and JRM were all involved in the development of the PARIHS framework. Further, IDG, JRM, and LW are all members of the BMC Implementation Science Editorial Board.

\section{Author details}

'Department of Women's and Children's health, Uppsala Global Health Research on Implementation and Sustainability (UGHRIS), Uppsala, Sweden. ${ }^{2}$ Institute for Global Health, University College London, London, UK. ${ }^{3}$ School of Education, Health, and Social Studies, Dalarna University, Falun, Sweden.

${ }^{4}$ Adelaide Nursing School, University of Adelaide, Adelaide, Australia. ${ }^{5}$ Department of Medicine and Health, Linköping University, Linköping, Sweden. ${ }^{6}$ Department of Public Health and Caring Science, Uppsala University, Uppsala, Sweden. ${ }^{7}$ School of Epidemiology and Public Health, University of Ottawa, Ottawa, Canada. ${ }^{8}$ Ottawa Hospital Research Institute, Ottawa, Canada. ${ }^{9}$ University Library, Uppsala University, Uppsala, Sweden.

${ }^{10}$ Caring Futures Institute, College of Nursing and Health Sciences, Flinders University, Adelaide, Australia. "'Green Templeton College, University of Oxford, Oxford, UK. ${ }^{12}$ Division of Health Research, Faculty of Health and Medicine, Lancaster University, Lancashire, UK. ${ }^{13}$ Department of Health and Care Sciences, The Sahlgrenska Academy, University of Gothenburg, Gothenburg, Sweden.

Received: 23 January 2019 Accepted: 20 May 2020

Published online: 27 August 2020

\section{References}

1. Skolarus TA, Lehmann T, Tabak RG, Harris J, Lecy J, Sales AE. Assessing citation networks for dissemination and implementation research frameworks. Implement Sci. 2017;12(1):97.

2. Nilsen P. Making sense of implementation theories, models and frameworks. Implement Sci. 2015;10(1):53

3. Tabak RG, Khoong EC, Chambers DA, Brownson RC. Bridging research and practice: models for dissemination and implementation research. Am J Prev Med. 2012;43(3):337-50.

4. Birken SA, Powell BJ, Shea CM, Haines ER, Alexis Kirk M, Leeman J, et al, Criteria for selecting implementation science theories and frameworks: results from an international survey. Implement Sci. 2017;12(1):124.

5. Kitson A, Harvey G, McCormack B. Enabling the implementation of evidence based practice: a conceptual framework. Qual Health Care. 1998;7(3):149-58.

6. Rogers EM. Diffusion of Innovations. 5th ed. New York: The Free Press; 2003.

7. Rycroft-Malone J, Bucknall T. Models and frameworks for implementing evidence-based practice: linking evidence to action. Oxford: John Wiley \& Sons; 2010 .

8. Rycroft-Malone J, Kitson A, Harvey G, McCormack B, Seers K, Titchen A, et al. Ingredients for change: revisiting a conceptual framework. Qual Saf Health Care. 2002;11(2):174-80.

9. Rycroft-Malone J, Harvey G, Seers K, Kitson A, McCormack B, Titchen A. An exploration of the factors that influence the implementation of evidence into practice. J Clin Nurs. 2004;13(8):913-24.

10. Harvey $G$, Kitson A. Implementing evidence-based practice in healthcare: a facilitation guide: Routledge; 2015.

11. Field B, Booth A, llott I, Gerrish K. Using the Knowledge to Action Framework in practice: a citation analysis and systematic review. Implement Sci. 2014;9:172. 
12. Kirk MA, Kelley C, Yankey N, Birken SA, Abadie B, Damschroder L. A systematic review of the use of the Consolidated Framework for Implementation Research. Implement Sci. 2016;11:72.

13. Helfrich CD, Damschroder LJ, Hagedorn HJ, Daggett GS, Sahay A, Ritchie M, et al. A critical synthesis of literature on the Promoting Action on Research Implementation in Health Services (PARIHS) framework. Implement Sci. 2010;5(1):82

14. Moher D, Liberati A, Tetzlaff J, Altman DG, Group P. Preferred reporting items for systematic reviews and meta-analyses: the PRISMA statement. PLoS Med. 2009;6(7):e1000097.

15. Sandelowski M. Real qualitative researchers do not count: the use of numbers in qualitative research. Res Nurs Health. 2001;24(3):230-40.

16. Graneheim UH, Lindgren BM, Lundman B. Methodological challenges in qualitative content analysis: A discussion paper. Nurse Educ Today. 2017;56: 29-34.

17. Elo S, Kyngas $\mathrm{H}$. The qualitative content analysis process. J Adv Nurs. 2008; 62(1):107-15

18. Kitson AL, Rycroft-Malone J, Harvey G, McCormack B, Seers K, Titchen A. Evaluating the successful implementation of evidence into practice using the PARiHS framework: theoretical and practical challenges. Implement Sci. 2008;3(1):1.

19. Harvey G, Loftus-Hills A, Rycroft-Malone J, Titchen A, Kitson A, McCormack B, et al. Getting evidence into practice: the role and function of facilitation. J Adv Nurs. 2002;37(6):577-88.

20. Rycroft-Malone J. The PARIHS framework--a framework for guiding the implementation of evidence-based practice. J Nurs Care Qual. 2004;19(4): 297-304.

21. Rycroft-Malone J, Seers K, Titchen A, Harvey G, Kitson A, McCormack B. What counts as evidence in evidence-based practice? J Adv Nurs. 2004; 47(1):81-90

22. McCormack B, Kitson A, Harvey G, Rycroft-Malone J, Titchen A, Seers K. Getting evidence into practice: the meaning of 'context'. J Adv Nurs. 2002; 38(1):94-104.

23. Chinman M, Daniels K, Smith J, McCarthy S, Medoff D, Peeples A, et al Provision of peer specialist services in VA patient aligned care teams: protocol for testing a cluster randomized implementation trial. Implement Sci. 2017;12(1):57.

24. Gordon EJ, Lee J, Kang RH, Caicedo JC, Holl JL, Ladner DP, et al. A complex culturally targeted intervention to reduce Hispanic disparities in living kidney donor transplantation: an effectiveness-implementation hybrid study protocol. BMC Health Serv Res. 2018;18(1):368.

25. Roberge P, Fournier L, Brouillet $H$, Hudon C, Houle J, Provencher MD, et al. Implementing a knowledge application program for anxiety and depression in community-based primary mental health care: a multiple case study research protocol. Implement Sci. 2013;8(1):26.

26. Blanco-Mavillard I, Bennasar-Veny M, De Pedro-Gomez JE, Moya-Suarez AB, Parra-Garcia G, Rodriguez-Calero MA, et al. Implementation of a knowledge mobilization model to prevent peripheral venous catheter-related adverse events: PREBACP study-a multicenter cluster-randomized trial protocol. Implement Sci. 2018;13(1):100.

27. Bucknall TK, Harvey G, Considine J, Mitchell I, Rycroft-Malone J, Graham ID, et al. Prioritising Responses Of Nurses To deteriorating patient Observations (PRONTO) protocol: testing the effectiveness of a facilitation intervention in a pragmatic, cluster-randomised trial with an embedded process evaluation and cost analysis. Implement Sci. 2017;12(1):85.

28. Chouinard MC, Hudon C, Dubois MF, Roberge P, Loignon C, Tchouaket E, et al. Case management and self-management support for frequent users with chronic disease in primary care: a pragmatic randomized controlled trial. BMC Health Serv Res. 2013:13(1):49.

29. Cully JA, Armento ME, Mott J, Nadorff MR, Naik AD, Stanley MA, et al. Brief cognitive behavioral therapy in primary care: a hybrid type 2 patient-randomized effectiveness-implementation design. Implement Sci. 2012;7(1):64

30. Gurung R, Jha AK, Pyakurel S, Gurung A, Litorp H, Wrammert J, et al. Scaling Up Safer Birth Bundle Through Quality Improvement in Nepal (SUSTAIN)-a stepped wedge cluster randomized controlled trial in public hospitals. Implement Sci. 2019;14(1):65

31. Owen RR, Drummond KL, Viverito KM, Marchant K, Pope SK, Smith JL, et al. Monitoring and managing metabolic effects of antipsychotics: a cluster randomized trial of an intervention combining evidence-based quality improvement and external facilitation. Implement Sci. 2013;8(1):120.
32. Powell K, Kitson A, Hoon E, Newbury J, Wilson A, Beilby J. A study protocol for applying the co-creating knowledge translation framework to a population health study. Implement Sci. 2013;8(1):98.

33. Rycroft-Malone J, Anderson R, Crane RS, Gibson A, Gradinger F, Owen Griffiths $H$, et al. Accessibility and implementation in UK services of an effective depression relapse prevention programme - mindfulness-based cognitive therapy (MBCT): ASPIRE study protocol. Implement Sci. 2014;9(1): 62.

34. Rycroft-Malone J, Dopson S, Degner L, Hutchinson AM, Morgan D, Stewart $\mathrm{N}$, et al. Study protocol for the translating research in elder care (TREC): building context through case studies in long-term care project (project two). Implement Sci. 2009;4(1):53.

35. Rycroft-Malone J, Wilkinson JE, Burton CR, Andrews G, Ariss S, Baker R, et al. Implementing health research through academic and clinical partnerships: a realistic evaluation of the Collaborations for Leadership in Applied Health Research and Care (CLAHRC). Implement Sci. 2011;6(1):74.

36. Kilbourne AM, Almirall D, Eisenberg D, Waxmonsky J, Goodrich DE, Fortney JC, et al. Protocol: Adaptive Implementation of Effective Programs Trial (ADEPT): cluster randomized SMART trial comparing a standard versus enhanced implementation strategy to improve outcomes of a mood disorders program. Implement Sci. 2014;9(1):132.

37. McGilton KS, Davis A, Mahomed N, Flannery J, Jaglal S, Cott C, et al. An inpatient rehabilitation model of care targeting patients with cognitive impairment. BMC Geriatr. 2012;12:21.

38. Botti M, Kent B, Bucknall T, Duke M, Johnstone MJ, Considine J, et al. Development of a Management Algorithm for Post-operative Pain (MAPP) after total knee and total hip replacement: study rationale and design. Implement Sci. 2014;9(1):110.

39. Cadilhac DA, Andrew NE, Kilkenny MF, Hill K, Grabsch B, Lannin NA, et al. Improving quality and outcomes of stroke care in hospitals: protocol and statistical analysis plan for the Stroke123 implementation study. Int I Stroke. 2018;13(1):96-106.

40. Perez J, Russo DA, Stochl J, Byford S, Zimbron J, Graffy JP, et al. Comparison of high and low intensity contact between secondary and primary care to detect people at ultra-high risk for psychosis: study protocol for a theorybased, cluster randomized controlled trial. Trials. 2013;14(1):222.

41. Ray-Barruel G, Cooke M, Mitchell M, Chopra V, Rickard CM. Implementing the I-DECIDED clinical decision-making tool for peripheral intravenous catheter assessment and safe removal: protocol for an interrupted timeseries study. BMJ Open. 2018;8(6):e021290.

42. Saint $\mathrm{S}$, Olmsted RN, Fakih MG, Kowalski CP, Watson SR, Sales AE, et al. Translating health care-associated urinary tract infection prevention research into practice via the bladder bundle. Joint Commission Journal on Quality and Patient Safety. 2009;35(9):449-55.

43. Sampson EL, Feast A, Blighe A, Froggatt K, Hunter R, Marston L, et al. Evidence-based intervention to reduce avoidable hospital admissions in care home residents (the Better Health in Residents in Care Homes $(\mathrm{BHiRCH})$ study): protocol for a pilot cluster randomised trial. BMJ Open. 2019;9(5):e026510

44. Seers K, Cox K, Crichton NJ, Edwards RT, Eldh AC, Estabrooks CA, et al. FIRE (Facilitating Implementation of Research Evidence): a study protocol. Implement Sci. 2012;7(1):25.

45. Skene C, Gerrish K, Price F, Pilling E, Bayliss P. Developing family-centred care in a neonatal intensive care unit: an action research study protocol. J Adv Nurs. 2016:72(3):658-68

46. Wallin L, Malqvist M, Nga NT, Eriksson L, Persson LA, Hoa DP, et al. Implementing knowledge into practice for improved neonatal survival; a cluster-randomised, community-based trial in Quang Ninh province. Vietnam. BMC Health Serv Res. 2011;11:239.

47. Conklin J, Kothari A, Stolee P, Chambers L, Forbes D, Le Clair K. Knowledgeto-action processes in SHRTN collaborative communities of practice: a study protocol. Implement Sci. 2011;6(1):12

48. Estabrooks CA, Squires JE, Cummings GG, Teare GF, Norton PG. Study protocol for the translating research in elder care (TREC): building context an organizational monitoring program in long-term care project (project one). Implement Sci. 2009:4(1):52.

49. Kitson AL, Schultz TJ, Long L, Shanks A, Wiechula R, Chapman I, et al. The prevention and reduction of weight loss in an acute tertiary care setting: protocol for a pragmatic stepped wedge randomised cluster trial (the PRoWL project). BMC Health Serv Res. 2013:13(1):299. 
50. Noyes JP, Williams A, Allen D, Brocklehurst P, Carter C, Gregory JW, et al. Evidence into practice: evaluating a child-centred intervention for diabetes medicine management. The EPIC Project. BMC Pediatr. 2010;10:70.

51. Chao MT, Chang A, Reddy S, Harrison JD, Acquah J, Toveg M, et al. Adjunctive acupuncture for pain and symptom management in the inpatient setting: protocol for a pilot hybrid effectiveness-implementation study. J Integr Med. 2016;14(3):228-38.

52. Hack TF, Ruether JD, Weir LM, Grenier D, Degner LF. Study protocol: addressing evidence and context to facilitate transfer and uptake of consultation recording use in oncology: a knowledge translation implementation study. Implement Sci. 2011;6(1):20

53. Stetler CB, Ritchie J, Rycroft-Malone J, Schultz A, Charns M. Improving quality of care through routine, successful implementation of evidencebased practice at the bedside: an organizational case study protocol using the Pettigrew and Whipp model of strategic change. Implement Sci. 2007; 2(1):3.

54. Urquhart R, Porter GA, Grunfeld E, Sargeant J. Exploring the interpersonal-, organization-, and system-level factors that influence the implementation and use of an innovation-synoptic reporting-in cancer care. Implement Sci. 2012;7(1):12

55. Watkins $V$, Nagle C, Kent B, Hutchinson AM. Labouring Together: collaborative alliances in maternity care in Victoria, Australia-protocol of a mixed-methods study. BMJ Open. 2017;7(3):e014262.

56. De Pedro-Gomez J, Morales-Asencio JM, Bennasar-Veny M, Artigues-Vives G, Perello-Campaner C, Gomez-Picard P. Determining factors in evidencebased clinical practice among hospital and primary care nursing staff. J Adv Nurs. 2012;68(2):452-9.

57. Slaughter SE, Estabrooks CA, Jones CA, Wagg AS, Eliasziw M. Sustaining Transfers through Affordable Research Translation (START): study protocol to assess knowledge translation interventions in continuing care settings. Trials. 2013;14(1):355

58. Eriksson L, Huy TQ, Duc DM, Ekholm Selling K, Hoa DP, Thuy NT, et al. Process evaluation of a knowledge translation intervention using facilitation of local stakeholder groups to improve neonatal survival in the Quang Ninh province. Vietnam. Trials. 2016;17:23.

59. Eriksson L, Nga NT, Hoa DP, Persson LA, Ewald U, Wallin L. Newborn care and knowledge translation - perceptions among primary healthcare staff in northern Vietnam. Implement Sci. 2011;6(1):29.

60. Long-Tounsel R, Wilson J, Adams C, Reising DL. Urban and Suburban Hospital System Implementation of Multipoint Access Targeted Temperature Management in Postcardiac Arrest Patients. Therapeutic Hypothermia and Temperature Management. 2014;4(1):43-50.

61. McWilliam CL, Kothari A, Ward-Griffin C, Forbes D, Leipert B, South West Community Care Access Centre Home Care C. Evolving the theory and praxis of knowledge translation through social interaction: a social phenomenological study. Implement Sci. 2009;4(1):26.

62. Obrecht JA, Van Hulle VC, Ryan CS. Implementation of evidence-based practice for a pediatric pain assessment instrument. Clin Nurse Spec. 2014; 28(2):97-104.

63. Allen M, Hall L, Halton K, Graves N. Improving hospital environmental hygiene with the use of a targeted multi-modal bundle strategy. Infection Disease \& Health. 2018;23(2):107-13.

64. Bahtsevani C, Idvall E. To Assess Prerequisites Before an Implementation Strategy in an Orthopaedic Department in Sweden. Orthop Nurs. 2016;35(2): 100-7.

65. Bamford D, Rothwell K, Tyrrell P, Boaden R. Improving care for people after stroke: how change was actively facilitated. J Health Organ Manag. 2013; 27(5):548-60.

66. Brenner LA, Breshears RE, Betthauser LM, Bellon KK, Holman E, Harwood JE, et al. Implementation of a suicide nomenclature within two VA healthcare settings. J Clin Psychol Med Settings. 2011;18(2):116-28.

67. Brown D, McCormack B. Exploring psychological safety as a component of facilitation within the Promoting Action on Research Implementation in Health Services framework. J Clin Nurs. 2016;25(19-20):2921-32.

68. Diffin J, Ewing G, Harvey G, Grande G. Facilitating successful implementation of a person-centred intervention to support family carers within palliative care: a qualitative study of the Carer Support Needs Assessment Tool (CSNA T) intervention. BMC Palliat Care. 2018;17(1):129.

69. Diffin J, Ewing G, Harvey G, Grande G. The Influence of Context and Practitioner Attitudes on Implementation of Person-Centered Assessment and Support for Family Carers Within Palliative Care. Worldviews Evid Based Nurs. 2018;15(5):377-85.

70. Drainoni ML, Koppelman EA, Feldman JA, Walley AY, Mitchell PM, Ellison J, et al. Why is it so hard to implement change? A qualitative examination of barriers and facilitators to distribution of naloxone for overdose prevention in a safety net environment. BMC Res Notes. 2016;9(1):465.

71. Ellis I, Howard P, Larson A, Robertson J. From workshop to work practice: An exploration of context and facilitation in the development of evidencebased practice. Worldviews Evid Based Nurs. 2005;2(2):84-93.

72. Gerrish K, Laker S, Taylor C, Kennedy F, McDonnell A. Enhancing the quality of oral nutrition support for hospitalized patients: a mixed methods knowledge translation study (The EQONS study). J Adv Nurs. 2016;72(12): 3182-94.

73. Gesthalter YB, Koppelman E, Bolton R, Slatore CG, Yoon SH, Cain HC, et al. Evaluations of Implementation at Early-Adopting Lung Cancer Screening Programs: Lessons Learned. Chest. 2017;152(1):70-80.

74. Harris $M$, Jones $P$, Heartfield $M$, Allstrom $M$, Hancock J, Lawn S, et al. Changing practice to support self-management and recovery in mental illness: application of an implementation model. Aust J Prim Health. 2015; 21(3):279-85.

75. Harvey G, McCormack B, Kitson A, Lynch E, Titchen A. Designing and implementing two facilitation interventions within the 'Facilitating Implementation of Research Evidence (FIRE)' study: a qualitative analysis from an external facilitators' perspective. Implement Sci. 2018;13(1):141.

76. Houle SK, Charrois TL, Faruquee CF, Tsuyuki RT, Rosenthal MM. A randomized controlled study of practice facilitation to improve the provision of medication management services in Alberta community pharmacies. Res Social Adm Pharm. 2017;13(2):339-48.

77. Jangland E, Gunningberg L. Improving patient participation in a challenging context: a 2-year evaluation study of an implementation project. J Nurs Manag. 2017;25(4):266-75.

78. Lewis A, Kitson A, Harvey G. Improving oral health for older people in the home care setting: An exploratory implementation study. Australas J Ageing. 2016;35(4):273-80.

79. Lindsay JA, Kauth MR, Hudson S, Martin LA, Ramsey DJ, Daily L, et al. Implementation of video telehealth to improve access to evidence-based psychotherapy for posttraumatic stress disorder. Telemed J E Health. 2015; 21(6):467-72.

80. Mekki TE, Oye C, Kristensen B, Dahl H, Haaland A, Nordin KA, et al. The inter-play between facilitation and context in the promoting action on research implementation in health services framework: A qualitative exploratory implementation study embedded in a cluster randomized controlled trial to reduce restraint in nursing homes. J Adv Nurs. 2017; 73(11):2622-32

81. Parlour R, McCormack B. Blending critical realist and emancipatory practice development methodologies: making critical realism work in nursing research. Nurs Inq. 2012;19(4):308-21.

82. Persson LA, Nga NT, Malqvist M, Thi Phuong Hoa D, Eriksson L, Wallin L, et al. Effect of Facilitation of Local Maternal-and-Newborn Stakeholder Groups on Neonatal Mortality: Cluster-Randomized Controlled Trial. PLoS Med. 2013;10(5):e1001445.

83. Rycroft-Malone J, Fontenla M, Bick D, Seers K. Protocol-based care: Impact on roles and service delivery. Journal of Evaluation in Clinical Practice. 2008; 14(5):867-73.

84. Rycroft-Malone J, Seers K, Crichton N, Chandler J, Hawkes CA, Allen C, et al. A pragmatic cluster randomised trial evaluating three implementation interventions. Implement Sci. 2012;7(1):80.

85. Rycroft-Malone J, Seers K, Chandler J, Hawkes CA, Crichton N, Allen C, et al. The role of evidence, context, and facilitation in an implementation trial: implications for the development of the PARIHS framework. Implement Sci. 2013;8(1):28.

86. Rycroft-Malone J, Seers K, Eldh AC, Cox K, Crichton N, Harvey G, et al. A realist process evaluation within the Facilitating Implementation of Research Evidence (FIRE) cluster randomised controlled international trial: an exemplar. Implement Sci. 2018;13(1):138.

87. Slaughter SE, Estabrooks CA. Optimizing the mobility of residents with dementia: a pilot study promoting healthcare aide uptake of a simple mobility innovation in diverse nursing home settings. BMC Geriatr. 2013; 13(1):110.

88. Sving E, Fredriksson L, Gunningberg L, Mamhidir AG. Getting evidencebased pressure ulcer prevention into practice: a process evaluation of a 
multifaceted intervention in a hospital setting. J Clin Nurs. 2017;26(19-20): 3200-11.

89. Walsh K, Ford K, Morley C, McLeod E, McKenzie D, Chalmers L, et al. The Development and Implementation of a Participatory and Solution-Focused Framework for Clinical Research: a case example. Collegian. 2017;24(4): 331-8.

90. Mignogna J, Hundt NE, Kauth MR, Kunik ME, Sorocco KH, Naik AD, et al. Implementing brief cognitive behavioral therapy in primary care: A pilot study. Transl Behav Med. 2014;4(2):175-83.

91. Alkema GE, Frey D. Implications of translating research into practice: a medication management intervention. Home Health Care Serv Q. 2006;25(12):33-54.

92. Kilbourne AM, Abraham KM, Goodrich DE, Bowersox NW, Almirall D, Lai Z, et al. Cluster randomized adaptive implementation trial comparing a standard versus enhanced implementation intervention to improve uptake of an effective re-engagement program for patients with serious mental illness. Implement Sci. 2013;8(1):136.

93. Mignogna J, Martin LA, Harik J, Hundt NE, Kauth M, Naik AD, et al. "I had to somehow still be flexible": exploring adaptations during implementation of brief cognitive behavioral therapy in primary care. Implement Sci. 2018; 13(1):76.

94. Westergren A. Action-oriented study circles facilitate efforts in nursing homes to "go from feeding to serving": conceptual perspectives on knowledge translation and workplace learning. J Aging Res. 2012;2012: 627371

95. Baloh J, Zhu X, Ward MM. Types of internal facilitation activities in hospitals implementing evidence-based interventions. Health Care Manage Rev. 2018; 43(3):229-37.

96. Snelgrove-Clarke E, Davies B, Flowerdew G, Young D. Implementing a Fetal Health Surveillance Guideline in Clinical Practice: A Pragmatic Randomized Controlled Trial of Action Learning. Worldviews Evid Based Nurs. 2015;12(5): 281-8.

97. Wallin L, Rudberg A, Gunningberg L. Staff experiences in implementing guidelines for Kangaroo Mother Care--a qualitative study. Int J Nurs Stud. 2005;42(1):61-73.

98. Bidassie B, Williams LS, Woodward-Hagg H, Matthias MS, Damush TM. Key components of external facilitation in an acute stroke quality improvement collaborative in the Veterans Health Administration. Implement Sci. 2015; 10(1):69.

99. Doran D, Haynes BR, Estabrooks CA, Kushniruk A, Dubrowski A, Bajnok I, et al. The role of organizational context and individual nurse characteristics in explaining variation in use of information technologies in evidence based practice. Implement Sci. 2012;7:122.

100. Fortney J, Enderle M, McDougall S, Clothier J, Otero J, Altman L, et al. Implementation outcomes of evidence-based quality improvement for depression in VA community based outpatient clinics. Implement Sci. 2012; 7(1):30.

101. Elsborg Foss J, Kvigne K, Wilde Larsson B, Athlin E. A model (CMBP) for collaboration between university college and nursing practice to promote research utilization in students' clinical placements: a pilot study. Nurse Educ Pract. 2014;14(4):396-402

102. Johnson S, Ostaszkiewicz J, O'Connell B. Moving beyond resistance to restraint minimization: a case study of change management in aged care. Worldviews Evid Based Nurs. 2009;6(4):210-8.

103. Kavanagh T, Stevens B, Seers K, Sidani S, Watt-Watson J. Process evaluation of appreciative inquiry to translate pain management evidence into pediatric nursing practice. Implement Sci. 2010;5(1):90.

104. Kinley J, Stone L, Dewey M, Levy J, Stewart R, McCrone P, et al. The effect of using high facilitation when implementing the Gold Standards Framework in Care Homes programme: a cluster randomised controlled trial. Palliat Med. 2014;28(9):1099-109.

105. Lewis A, Harvey G, Hogan M, Kitson A. Can oral healthcare for older people be embedded into routine community aged care practice? A realist evaluation using normalisation process theory. Int J Nurs Stud. 2019;94:32-41.

106. McGilton KS, Sorin-Peters R, Rochon E, Boscart V, Fox M, Chu CH, et al. The effects of an interprofessional patient-centered communication intervention for patients with communication disorders. Appl Nurs Res. 2018;39:189-94.

107. McLean P, Torkington R, Ratsch A. Development, implementation, and outcomes of post-stroke mood assessment pathways: implications for social workers. Australian Social Work. 2019:72(3):336-56.
108. O'Halloran PD, Cran GW, Beringer TR, Kernohan G, Orr J, Dunlop L, et al. Factors affecting adherence to use of hip protectors amongst residents of nursing homes--a correlation study. Int J Nurs Stud. 2007;44(5):672-86.

109. Pallangyo EN, Mbekenga C, Kallestal C, Rubertsson C, Olsson P. "If really we are committed things can change, starting from us": Healthcare providers' perceptions of postpartum care and its potential for improvement in lowincome suburbs in Dar es Salaam. Tanzania. Sex Reprod Healthc. 2017;11:7-12.

110. Pallangyo E, Mbekenga C, Olsson P, Eriksson L, Bergstrom A. Implementation of a facilitation intervention to improve postpartum care in a low-resource suburb of Dar es Salaam. Tanzania. Implement Sci. 2018; 13(1):102.

111. Russell-Babin KA, Miley H. Implementing the best available evidence in early delirium identification in elderly hip surgery patients. Int J Evid Based Healthc. 2013;11(1):39-45.

112. Rycroft-Malone J, Wilkinson J, Burton CR, Harvey G, McCormack B, Graham I, et al. Collaborative action around implementation in Collaborations for Leadership in Applied Health Research and Care: towards a programme theory. J Health Serv Res Policy. 2013;18(3 Suppl):13-26.

113. Seers K, Rycroft-Malone J, Cox K. Crichton N, Edwards RT, Eldh AC, et al. Facilitating Implementation of Research Evidence (FIRE): an international cluster randomised controlled trial to evaluate two models of facilitation informed by the Promoting Action on Research Implementation in Health Services (PARIHS) framework. Implement Sci. 2018;13(1):137.

114. Sigel BA, Kramer TL, Conners-Burrow NA, Church JK, Worley KB, Mitrani NA. Statewide dissemination of trauma-focused cognitive-behavioral therapy (TF-CBT). Children and Youth Services Review. 2013;35(6):1023-9.

115. Stevens BJ, Yamada J, Promislow S, Barwick M, Pinard M, Pain CTiCs. Pain Assessment and Management After a Knowledge Translation Booster Intervention. Pediatrics. 2016;138(4)

116. Sving E, Hogman M, Mamhidir AG, Gunningberg L. Getting evidence-based pressure ulcer prevention into practice: a multi-faceted unit-tailored intervention in a hospital setting. Int Wound J. 2016;13(5):645-54.

117. Tian L, Yang Y, Sui W, Hu Y, Li H, Wang F, et al. Implementation of evidence into practice for cancer-related fatigue management of hospitalized adult patients using the PARIHS framework. PLoS One. 2017;12(10):e0187257.

118. Tucker SJ, Bieber PL, Attlesey-Pries JM, Olson ME, Dierkhising RA. Outcomes and challenges in implementing hourly rounds to reduce falls in orthopedic units. Worldviews Evid Based Nurs. 2012;9(1):18-29.

119. Weir C, Brunker C, Butler J, Supiano MA. Making cognitive decision support work: Facilitating adoption, knowledge and behavior change through Ql. J Biomed Inform. 2017;71S:S32-S8.

120. Williams BR, Woodby LL, Bailey FA, Burgio KL. Formative evaluation of a multi-component, education-based intervention to improve processes of end-of-life care. Gerontol Geriatr Educ. 2014;35(1):4-22.

121. Arslan Yurumezoglu H, Kocaman G. Pilot study for evidence-based nursing management: improving the levels of job satisfaction, organizational commitment, and intent to leave among nurses in Turkey. Nurs Health Sci. 2012;14(2):221-8.

122. Brosey LA, March KS. Effectiveness of structured hourly nurse rounding on patient satisfaction and clinical outcomes. J Nurs Care Qual. 2015;30(2):153-9.

123. Chinman M, Acosta J, Ebener P, Burkhart Q, Malone PS, Paddock SM, et al. Intervening with practitioners to improve the quality of prevention: oneyear findings from a randomized trial of assets-getting to outcomes. J Prim Prev. 2013;34(3):173-91.

124. Glegg S. Knowledge brokering as an intervention in paediatric rehabilitation practice. International Journal of Therapy and Rehabilitation. 2010;17(4):203-10.

125. Harvey G, Oliver K, Humphreys J, Rothwell K, Hegarty J. Improving the identification and management of chronic kidney disease in primary care: lessons from a staged improvement collaborative. Int J Qual Health Care. 2015;27(1):10-6.

126. Humphreys J, Harvey G, Coleiro M, Butler B, Barclay A, Gwozdziewicz M, et al. A collaborative project to improve identification and management of patients with chronic kidney disease in a primary care setting in Greater Manchester. BMJ Qual Saf. 2012;21(8):700-8.

127. Kauth MR, Sullivan G, Blevins D, Cully JA, Landes RD, Said Q, et al. Employing external facilitation to implement cognitive behavioral therapy in VA clinics: a pilot study. Implement Sci. 2010;5(1):75.

128. Almblad AC, Siltberg P, Engvall G, Malqvist M. Implementation of Pediatric Early Warning Score; Adherence to Guidelines and Influence of Context. J Pediatr Nurs. 2018:38:33-9. 
129. Amaya-Jackson L, Hagele D, Sideris J, Potter D, Briggs EC, Keen L, et al. Pilot to policy: statewide dissemination and implementation of evidence-based treatment for traumatized youth. BMC Health Serv Res. 2018;18(1):589.

130. Anderson DR, Zlateva I, Coman EN, Khatri K, Tian T, Kerns RD. Improving pain care through implementation of the Stepped Care Model at a multisite community health center. J Pain Res. 2016;9:1021-9.

131. Bailey FA, Williams BR, Woodby LL, Goode PS, Redden DT, Houston TK, et al. Intervention to improve care at life's end in inpatient settings: the BEACON trial. J Gen Intern Med. 2014;29(6):836-43.

132. Bunch AM, Leasure AR, Carithers C, Burnette RE Jr, Berryman MS Sr. Implementation of a rapid chest pain protocol in the emergency department: A quality improvement project. J Am Assoc Nurse Pract. 2016;28(2):75-83.

133. Gutmanis I, Snyder M, Harvey D, Hillier LM, LeClair JK. Health Care Redesign for Responsive Behaviours - The Behavioural Supports Ontario Experience: Lessons Learned and Keys to Success. Canadian Journal of Community Mental Health. 2015;34(1):45-63.

134. McGilton KS, Rochon E, Sidani S, Shaw A, Ben-David BM, Saragosa M, et al. Can We Help Care Providers Communicate More Effectively With Persons Having Dementia Living in Long-Term Care Homes? Am J Alzheimers Dis Other Demen. 2017;32(1):41-50.

135. Murphy AL, Gardner DM, Kutcher SP, Martin-Misener R. A theory-informed approach to mental health care capacity building for pharmacists. Int J Ment Health Syst. 2014;8(1):46.

136. Musanti R, O'Keefe T, Silverstein W. Partners in caring: an innovative nursing model of care delivery. Nurs Adm Q. 2012;36(3):217-24.

137. O'Brien A, Redley B, Wood B, Botti M, Hutchinson AF. STOPDVTs: Development and testing of a clinical assessment tool to guide nursing assessment of postoperative patients for Deep Vein Thrombosis. J Clin Nurs. 2018;27(9-10):1803-11.

138. Orsted HL, Rosenthal S, Woodbury MG. Pressure ulcer awareness and prevention program: a quality improvement program through the Canadian Association of Wound Care. J Wound Ostomy Continence Nurs. 2009;36(2): $178-83$

139. Rutledge DN, Skelton K. Clinical expert facilitators of evidence-based practice: a community hospital program. J Nurses Staff Dev. 2011;27(5):231-5.

140. Ryan D, Barnett R, Cott C, Dalziel W, Gutmanis I, Jewell D, et al. Geriatrics, interprofessional practice, and interorganizational collaboration: a knowledge-to-practice intervention for primary care teams. J Contin Educ Health Prof. 2013;33(3):180-9.

141. Sadasivam RS, Hogan TP, Volkman JE, Smith BM, Coley HL, Williams JH, et al. Implementing point of care "e-referrals" in 137 clinics to increase access to a quit smoking internet system: the Quit-Primo and National Dental PBRN HI-QUIT Studies. Transl Behav Med. 2013;3(4):370-8.

142. Smith SN, Almirall D, Prenovost K, Liebrecht C, Kyle J, Eisenberg D, et al. Change in patient outcomes after augmenting a low-level implementation strategy in community practices that are slow to adopt a collaborative chronic care model: a cluster randomized implementation trial. Med Care. 2019;57(7):503-11.

143. Stevens BJ, Yamada J, Estabrooks CA, Stinson J, Campbell F, Scott SD, et al. Pain in hospitalized children: Effect of a multidimensional knowledge translation strategy on pain process and clinical outcomes. Pain. 2014;155(1):60-8.

144. Tilson JK, Mickan S. Promoting physical therapists' of research evidence to inform clinical practice: part 1--theoretical foundation, evidence, and description of the PEAK program. BMC Med Educ. 2014;14(1):125.

145. Tistad M, Palmcrantz S, Wallin L, Ehrenberg A, Olsson CB, Tomson G, et al. Developing leadership in managers to facilitate the implementation of national guideline recommendations: a process evaluation of feasibility and usefulness. Int J Health Policy Manag. 2016;5(8):477-86.

146. Toole BM, Stichler JF, Ecoff L, Kath L. Promoting nurses' knowledge in evidence-based practice: do educational methods matter? J Nurses Prof Dev. 2013;29(4):173-81

147. Westergren A, Axelsson C, Lilja-Andersson P, Lindholm C, Petersson K, Ulander K. Study circles improve the precision in nutritional care in special accommodations. Food Nutr Res. 2009;53.

148. Young A. Institutional interventions to prevent and treat undernutrition. Advanced Nutrition and Dietetics in Nutrition Support2018. p. 176-183.

149. Balbale SN, Hill JN, Guihan M, Hogan TP, Cameron KA, Goldstein B, et al. Evaluating implementation of methicillin-resistant Staphylococcus aureus (MRSA) prevention guidelines in spinal cord injury centers using the PARIHS framework: a mixed methods study. Implement Sci. 2015;10(1):130.
150. Bergstrom A, Peterson S, Namusoko S, Waiswa P, Wallin L. Knowledge translation in Uganda: a qualitative study of Ugandan midwives' and managers' perceived relevance of the sub-elements of the context cornerstone in the PARIHS framework. Implement Sci. 2012;7(1):117.

151. Boblin SL, Ireland S, Kirkpatrick H, Robertson K. Using Stake's qualitative case study approach to explore implementation of evidence-based practice. Qual Health Res. 2013;23(9):1267-75.

152. Cammer A, Morgan D, Stewart N, McGilton K, Rycroft-Malone J, Dopson S, et al. The hidden complexity of long-term care: how context mediates knowledge translation and use of best practices. Gerontologist. 2014;54(6): 1013-23.

153. Cummings GG, Estabrooks CA, Midodzi WK, Wallin L, Hayduk L. Influence of organizational characteristics and context on research utilization. Nurs Res. 2007:56(4 Suppl):S24-39.

154. Estabrooks CA, Midodzi WK, Cummings GG, Wallin L. Predicting research use in nursing organizations: a multilevel analysis. Nurs Res. 2007;56(4 Suppl):S7-23.

155. Estabrooks CA, Squires JE, Cummings GG, Birdsell JM, Norton PG. Development and assessment of the Alberta Context Tool. BMC Health Serv Res. 2009;9:234.

156. Estabrooks CA, Squires JE, Hayduk LA, Cummings GG, Norton PG. Advancing the argument for validity of the Alberta Context Tool with healthcare aides in residential long-term care. BMC Med Res Methodol. 2011;11:107.

157. Gagliardi AR, Webster F, Brouwers MC, Baxter NN, Finelli A, Gallinger S. How does context influence collaborative decision-making for health services planning, delivery and evaluation? BMC Health Serv Res. 2014;14:545.

158. Gibb H. An environmental scan of an aged care workplace using the PARiHS model: assessing preparedness for change. J Nurs Manag. 2013; 21(2):293-303.

159. Helfrich CD, Li YF, Sharp ND, Sales AE. Organizational readiness to change assessment (ORCA): development of an instrument based on the Promoting Action on Research in Health Senvices (PARIHS) framework. Implement Sci. 2009:4(1):38.

160. Kristensen HK, Hounsgaard L. Implementation of coherent, evidencebased pathways in Danish rehabilitation practice. Disabil Rehabil. 2013; 35(23):2021-8.

161. Malte CA, McFall M, Chow B, Beckham JC, Carmody TP, Saxon AJ. Survey of providers' attitudes toward integrating smoking cessation treatment into posttraumatic stress disorder care. Psychol Addict Behav. 2013;27(1):249-55.

162. McCormack B, McCarthy G, Wright J, Slater P, Coffey A. Development and testing of the Context Assessment Index (CAl). Worldviews Evid Based Nurs. 2009;6(1):27-35.

163. McCullough MB, Chou AF, Solomon JL, Petrakis BA, Kim B, Park AM, et al. The interplay of contextual elements in implementation: an ethnographic case study. BMC Health Serv Res. 2015;15(1):62.

164. Palmcrantz S, Tistad M, Eldh AC, Holmqvist LW, Ehrenberg A, Tomson G, et al. Assessing feasibility and acceptability of study procedures: getting ready for implementation of national stroke guidelines in out-patient health care. BMC Health Serv Res. 2015;15:517.

165. Schultz TJ, Kitson AL. Measuring the context of care in an Australian acute care hospital: a nurse survey. Implement Sci. 2010;5(1):60.

166. Stolee P, Steeves B, Manderson BL, Toscan JL, Glenny C, Berg K. Health information use in home care: brainstorming barriers, facilitators, and recommendations. Home Health Care Serv Q. 2010;29(1):37-53.

167. Urquhart R, Sargeant J, Porter GA. Factors related to the implementation and use of an innovation in cancer surgery. Current Oncology. 2011;18(6): 271-9.

168. Watts BV, Shiner B, Zubkoff L, Carpenter-Song E, Ronconi JM, Coldwell CM. Implementation of evidence-based psychotherapies for posttraumatic stress disorder in VA specialty clinics. Psychiatr Serv. 2014;65(5):648-53.

169. Wente SJ, Kleiber C. An exploration of context and the use of evidencebased nonpharmacological practices in emergency departments. Worldviews Evid Based Nurs. 2013;10(4):187-97.

170. Zubkoff L, Carpenter-Song E, Shiner B, Ronconi JM, Watts BV. Clinicians' perception of patient readiness for treatment: an emerging theme in implementation science? Adm Policy Ment Health. 2016;43(2):250-8.

171. Arling PA, Doebbeling BN, Fox RL. Improving the implementation of evidence-based practice and information systems in healthcare. International Journal of Healthcare Information Systems and Informatics. 2011;6(2):37-59. 
172. Bahtsevani C, Willman A, Khalaf A, Ostman M. Developing an instrument for evaluating implementation of clinical practice guidelines: a test-retest study. J Eval Clin Pract. 2008;14(5):839-46.

173. Boaz A, Baeza J, Fraser A. Does the 'diffusion of innovations' model enrich understanding of research use? Case studies of the implementation of thrombolysis services for stroke. J Health Serv Res Policy. 2016;21(4):229-34.

174. Bostrom AM, Wallin L, Nordstrom G. Evidence-based practice and determinants of research use in elderly care in Sweden. J Eval Clin Pract. 2007;13(4):665-73.

175. Butow $P$, Williams $D$, Thewes $B$, Tesson $S$, Sharpe $L$, Smith $A B$, et al. A psychological intervention (ConquerFear) for treating fear of cancer recurrence: views of study therapists regarding sustainability. Psychooncology. 2019;28(3):533-9.

176. Carlan NA, Kramer DM, Bigelow P, Wells R, Garritano E, Vi P. Digging into construction: social networks and their potential impact on knowledge transfer. Work. 2012;42(2):223-32.

177. Chou AF, Graber CJ, Zhang Y, Jones M, Goetz MB, Madaras-Kelly K, et al. Specifying an implementation framework for Veterans Affairs antimicrobial stewardship programmes: using a factor analysis approach. J Antimicrob Chemother. 2018;73(9):2559-66.

178. Conklin J, Stolee P. A model for evaluating knowledge exchange in a network context. Can J Nurs Res. 2008;40(2):116-24.

179. Conklin J, Lusk E, Harris M, Stolee P. Knowledge brokers in a knowledge network: the case of Seniors Health Research Transfer Network knowledge brokers. Implement Sci. 2013;8(1):7.

180. Cummings GG, Hutchinson AM, Scott SD, Norton PG, Estabrooks CA. The relationship between characteristics of context and research utilization in a pediatric setting. BMC Health Serv Res. 2010;10:168.

181. Eldh AC, Fredriksson M, Halford C, Wallin L, Dahlstrom T, Vengberg S, et al. Facilitators and barriers to applying a national quality registry for quality improvement in stroke care. BMC Health Serv Res. 2014;14(1):354.

182. Elnitsky CA, Powell-Cope G, Besterman-Dahan KL, Rugs D, Ullrich PM. Implementation of safe patient handling in the U.S. Veterans Health System: a qualitative study of internal facilitators' perceptions. Worldviews Evid Based Nurs. 2015;12(4):208-16.

183. Eriksson C, Eriksson G, Johansson U, Guidetti S. Occupational therapists' perceptions of implementing a client-centered intervention in close collaboration with researchers: a mixed methods study. Scand J Occup Ther. 2019:1-12.

184. Forberg U, Unbeck M, Wallin L, Johansson E, Petzold M, Ygge BM, et al. Effects of computer reminders on complications of peripheral venous catheters and nurses' adherence to a guideline in paediatric care--a cluster randomised study. Implement Sci. 2016;11:10.

185. Gifford E, Tavakoli S, Wisdom J, Hamlett-Berry K. Implementation of smoking cessation treatment in VHA substance use disorder residential treatment programs. Psychiatr Serv. 2015;66(3):295-302.

186. Hack TF, Ruether JD, Weir LM, Grenier D, Degner LF. Promoting consultation recording practice in oncology: identification of critical implementation factors and determination of patient benefit. Psychooncology. 2013;22(6):1273-82.

187. Hill JN, Guihan M, Hogan TP, Smith BM, LaVela SL, Weaver FM, et al. Use of the PARIHS Framework for Retrospective and Prospective Implementation Evaluations. Worldviews Evid Based Nurs. 2017;14(2):99-107.

188. Holt NL, Pankow K, Camire M, Cote J, Fraser-Thomas J, MacDonald DJ, et al. Factors associated with using research evidence in national sport organisations. J Sports Sci. 2018;36(10):1111-7.

189. Hurtubise K, Rivard L, Heguy L, Berbari J, Camden C. Virtual knowledge brokering: describing the roles and strategies used by knowledge brokers in a pediatric physiotherapy virtual community of practice. J Contin Educ Health Prof. 2016;36(3):186-94.

190. Holge-Hazelton B, Bruun LZ, Slater P, McCormack B, Thomsen TG, Klausen $\mathrm{SH}$, et al. Danish Translation and Adaptation of the Context Assessment Index With Implications for Evidence-Based Practice. Worldviews Evid Based Nurs. 2019;16(3):221-9.

191. Ismail A, Squires J, Forgeron P, Polomeno V, Gharaibeh H, Harrison D. The influence of context on utilizing research evidence for pain management in Jordanian Pediatric Intensive Care Units (PICU). J Pediatr Nurs. 2018;38:e39-46.

192. Jansson I, Forsberg A. How do nurses and ward managers perceive that evidence-based sources are obtained to inform relevant nursing interventions? - an exploratory study. Journal of Clinical Nursing. 2016;25(56):769-76.
193. Jansson I, Pilhamar E, Forsberg A. Factors and conditions that have an impact in relation to the successful implementation and maintenance of individual care plans. Worldviews Evid Based Nurs. 2011;8(2):66-75.

194. Kramer DM, Wells RP, Carlan N, Aversa T, Bigelow PP, Dixon SM, et al. Did you have an impact? a theory-based method for planning and evaluating knowledge-transfer and exchange activities in occupational health and safety. International Journal of Occupational Safety and Ergonomics. 2013;19(1):41-62.

195. Lo TKT, Hoben M, Norton PG, Teare GF, Estabrooks CA. Importance of clinical educators to research use and suggestions for better efficiency and effectiveness: results of a cross-sectional survey of care aides in Canadian long-term care facilities. BMJ Open. 2018;8(7):e020074.

196. Lundell S, Tistad M, Rehn B, Wiklund M, Holmner A, Wadell K. Building COPD care on shaky ground: a mixed methods study from Swedish primary care professional perspective. BMC Health Serv Res. 2017;17(1):467.

197. McCalman J, Tsey K, Bainbridge R, Rowley K, Percival N, O'Donoghue L, et al The characteristics, implementation and effects of Aboriginal and Torres Strait Islander health promotion tools: a systematic literature search. BMC Public Health. 2014;14(1):712.

198. McKillop A, Crisp J, Walsh K. Barriers and enablers to implementation of a New Zealand-wide guideline for assessment and management of cardiovascular risk in primary health care: a template analysis. Worldviews Evid Based Nurs. 2012;9(3):159-71.

199. Meherali SM, Paul P, Profetto-McGrath J. Use of research by undergraduate nursing students: a qualitative descriptive study. Qualitative Report. 2017; 22(2):634-54.

200. Naik AD, Lawrence B, Kiefer L, Ramos K, Utech A, Masozera N, et al. Building a primary care/research partnership: lessons learned from a telehealth intervention for diabetes and depression. Fam Pract. 2015;32(2):216-23.

201. Nygardh A, Ahlstrom G, Wann-Hansson C. Handling a challenging context: experiences of facilitating evidence-based elderly care. J Nurs Manag. 2016; 24(2):201-10.

202. Peirson L, Ciliska D, Dobbins M, Mowat D. Building capacity for evidence informed decision making in public health: a case study of organizational change. BMC Public Health. 2012;12(1):137.

203. Perry L, Bellchambers H, Howie A, Moxey A, Parkinson L, Capra S, et al. Examination of the utility of the promoting action on research implementation in health services framework for implementation of evidence based practice in residential aged care settings. J Adv Nurs. 2011;67(10):2139-50.

204. Sandstrom B, Willman A, Svensson B, Borglin G. Perceptions of national guidelines and their (non) implementation in mental healthcare: a deductive and inductive content analysis. Implement Sci. 2015;10(1):43.

205. Sharp ND, Pineros SL, Hsu C, Starks H, Sales AE. A qualitative study to identify barriers and facilitators to implementation of pilot interventions in the Veterans Health Administration (VHA) Northwest Network. Worldviews Evid Based Nurs. 2004;1(2):129-39.

206. Stetler CB, Legro MW, Rycroft-Malone J, Bowman C, Curran G, Guihan M, et al. Role of "external facilitation" in implementation of research findings: a qualitative evaluation of facilitation experiences in the Veterans Health Administration. Implement Sci. 2006;1(1):23.

207. Stevens B, Riahi S, Cardoso R, Ballantyne M, Yamada J, Beyene J, et al. The influence of context on pain practices in the NICU: perceptions of health care professionals. Qual Health Res. 2011;21(6):757-70.

208. Ullrich PM, Lavela SL, Evans CT, Miskevics S, Weaver FM, Goldstein B. Associations between perceptions of evidence and adoption of H1N1 influenza infection prevention strategies among healthcare workers providing care to persons with spinal cord injury. J Adv Nurs. 2014;70(8):1793-800.

209. Ullrich PM, Sahay A, Stetler CB. Use of implementation theory: a focus on PARIHS. Worldviews Evid Based Nurs. 2014;11(1):26-34.

210. Vabo G, Slettebo A, Fossum M. Participants' perceptions of an intervention implemented in an Action Research Nursing Documentation Project. J Clin Nurs. 2017;26(7-8):983-93.

211. Wallin L, Estabrooks CA, Midodzi WK, Cummings GG. Development and validation of a derived measure of research utilization by nurses. Nurs Res. 2006;55(3):149-60.

212. Ward MM, Baloh J, Zhu X, Stewart GL. Promoting Action on Research Implementation in Health Services framework applied to TeamSTEPPS implementation in small rural hospitals. Health Care Manage Rev. 2017:42(1):2-13.

213. Wilde S, Sonley A, Crane C, Ford T, Raja A, Robson J, et al. Mindfulness Training in UK Secondary Schools: a Multiple Case Study Approach to Identification of Cornerstones of Implementation. Mindfulness (N Y). 2019;10(2):376-89. 
214. Øye C, Mekki TE, Skaar R, Dahl H, Forland O, Jacobsen FF. Evidence molded by contact with staff culture and patient milieu: an analysis of the social process of knowledge utilization in nursing homes. Vocations and Learning. 2015;8(3):319-34.

215. Benoit B, Semenic S. Barriers and facilitators to implementing the BabyFriendly hospital initiative in neonatal intensive care units. J Obstet Gynecol Neonatal Nurs. 2014;43(5):614-24

216. Campbell TD, Profetto-McGrath J. Skills and attributes required by clinical nurse specialists to promote evidence-based practice. Clin Nurse Spec. 2013; 27(5):245-54.

217. Douglas NF, Hinckley JJ, Haley WE, Andel R, Chisolm TH, Eddins AC. Perceptions of speech-language pathologists linked to evidence-based practice use in skilled nursing facilities. Am J Speech Lang Pathol. 2014; 23(4):612-24.

218. Gunningberg L, Brudin L, Idvall E. Nurse Managers' prerequisite for nursing development: a survey on pressure ulcers and contextual factors in hospital organizations. J Nurs Manag. 2010;18(6):757-66.

219. Hagedorn HJ, Heideman PW. The relationship between baseline Organizational Readiness to Change Assessment subscale scores and implementation of hepatitis prevention services in substance use disorders treatment clinics: a case study. Implement Sci. 2010;5(1):46.

220. Henry SR, Hagedorn HJ, Feld JE, Golden JF, Horns H, Knapp HE, et al. A formative evaluation of organizational readiness to implement nurseinitiated HIV rapid testing in two Veterans Health Administration Substance Use Disorder Clinics. Journal of HIV/AIDS \& Social Services. 2010;9(1):7-26.

221. Halleberg Nyman M, Forsman H, Wallin L, Ostaszkiewicz J, Hommel A, Eldh AC. Promoting evidence-based urinary incontinence management in acute nursing and rehabilitation care-a process evaluation of an implementation intervention in the orthopaedic context. J Eval Clin Pract. 2019;25(2):282-9.

222. Jacobsen FF, Mekki TE, Forland O, Folkestad B, Kirkevold O, Skar R, et al. A mixed method study of an education intervention to reduce use of restraint and implement person-centered dementia care in nursing homes. BMC Nurs. 2017;16(1):55.

223. Kirkpatrick H, Boblin S, Ireland S, Robertson K. The nurse as bricoleur in falls prevention: learning from a case study of the implementation of fall prevention best practices. Worldviews Evid Based Nurs. 2014;11(2):118-25.

224. Stryczek K, Lea C, Gillespie C, Sayre G, Wanner S, Rinne ST, et al. Deimplementing inhaled corticosteroids to improve care and safety in COPD treatment: primary care providers' perspectives. J Gen Intern Med. 2020; 35(1):51-6.

225. Bokhour BG, Saifu H, Goetz MB, Fix GM, Burgess J, Fletcher MD, et al. The role of evidence and context for implementing a multimodal intervention to increase HIV testing. Implement Sci. 2015;10(1):22.

226. Garvin JH, Kim Y, Gobbel GT, Matheny ME, Redd A, Bray BE, et al. Automating quality measures for heart failure using natural language processing: a descriptive study in the Department of Veterans Affairs. JMIR Med Inform. 2018;6(1):e5.

227. Harrison JD, Reddy S, Liu R, Adler SR, Chao MT. Implementing an inpatient acupuncture service for pain and symptom management: identifying opportunities and challenges. J Altern Complement Med. 2019;25(5):503-8.

228. Hawkins EJ, Malte CA, Hagedorn HJ, Berger D, Frank A, Lott A, et al. Survey of primary care and mental health prescribers' perspectives on reducing opioid and benzodiazepine co-prescribing among veterans. Pain Med. 2017; 18(3):454-67.

229. Hoben M, Estabrooks CA, Squires JE, Behrens J. Factor Structure, Reliability and Measurement Invariance of the Alberta Context Tool and the Conceptual Research Utilization Scale, for German Residential Long Term Care. Front Psychol. 2016;7:1339.

230. Hofler LG, Cordes S, Cwiak CA, Goedken P, Jamieson DJ, Kottke M. Implementing immediate postpartum long-acting reversible contraception programs. Obstet Gynecol. 2017;129(1):3-9.

231. Hommel A, Gunningberg L, Idvall E, Baath C. Successful factors to prevent pressure ulcers - an interview study. J Clin Nurs. 2017;26(1-2):182-9.

232. Kothari A, Boyko JA, Conklin J, Stolee P, Sibbald SL. Communities of practice for supporting health systems change: a missed opportunity. Health Res Policy Syst. 2015;13(1):33.

233. Kristensen HK, Borg T, Hounsgaard L. Aspects affecting occupational therapists' reasoning when implementing research-based evidence in stroke rehabilitation. Scand J Occup Ther. 2012;19(2):118-31.
234. McCullough MB, Gillespie C, Petrakis BA, Jones EA, Park AM, Lukas CV, et al. Forming and activating an internal facilitation group for successful implementation: A qualitative study. Res Social Adm Pharm. 2017;13(5):1014-27.

235. Mocumbi S, McKee K, Munguambe K, Chiau R, Högberg U, Hanson C, et al. Ready to deliver maternal and newborn care? Health providers' perceptions of their work context in rural Mozambique. Global Health Action. 2018;11(1).

236. Murphy JE, Washington D, Xuan Z, Paasche-Orlow MK, Drainoni ML. Identifying and addressing language needs in primary care: a pilot implementation study. J Racial Ethn Health Disparities. 2019;6(3):505-16.

237. Rycroft-Malone J, Fontenla M, Bick D, Seers K. A realistic evaluation: the case of protocol-based care. Implement Sci. 2010;5(1):38.

238. Shimada SL, Hogan TP, Rao SR, Allison JJ, Quill AL, Feng H, et al. Patientprovider secure messaging in VA: variations in adoption and association with urgent care utilization. Med Care. 2013;51(3 Suppl 1):S21-8.

239. Stolee P, Hiller LM, Etkin M, McLeod J. "Flying by the seat of our pants": current processes to share best practices to deal with elder abuse. J Elder Abuse Negl. 2012;24(2):179-94.

240. Tukey MH, Clark JA, Bolton R, Kelley MJ, Slatore CG, Au DH, et al. Readiness for Implementation of Lung Cancer Screening. A National Survey of Veterans Affairs Pulmonologists. Ann Am Thorac Soc. 2016;13(10):1794-801.

241. Xiang X, Robinson-Lane SG, Rosenberg W, Alvarez R. Implementing and sustaining evidence-based practice in health care: The Bridge Model experience. J Gerontol Soc Work. 2018;61(3):280-94.

242. Zubkoff L, Shiner B, Watts BV. Staff Perceptions of Substance Use Disorder Treatment in VA Primary Care-Mental Health Integrated Clinics. J Subst Abuse Treat. 2016;70:44-9.

243. Estabrooks CA, Kenny DJ, Adewale AJ, Cummings GG, Mallidou AA. A comparison of research utilization among nurses working in Canadian civilian and United States Army healthcare settings. Res Nurs Health. 2007;30(3):282-96.

244. Ireland S, Kirkpatrick H, Boblin S, Robertson K. The real world journey of implementing fall prevention best practices in three acute care hospitals: a case study. Worldviews Evid Based Nurs. 2013;10(2):95-103.

245. Kristensen HK, Borg T, Hounsgaard L. Facilitation of research-based evidence within occupational therapy in stroke rehabilitation. British Journal of Occupational Therapy. 2011;74(10):473-83.

246. Lavoie-Tremblay M, Richer MC, Marchionni C, Cyr G, Biron AD, Aubry M, et al. Implementation of evidence-based practices in the context of a redevelopment project in a Canadian healthcare organization. J Nurs Scholarsh. 2012:44(4):418-27.

247. Leclair LL, Ripat JD, Wener PF, Cooper JE, Johnson LA, Davis EL, et al. Advancing the use of theory in occupational therapy: a collaborative process. Can J Occup Ther. 2013;80(3):181-93.

248. Matthew-Maich N, Ploeg J, Dobbins M, Jack S. Supporting the Uptake of Nursing Guidelines: what you really need to know to move nursing guidelines into practice. Worldviews Evid Based Nurs. 2013;10(2):104-15.

249. Ranse K, Yates P, Coyer F. Factors influencing the provision of end-of-life care in critical care settings: development and testing of a survey instrument. J Adv Nurs. 2015;71(3):697-709.

250. Squires JE, Estabrooks CA, Scott SD, Cummings GG, Hayduk L, Kang SH, et al. The influence of organizational context on the use of research by nurses in Canadian pediatric hospitals. BMC Health Serv Res. 2013;13(1):351.

251. Svensson S, Ohlsson K, Wann-Hansson C. Development and implementation of a standardized care plan for carotid endarterectomy. J Vasc Nurs. 2012; 30(2):44-53.

252. Tierney S, Kislov R, Deaton C. A qualitative study of a primary-care based intervention to improve the management of patients with heart failure: the dynamic relationship between facilitation and context. BMC Fam Pract. 2014;15(1):153.

253. Urquhart R, Porter GA, Sargeant J, Jackson L, Grunfeld E. Multi-level factors influence the implementation and use of complex innovations in cancer care: a multiple case study of synoptic reporting. Implement Sci. 2014;9(1): 121.

254. Warner G. Synthesizing research evidence for therapists providing homebased rehabilitative care. Physical \& Occupational Therapy In Geriatrics. 2013;31(2):115-27.

255. Warner G, Stadnyk R. What is the evidence and context for implementing family-centered care for older adults? Physical \& Occupational Therapy In Geriatrics. 2014;32(3):255-70.

256. Wilson M, Sleutel M, Newcomb P, Behan D, Walsh J, Wells JN, et al. Empowering nurses with evidence-based practice environments: surveying 
Magnet(R), Pathway to Excellence(R), and non-magnet facilities in one healthcare system. Worldviews Evid Based Nurs. 2015;12(1):12-21.

257. Abrahamson K, Miech E, Davila HW, Mueller C, Cooke V, Arling G. Pay-forperformance policy and data-driven decision making within nursing homes: a qualitative study. BMJ Qual Saf. 2015;24(5):311-7.

258. Backman C, Hebert PC, Jennings A, Neilipovitz D, Choudhri O, lyengar A, et al. Implementation of a multimodal patient safety improvement program "SafetyLEAP" in intensive care units. Int J Health Care Qual Assur. 2018;31(2): 140-9.

259. Brobeck E, Odencrants S, Bergh H, Hildingh C. Health promotion practice and its implementation in Swedish health care. Int Nurs Rev. 2013;60(3): 374-80.

260. Brown D, McCormack BG. Developing the practice context to enable more effective pain management with older people: an action research approach. Implement Sci. 2011;6(1):9.

261. Carlfjord S, Andersson A, Bendtsen P, Nilsen P, Lindberg M. Applying the REAIM framework to evaluate two implementation strategies used to introduce a tool for lifestyle intervention in Swedish primary health care. Health Promot Int. 2012;27(2):167-76.

262. Carlfjord S, Kristenson M, Lindberg M. Experiences of working with the tobacco issue in the context of health promoting hospitals and health services: a qualitative study. Int J Environ Res Public Health. 2011;8(2):498-513.

263. Cranley LA, Birdsell JM, Norton PG, Morgan DG, Estabrooks CA. Insights into the impact and use of research results in a residential long-term care facility: a case study. Implement Sci. 2012;7(1):90.

264. Dogherty EJ, Harrison MB, Graham ID, Vandyk AD, Keeping-Burke L. Turning knowledge into action at the point-of-care: the collective experience of nurses facilitating the implementation of evidence-based practice. Worldviews Evid Based Nurs. 2013;10(3):129-39.

265. Espirito Santo A, Choquette A. Experience of adapting and implementing an evidence-based nursing guideline for prevention of diaper dermatitis in a paediatric oncology setting. Int J Evid Based Healthc. 2013;11(2):121-7.

266. Harvey G, Kitson A, Munn Z. Promoting continence in nursing homes in four European countries: the use of PACES as a mechanism for improving the uptake of evidence-based recommendations. Int J Evid Based Healthc. 2012;10(4):388-96.

267. Hermansyah A, Sainsbury E, Krass I. The operation of a Research and Development (R\&D) program and its significance for practice change in community pharmacy. PLoS One. 2017;12(9):e0184954.

268. Johnston CC, Gagnon A, Rennick J, Rosmus C, Patenaude H, Ellis J, et al. One-on-one coaching to improve pain assessment and management practices of pediatric nurses. J Pediatr Nurs. 2007;22(6):467-78.

269. Kinley J, Denton L, Scott S. Development and implementation of the Steps to Successful Palliative Care programme in residential care homes for people with a learning disability. Int J Palliat Nurs. 2018;24(10):492-502.

270. Kinley J, Denton L, Levy J. Improving the approach to future care planning in care homes. Int J Palliat Nurs. 2018;24(12):576-83.

271. Marfurt-Russenberger K, Axelin A, Kesselring A, Franck LS, Cignacco E. The experiences of professionals regarding involvement of parents in neonatal pain management. J Obstet Gynecol Neonatal Nurs. 2016;45(5):671-83.

272. Meagher-Stewart D, Solberg SM, Warner G, MacDonald JA, McPherson C, Seaman P. Understanding the role of communities of practice in evidence-informed decision making in public health. Qual Health Res. 2012;22(6):723-39.

273. Meyer-Zehnder B, Albisser Schleger H, Tanner S, Schnurrer V, Vogt DR, Reiter-Theil S, et al. How to introduce medical ethics at the bedside Factors influencing the implementation of an ethical decision-making model. BMC Med Ethics. 2017;18(1):16.

274. Nguyen TN, Wilson A. Hospital readiness for undertaking evidence-based practice: a survey. Nurs Health Sci. 2016;18(4):465-72.

275. Painter P, Clark L, Olausson J. Physical function and physical activity assessment and promotion in the hemodialysis clinic: a qualitative study. Am J Kidney Dis. 2014;64(3):425-33

276. Powell-Cope G, Moore DH, Weaver FM, Thomason S. Perceptions of practice guidelines for people with spinal cord injury. Rehabil Nurs. 2015;40(2):100-10.

277. Powrie SL, Danly D, Corbett CF, Purath J, Dupler A. Using implementation science to facilitate evidence-based practice changes to promote optimal outcomes for orthopaedic patients. Orthop Nurs. 2014;33(2):109-14.

278. Scott SD, Estabrooks CA, Allen M, Pollock C. A context of uncertainty: how context shapes nurses' research utilization behaviors. Qual Health Res. 2008; 18(3):347-57.
279. Skene C, Gerrish K, Price F, Pilling E, Bayliss P, Gillespie S. Developing familycentred care in a neonatal intensive care unit: an action research study. Intensive Crit Care Nurs. 2019;50:54-62.

280. Squires JE, Aloisio LD, Grimshaw JM, Bashir K, Dorrance K, Coughlin M, et al. Attributes of context relevant to healthcare professionals' use of research evidence in clinical practice: a multi-study analysis. Implement Sci. 2019;14(1):52.

281. Stenberg M, Wann-Hansson C. Health care professionals' attitudes and compliance to clinical practice guidelines to prevent falls and fall injuries. Worldviews Evid Based Nurs. 2011;8(2):87-95.

282. Thunberg G, Ferm U, Blom A, Karlsson M, Nilsson S. Implementation of pictorial support for communication with people who have been forced to flee: experiences from neonatal care. J Child Health Care. 2019;23(2):311-36

283. Tishelman C, Bergenmar M, Bernhardson BM, Blomberg K, Borjeson S, Foderus $\mathrm{H}$, et al. Using undergraduate nursing students as mediators in a knowledge transfer programme for care for patients with advanced cancer. Eur J Cancer Care (Engl). 2008;17(3):253-60.

284. Wedge C, Gosney M. Pressure-relieving equipment: promoting its correct use amongst nurses via differing modes of educational delivery. J Clin Nurs. 2005;14(4):473-8.

285. Anderson D, Wang S, Zlateva I. Comprehensive assessment of chronic pain management in primary care: A first phase of a quality improvement initiative at a multisite community health center. Quality in Primary Care. 2012;20(6):421-33.

286. Sauto Arce R, De Ormijana AS, Orueta JF, Gagnon MP, Nuno-Solinis R. A qualitative study on clinicians' perceptions about the implementation of a population risk stratification tool in primary care practice of the Basque health service. BMC Fam Pract. 2014;15(1):150

287. Bergstrom A, Skeen S, Duc DM, Blandon EZ, Estabrooks C, Gustavsson P, et al. Health system context and implementation of evidence-based practices-development and validation of the Context Assessment for Community Health (COACH) tool for low- and middle-income settings. Implement Sci. 2015;10(1):120.

288. Bramley L, Manning JC, Cooper J. Engaging and developing front-line clinical nurses to drive care excellence: evaluating the Chief Nurse Excellence in Care Junior Fellowship initiative. Journal of Research in Nursing. 2018;23(8):678-89.

289. Capasso V, Collins J, Griffith C, Lasala CA, Kilroy S, Martin AT, et al. Outcomes of a clinical nurse specialist-initiated wound care education program: using the promoting action on research implementation in health services framework. Clin Nurse Spec. 2009;23(5):252-7.

290. Conklin J, Cohen-Schneider R, Linkewich B, Legault E. Enacting change through action learning: mobilizing and managing power and emotion. Action Learning: Research and Practice. 2012;9(3):275-95.

291. Curran GM, Woo SM, Hepner KA, Lai WP, Kramer TL, Drummond KL, et al. Training Substance Use Disorder Counselors in Cognitive Behavioral Therapy for Depression: Development and Initial Exploration of an Online Training Program. J Subst Abuse Treat. 2015;58:33-42.

292. Damschroder LJ, Moin T, Datta SK, Reardon CM, Steinle N, Weinreb J, et al. Implementation and evaluation of the VA DPP clinical demonstration: protocol for a multi-site non-randomized hybrid effectivenessimplementation type III trial. Implement Sci. 2015;10:68.

293. Doran DM, Haynes RB, Kushniruk A, Straus S, Grimshaw J, Hall LM, et al. Supporting evidence-based practice for nurses through information technologies. Worldviews on Evidence-Based Nursing. 2010;7(1):4-15.

294. Estrada N. Exploring perceptions of a learning organization by RNs and relationship to EBP beliefs and implementation in the acute care setting Worldviews Evid Based Nurs. 2009;6(4):200-9.

295. Fitzgerald L, Harvey G. Translational networks in healthcare? Evidence on the design and initiation of organizational networks for knowledge mobilization. Soc Sci Med. 2015;138:192-200.

296. Forgeron PA, Jongudomkarn D, Evans J, Finley GA, Thienthong S, Siripul P, et al. Children's pain assessment in northeastern Thailand: perspectives of health professionals. Qual Health Res. 2009;19(1):71-81.

297. Friberger MG, Falkman G. Collaboration processes, outcomes, challenges and enablers of distributed clinical communities of practice. Behaviour \& Information Technology. 2013;32(6):519-31.

298. Graham LA, Maddox TM, Itani KM, Hawn MT. Coronary stents and subsequent surgery: reported provider attitudes and practice patterns. Am Surg. 2013;79(5):514-23. 
299. Hefter GB, Gerson L. Increasing adherence to scheduled outpatient dobutamine stress echocardiograms. The Journal for Nurse Practitioners. 2010;6(10):768-74.

300. Hunter SB, Chinman M, Ebener P, Imm P, Wandersman A, Ryan GW. Technica assistance as a prevention capacity-building tool: a demonstration using the getting to outcomes framework. Health Educ Behav. 2009;36(5):810-28.

301. Mallidou AA, Cummings GG, Ginsburg LR, Chuang YT, Kang S, Norton PG, et al. Staff, space, and time as dimensions of organizational slack: a psychometric assessment. Health Care Manage Rev. 2011;36(3):252-64.

302. Nilsson Kajermo K, Boe H, Johansson E, Henriksen E, McCormack B, Gustavsson JP, et al. Swedish translation, adaptation and psychometric evaluation of the Context Assessment Index (CAI). Worldviews Evid Based Nurs. 2013;10(1):41-50

303. Powers JS, Preshong M, Smith P. A model of regulatory alignment to enhance the long-term care survey process in a Veterans Health Care Network. Am J Med Qual. 2016;31(5):470-5.

304. Ryan BJ, Franklin RC, Burkle FM, Smith EC, Aitken P, Watt K, et al. Ranking and prioritizing strategies for reducing mortality and morbidity from noncommunicable diseases post disaster: An Australian perspective. International Journal of Disaster Risk Reduction. 2018;27:223-38.

305. Shuman CJ, Ploutz-Snyder RJ, Titler MG. Development and Testing of the Nurse Manager EBP Competency Scale. West J Nurs Res. 2018;40(2):175-90.

306. Shuman CJ, Powers K, Banaszak-Holl J, Titler MG. Unit leadership and climates for evidence-based practice implementation in acute care: a crosssectional descriptive study. J Nurs Scholarsh. 2019;51(1):114-24.

307. Siraj-Blatchford I, Taggart B, Sylva K, Sammons P, Melhuish E. Towards the transformation of practice in early childhood education: the effective provision of pre-school education (EPPE) project. Cambridge Journal of Education. 2008;38(1):23-36.

308. Squires JE, Hayduk L, Hutchinson AM, Mallick R, Norton PG, Cummings GG, et al. Reliability and Validity of the Alberta Context Tool (ACT) with Professional Nurses: Findings from a Multi-Study Analysis. PLoS One. 2015;10(6):e0127405.

309. Tucker SJ, Olson ME, Frusti DK. Evidence-Based Practice Self-efficacy Scale Preliminary Reliability and Validity. Clinical Nurse Specialist. 2009; 23(4):207-15.

310. Urquhart R, Jackson L, Sargeant J, Porter GA, Grunfeld E. Health system-level factors influence the implementation of complex innovations in cancer care. Healthc Policy. 2015;11(2):102-18.

311. Vetter MJ. The influence of clinical decision support on diagnostic accuracy in nurse practitioners. Worldviews Evid Based Nurs. 2015;12(6):355-63.

312. Weaver FM, Smith B, LaVela S, Wallace C, Evans CT, Hammond M, et al. Interventions to increase influenza vaccination rates in veterans with spinal cord injuries and disorders. J Spinal Cord Med. 2007;30(1):10-9.

313. Liedgren $P$, Elvhage $G$, Ehrenberg A, Kullberg C. The use of decision support systems in social work: a scoping study literature review. Journal of Evidence-Informed Social Work. 2016;13(1):1-20.

314. Brown D, McCormack B. Developing postoperative pain management: utilising the promoting action on research implementation in health services (PARIHS) framework. Worldviews Evid Based Nurs. 2005;2(3):131-41.

315. McCalman J, Bainbridge R, Percival N, Tsey K. The effectiveness of implementation in Indigenous Australian healthcare: An overview of literature reviews. International Journal for Equity in Health. 2016;15(1).

316. Meijers JM, Janssen MA, Cummings GG, Wallin L, Estabrooks CA. R YGH. Assessing the relationships between contextual factors and research utilization in nursing: systematic literature review. J Adv Nurs. 2006;55(5): 622-35.

317. Milner M, Estabrooks CA, Myrick F. Research utilization and clinical nurse educators: A systematic review. J Eval Clin Pract. 2006;12(6):639-55.

318. Pfadenhauer LM, Gerhardus A, Mozygemba K, Lysdahl KB, Booth A, Hofmann B, et al. Making sense of complexity in context and implementation: the Context and Implementation of Complex Interventions (CICI) framework. Implement Sci. 2017;12(1):21.

319. Toms G, Williams L, Rycroft-Malone J, Swales M, Feigenbaum J. The development and theoretical application of an implementation framework for dialectical behaviour therapy: a critical literature review. Borderline Personal Disord Emot Dysregul. 2019;6:2

320. Wood RL, Migliore LA, Nasshan SJ, Mirghani SR, Contasti AC. Confronting challenges in reducing heart failure 30-day readmissions: lessons learned with implications for evidence-based practice. Worldviews Evid Based Nurs. 2019;16(1):43-50.
321. Franx G, Dixon L, Wensing M, Pincus $H$. Implementation strategies for collaborative primary care-mental health models. Curr Opin Psychiatry. 2013; 26(5):502-10.

322. Hudon A, Gervais MJ, Hunt M. The contribution of conceptual frameworks to knowledge translation interventions in physical therapy. Phys Ther. 2015; 95(4):630-9.

323. Dogherty EJ, Harrison MB, Graham ID. Facilitation as a role and process in achieving evidence-based practice in nursing: a focused review of concept and meaning. Worldviews Evid Based Nurs. 2010;7(2):76-89.

324. Flottorp SA, Oxman AD, Krause J, Musila NR, Wensing M, Godycki-Cwirko M, et al. A checklist for identifying determinants of practice: a systematic review and synthesis of frameworks and taxonomies of factors that prevent or enable improvements in healthcare professional practice. Implement Sci. 2013;8(1):35

325. Aas RW, Tuntland H, Holte KA, Roe C, Lund T, Marklund S, et al. Workplace interventions for neck pain in workers. Cochrane Database Syst Rev. 2011;4: CD008160.

326. Geerligs L, Rankin NM, Shepherd HL, Butow P. Hospital-based interventions: a systematic review of staff-reported barriers and facilitators to implementation processes. Implement Sci. 2018;13(1):36.

327. McConnell T, O'Halloran P, Porter S, Donnelly M. Systematic realist review of key factors affecting the successful implementation and sustainability of the Liverpool care pathway for the dying patient. Worldviews Evid Based Nurs. 2013;10(4):218-37

328. Rogers JL. Transferring research into practice an integrative review. Clinical Nurse Specialist. 2009;23(4):192-9.

329. Salter KL, Kothari A. Using realist evaluation to open the black box of knowledge translation: a state-of-the-art review. Implement Sci. 2014; $9(1): 115$.

330. Sandstrom B, Borglin G, Nilsson R, Willman A. Promoting the implementation of evidence-based practice: a literature review focusing on the role of nursing leadership. Worldviews Evid Based Nurs. 2011; $8(4): 212-23$

331. Wahr JA, Abernathy JH 3rd, Lazarra EH, Keebler JR, Wall MH, Lynch I, et al. Medication safety in the operating room: literature and expert-based recommendations. Br J Anaesth. 2017:118(1):32-43.

332. Baskerville NB, Liddy C, Hogg W. Systematic review and meta-analysis of practice facilitation within primary care settings. Annals of Family Medicine. 2012;10(1):63-74.

333. Colquhoun HL, Letts LJ, Law MC, MacDermid JC, Missiuna CA. A scoping review of the use of theory in studies of knowledge translation. Can J Occup Ther. 2010;77(5):270-9.

334. Leeman J, Calancie L, Kegler MC, Escoffery CT, Herrmann AK, Thatcher E, et al. Developing theory to guide building practitioners' capacity to implement evidence-based interventions. Health Educ Behav. 2017;44(1):59-69.

335. Nilsen P, Bernhardsson S. Context matters in implementation science: a scoping review of determinant frameworks that describe contextual determinants for implementation outcomes. BMC Health Serv Res. 2019; 19(1):189.

336. O'Keefe-McCarthy S, Santiago C, Lau G. Ventilator-associated pneumonia bundled strategies: an evidence-based practice. Worldviews Evid Based Nurs. 2008;5(4):193-204.

337. Prihodova L, Guerin S, Tunney C, Kernohan WG. Key components of knowledge transfer and exchange in health services research: findings from a systematic scoping review. J Adv Nurs. 2019;75(2):313-26.

338. Ward V, House A, Hamer S. Developing a framework for transferring knowledge into action: a thematic analysis of the literature. J Health Serv Res Policy. 2009;14(3):156-64

339. Doran DM, Sidani S. Outcomes-focused knowledge translation: a framework for knowledge translation and patient outcomes improvement. Worldviews Evid Based Nurs. 2007:4(1):3-13.

340. Ritchie MJ, Dollar KM, Kearney LK, Kirchner JE. Responding to needs of clinical operations partners: transferring implementation facilitation knowledge and skills. Psychiatr Serv. 2014;65(2):141-3.

341. Damschroder LJ, Aron DC, Keith RE, Kirsh SR, Alexander JA, Lowery JC. Fostering implementation of health services research findings into practice: a consolidated framework for advancing implementation science. Implement Sci. 2009;4(1):50.

342. Florczak KL. Evidence-based practice: what's new is old. Nurs Sci Q. 2016; 29(2):108-12. 
343. Kavanagh T, Stevens B, Seers K, Sidani S, Watt-Watson J. Examining appreciative inquiry as a knowledge translation intervention in pain management. Canadian Journal of Nursing Research. 2008;40(2):40-56.

344. Kavanagh T, Watt-Watson J, Stevens B. An examination of the factors enabling the successful implementation of evidence-based acute pain practices into pediatric nursing. Childrens Health Care. 2007;36(3):303-21.

345. Rongey C, Asch S, Knight SJ. Access to care for vulnerable veterans with hepatitis C: a hybrid conceptual framework and a case study to guide translation. Transl Behav Med. 2011;1(4):644-51.

346. Rycroft-Malone J. Theory and knowledge translation: setting some coordinates. Nurs Res. 2007;56(4 Suppl):S78-85.

347. Stetler CB, Damschroder LJ, Helfrich CD, Hagedorn HJ. A Guide for applying a revised version of the PARIHS framework for implementation. Implement Sci. 2011;6(1):99.

348. Tucker S, Klotzbach L, Olsen G, Voss J, Huus B, Olsen R, et al. Lessons learned in translating research evidence on early intervention programs into clinical care. Mcn-the American Journal of Maternal-Child Nursing. 2006; 31(5):325-31.

349. Urquhart R, Sargeant J, Grunfeld E. Exploring the usefulness of two conceptual frameworks for understanding how organizational factors influence innovation implementation in cancer care. J Contin Educ Health Prof. 2013;33(1):48-58.

350. Wallin L, Profetto-McGrath J, Levers MJ. Implementing nursing practice guidelines: a complex undertaking. J Wound Ostomy Continence Nurs. 2005;32(5):294-300; discussion -1.

351. Owen S, Milburn C. Implementing research findings into practice: improving and developing services for women with serious and enduring mental health problems. J Psychiatr Ment Health Nurs. 2001;8(3):221-31.

352. Blackwood B. Can protocolised-weaning developed in the United States transfer to the United Kingdom context: a discussion. Intensive and Critical Care Nursing. 2003;19(4):215-25.

353. Gawlinski A, Rutledge D. Selecting a model for evidence-based practice changes: a practical approach. AACN Adv Crit Care. 2008;19(3):291-300.

354. Genuis SK. Evolving information in an evidence-based world: theoretical considerations. Canadian Journal of Information and Library Science. 2007; 31(3-4):209-31.

355. Hunt JB, Curran G, Kramer T, Mouden S, Ward-Jones S, Owen R, et al. Partnership for implementation of evidence-based mental health practices in rural federally qualified health centers: theory and methods. Prog Community Health Partnersh. 2012;6(3):389-98.

356. Pfadenhauer LM, Mozygemba K, Gerhardus A, Hofmann B, Booth A, Lysdahl $\mathrm{KB}$, et al. Context and implementation: a concept analysis towards conceptual maturity. Z Evid Fortbild Qual Gesundhwes. 2015;109(2):103-14.

357. Ruth T, Matusitz J. Comparative standards of evidence in social work. J Evid Based Soc Work. 2013;10(4):285-98.

358. Squires JE, Reay T, Moralejo D, Lefort SM, Hutchinson AM, Estabrooks CA. Designing strategies to implement research-based policies and procedures: a set of recommendations for nurse leaders based on the PARiHS framework. J Nurs Adm. 2012;42(5):293-7.

359. Harvey G, Kitson A. PARIHS revisited: from heuristic to integrated framework for the successful implementation of knowledge into practice. Implement Sci. 2016;11(1):33.

360. Larkin ME, Griffith CA, Capasso VA, Cierpial C, Gettings E, Walsh K, et al. Promoting research utilization using a conceptual framework. J Nurs Adm. 2007:37(11):510-6.

361. Spassiani NA, Parker Harris S, Hammel J. Exploring how knowledge translation can improve sustainability of community-based health initiatives for people with intellectual/developmental disabilities. J Appl Res Intellect Disabil. 2016;29(5):433-44.

362. Andrews GJ, Moon G. Space, place, and the evidence base: Part II-Rereading nursing environment through geographical research. Worldviews Evid Based Nurs. 2005;2(3):142-56.

363. Andrews GJ, Holmes D, Poland B, Lehoux P, Miller KL, Pringle D, et al. 'Airplanes are flying nursing homes': geographies in the concepts and locales of gerontological nursing practice. J Clin Nurs. 2005;14(8B): 109-20.

364. Bucknall T. A gaze through the lens of decision theory toward knowledge translation science. Nurs Res. 2007;56(4 Suppl):S60-6.

365. Gibson F. Evidence in action: fostering growth of research-based practice in children's cancer nursing. Eur J Oncol Nurs. 2005;9(1):8-20.
366. Bandeira AG, Witt RR, Lapão LV, Madruga JG. The use of a methodological framework in the implementation of evidence as part of nursing research Texto \& Contexto - Enfermagem. 2017;26(4).

367. Boucher J, Roper K, Underhill M, Berry D. Science and practice aligned within nursing: structure and process for evidence-based practice. J Nurs Adm. 2013;43(4):229-34.

368. Chambers LW, Luesby D, Brookman C, Harris M, Lusk E. The Seniors Health Research Transfer Network Knowledge Network Model: system-wide implementation for health and healthcare of seniors. Healthc Manage Forum. 2010;23(1):4-16.

369. Hartrick Doane G, Reimer-Kirkham S, Antifeau E, Stajduhar K. (Re)theorizing integrated knowledge translation: a heuristic for knowledge-as-action. ANS Adv Nurs Sci. 2015;38(3):175-86.

370. Ellen ME, Panisset U. Araujo de Carvalho I, Goodwin J, Beard J. A Knowledge Translation framework on ageing and health. Health Policy. 2017;121(3):282-91.

371. Harvey G, Fitzgerald L, Fielden S, McBride A, Waterman H, Bamford D, et al. The NIHR Collaborations for Leadership in Applied Health Research and Care (CLAHRC) for Greater Manchester: combining empirical, theoretical and experiential evidence to design and evaluate a large-scale implementation strategy. Implement Sci. 2011;6(1):96.

372. Hutchinson AM, Wilkinson JE, Kent B, Harrison MB. Using the Promoting Action on Research Implementation in Health Services Framework to Guide Research Use in the Practice Setting. Worldviews Evid Based Nurs. 2012;9(1): 59-61.

373. Hysong SJ, Woodard L, Garvin JH, Murawsky J, Petersen LA. Publishing protocols for partnered research. J Gen Intern Med. 2014;29 Suppl 4(4):8204.

374. Jeffs L, Sidani S, Rose D, Espin S, Smith O, Martin K, et al. Using theory and evidence to drive measurement of patient, nurse and organizational outcomes of professional nursing practice. Int J Nurs Pract. 2013;19(2):141-8.

375. Jukes M, Aspinall SL. Leadership and learning disability nursing. Br J Nurs. 2015;24(18):912-6.

376. Lynch EA, Mudge A, Knowles S, Kitson AL, Hunter SC, Harvey G. "There is nothing so practical as a good theory": a pragmatic guide for selecting theoretical approaches for implementation projects. BMC Health Serv Res. 2018;18(1):857.

377. Matthew-Maich N, Ploeg J, Jack S, Dobbins M. Transformative learning and research utilization in nursing practice: a missing link? Worldviews Evid Based Nurs. 2010;7(1):25-35.

378. Mitchell SA, Fisher CA, Hastings CE, Silverman LB, Wallen GR. A thematic analysis of theoretical models for translational science in nursing: mapping the field. Nurs Outlook. 2010;58(6):287-300.

379. O'Meara PF, Furness S, Gleeson R. Educating paramedics for the future: A holistic approach. Journal of Health and Human Services Administration. 2017;40(2):219-51

380. Persaud DD. Enhancing learning, innovation, adaptation, and sustainability in health care organizations: the ELIAS performance management framework. Health Care Manag (Frederick). 2014;33(3):183-204.

381. Schoville RR, Titler MG. Guiding healthcare technology implementation: a new integrated technology implementation model. Comput Inform Nurs. 2015;33(3):99-107; quiz E1.

382. Shah $V$, Warre $R$, Lee SK. Quality improvement initiatives in neonatal intensive care unit networks: achievements and challenges. Acad Pediatr. 2013;13(6 Suppl):S75-83.

383. Smith MC. Revisiting implementation theory: An interdisciplinary comparison between urban planning and healthcare implementation research. Environment and Planning C-Politics and Space. 2018;36(5):877-96.

384. Warner G, Townsend E. Applying knowledge translation theories to occupation. Occupational Therapy Now. 2012;14(2):19-21.

385. Young AM. Solving the wicked problem of hospital malnutrition. Nutrition \& Dietetics. 2015;72(3):200-4.

386. Rycroft-Malone J, Fontenla M, Seers K, Bick D. Protocol-based care: the standardisation of decision-making? J Clin Nurs. 2009;18(10):1490-500.

387. Tilson JK, Mickan S, Howard R, Sum JC, Zibell M, Cleary L, et al. Promoting physical therapists' use of research evidence to inform clinical practice: part 3--long term feasibility assessment of the PEAK program. BMC Med Educ. 2016;16:144.

388. Young AM, Banks MD, Mudge AM. Improving nutrition care and intake for older hospital patients through system-level dietary and mealtime interventions. Clin Nutr ESPEN. 2018;24:140-7. 
389. McCalman J, Bainbridge R, Percival N, Tsey K. The effectiveness of implementation in Indigenous Australian healthcare: an overview of literature reviews. Int J Equity Health. 2016;15(1):47.

390. Douglas NF, Campbell WN, Hinckley JJ. Implementation Science: Buzzword or Game Changer? J Speech Lang Hear Res. 2015;58(6):S1827-36.

391. Bauer MS, Damschroder L, Hagedorn H, Smith J, Kilbourne AM. An introduction to implementation science for the non-specialist. BMC Psychol. 2015;3:32.

\section{Publisher's Note}

Springer Nature remains neutral with regard to jurisdictional claims in published maps and institutional affiliations.

Ready to submit your research? Choose BMC and benefit from:

- fast, convenient online submission

- thorough peer review by experienced researchers in your field

- rapid publication on acceptance

- support for research data, including large and complex data types

- gold Open Access which fosters wider collaboration and increased citations

- maximum visibility for your research: over $100 \mathrm{M}$ website views per year

At $B M C$, research is always in progress.

Learn more biomedcentral.com/submissions 